Aus der Abteilung Mund-, Kiefer- und Gesichtschirurgie (Prof. Dr. med. Dr. med. dent. H. Schliephake) im Zentrum Zahn-, Mund- und Kieferheilkunde der Medizinischen Fakultät der Universität Göttingen

\title{
Untersuchungen von Extraktionsalveolen mit der Stützimmersionsendoskopie
}

\author{
Inaugural-Dissertation
}

zur Erlangung des Doktorgrades für Zahnheilkunde

\author{
der Medizinischen Fakultät \\ der Georg-August-Universität zu Göttingen \\ vorgelegt von \\ Isabell-Andrea Reindl, geb. Weber \\ aus Salzgitter-Bad
}

Göttingen 2011 
Dekan:

I. Berichterstatter:

II. Berichterstatter/in:

III. Berichterstatter/in:
Prof. Dr. med. C. Frömmel

Prof. Dr. med. Dr. med. dent. W. Engelke

Tag der mündlichen Prüfung: 
Inhaltsverzeichnis

1. Einleitung 8

1.1 Einführung in das Thema $\quad 8$

$\begin{array}{ll}1.2 \text { Endoskopie und Zahnheilkunde } & 10\end{array}$

1.2.1 Technische Durchführung der Alveoloskopie 14

1.3 Anatomie, Histologie und Physiologie der Extraktionsalveole 15

1.3.1 Desmodont 15

$\begin{array}{ll}\text { 1.3.2 Zellen } & 16\end{array}$

$\begin{array}{ll}\text { 1.3.3 Bindegewebsfasern } & 17\end{array}$

$\begin{array}{ll}\text { 1.3.4 Grundsubstanz } & 18\end{array}$

$\begin{array}{ll}\text { 1.3.5 Gefäße und Nerven } & 18\end{array}$

$\begin{array}{ll}\text { 1.3.6 Kieferknochen } & 20\end{array}$

1.4 Parodontopathien und alveolärer Knochenverlust 22

1.5 Iatrogener alveolärer Knochenverlust 23

1.6 Regeneration der Extraktionsalveole 25

1.7 Atrophie der Extraktionsalveole 28

1.8 Bestimmung alveolärer Defektsituationen 30

1.8.1 Direkte Vermessung 31

1.8.2 Lupenbrille $\quad 32$

1.8.3 Operationsmikroskop 33

1.8.4 Röntgenaufnahmen 35

$\begin{array}{ll}\text { 1.8.5 Endoskop } & 37\end{array}$

1.9 Ziel der Arbeit 39

2. Material und Methode $\quad 40$

$\begin{array}{ll}2.1 \text { Patienten } & 40\end{array}$

2.2 Befunderhebung und Aufklärung 41

2.3 Radiologische Untersuchung 43 
2.4 Durchführung der Zahnextraktion

2.5 Endoskopisches Instrumentarium 45

2.6 Durchführung der endoskopischen Messungen 48

2.7 Vermessung der Panoramaschichtaufnahmen $\quad 50$

2.8 Dokumentation der radiographischen und endoskopischen Bilder $\quad 52$

2.9 Auswertung 53

3. Ergebnisse

3.1 Auswertung der Vermessung der Alveolen 54

3.2 Vergleich der endoskopisch erhobenen Messwerte mit den

röntgenologischen Messwerten bezogen auf die Strecke AlveolenbodenLimbus alveolaris mesial

4. Diskussion

4.1 Methodische Aspekte der Defektbestimmung von Alveolen 72

4.2 Risiken für den Patienten 77

4.3 Darstellung anatomischer Strukturen in der Extraktionsalveole $\quad 78$

4.4 Kieferkammerhalt und mikrochirurgische Maßnahmen mit der $\begin{array}{ll}\text { Endoskopie } & 81\end{array}$

4.5 Klinische Bedeutung der Alveoloskopie $\quad 84$

$\begin{array}{ll}4.6 \text { Schlussfolgerungen } & 87\end{array}$

$\begin{array}{ll}\text { 5. Zusammenfassung } & 88\end{array}$

6. Abkürzungsverzeichnis 90

7. Literaturverzeichnis 92 


\section{Abbildungsverzeichnis}

Abb.1 Übersicht über die Verteilung der entfernten Zähne auf das Gesamtgebiss

Abb.2 Endoskop, Kamera Telcam DX 20212034 C-Mount 46

Abb.3 Endoskop, Lichtleiter, Stütz-Spülschaft 47

Abb.4 Schematische Darstellung: Sonde und Endoskop auf

Alveolenboden (Punkt 1)

Abb.5 Schematische Zeichnung: Endoskop am Limbus alveolaris oral (Punkt 4)

Abb.6 Schematische Zeichnung zur endoskopischen Vermessung

der Alveole in oraler, vestibulärer und approximaler Richtung

Abb.7 Schematische Zeichnung zur Vermessung der

Panoramaschichtaufnahme

Abb.8 Vermessung der Panoramaschichtaufnahme in zentraler und approximaler Richtung

Abb.9 Computergestützte Archivierung der Röntgenbilder sowie der intra operationem gewonnenen endoskopischen Bilddaten

Abb.10 Verteilung der endoskopisch untersuchten Alveolen auf Ober- und Unterkiefer

Abb.11 Box-Plot-Diagramme der endoskopisch erhobenen Messwerte der Strecken 1-2 und 1-3 der Oberkiefer-

Frontzahnextraktionsalveolen

Abb.12 Box-Plot-Diagramm der endoskopisch erhobenen Werte der Strecke 1-4 der Oberkiefer- Frontzahnextraktionsalveolen

Abb.13 Graphische Darstellung der Oberkiefer- Frontzahnextraktionsalveole (regio 13-23)

Abb.14 Box-Plot-Diagramm der röntgenologisch erhobenen Werte der Strecken rö1-2 und rö1-4 der Oberkiefer-Frontzähne 
Abb.15 Box-Plot-Diagramm der endoskopisch erhobenen Messwerte der

Strecken 1-2 und 1-3 der

Oberkiefer- Prämolarenextraktionsalveolen

Abb.16 Box-Plot-Diagramm der endoskopisch erhobenen Messwerte der

Strecke 1-4 der Oberkiefer- Prämolarenextraktionsalveolen

Abb.17 Graphische Darstellung der Oberkiefer-

Prämolarenextraktionsalveole (Zähne 14,15)

Abb.18 Graphische Darstellung der Oberkiefer-

Prämolarenextraktionsalveole (Zähne 24,25)

60

Abb.19 Box-Plot-Diagramm der röntgenologisch erhobenen Werte der

Strecken rö1-2 und rö1-4 der Oberkiefer- Prämolaren

Abb.20 Box-Plot-Diagramme der endoskopisch erhobenen Werte für die Strecken 1-2 und 1-3 der Unterkiefer-

Frontzahnextraktionsalveolen

Abb.21 Box-Plot-Diagramm der endoskopisch erhobenen Werte für die

Strecke 1-4 der Unterkiefer- Frontzahnextraktionsalveolen

Abb.22 Graphische Darstellung der Unterkiefer-

Frontzahnextraktionsalveole

Abb.23 Box-Plot-Diagramm der röntgenologisch erhobenen Werte der

Strecken rö1-2 und rö1-4 der Unterkiefer- Frontzähne

Abb.24 Box-Plot-Diagramm der endoskopisch erhobenen Werte für die

Strecken 1-2 und 1-3 der Unterkiefer- Prämolaren

Abb.25 Box-Plot-Diagramm der endoskopisch erhobenen Werte für die

Strecke 1-4 der Unterkiefer- Prämolarenextraktionsalveolen

Abb.26 Graphische Darstellung der Unterkiefer-

Prämolarenextraktionsalveolen

Abb.27 Box-Plot-Diagramm der röntgenologisch erhobenen Werte der Strecken rö1-2 und rö1-4 der Unterkiefer- Prämolaren 
Abb.28 Vergleich der endoskopisch erhaltenen Messwerte mit den korrigierten röntgenologischen Messwerten für die Strecken 1-4 und rö1-4 der Oberkiefer- Frontzahnalveole (Zähne 13-23)

Abb.29 Vergleich der endoskopisch erhaltenen Messwerte mit den korrigierten röntgenologischen Messwerten für die Strecken 1-4 und rö1-4 der Oberkiefer -Prämolarenalveolen (Zähne 14,15,24,25)

Abb.30 Vergleich der endoskopischen (blau) und korrigierten röntgenologischen (lila) Messwerte für die Strecken 1-4 und rö1-4 der Unterkiefer -Frontzahnalveolen

Abb. 31 Vergleich der endoskopischen (blau) und korrigierten röntgenologischen (lila) Messwerte für die Strecken 1-4 und rö1-4 der Unterkiefer- Prämolarenalveolen 


\section{Einleitung}

\subsection{Einführung in das Thema}

Die Definition Endoskopie leitet sich von den griechischen Wörtern -endo (innen, hinein) und -skopein (sehen) ab und bedeutet soviel wie: „Einblick nehmen in die inneren Hohlräume des menschlichen Körpers“".

Die Anwendung des Endoskops als diagnostisches und therapeutisches Hilfsmittel ist heute in vielen medizinischen Fachdisziplinen etabliert, so werden Operationen wie die Appendektomie oder die Cholezystektomie routinemäßig endoskopisch durchgeführt.

Das Endoskop wird als optisches Gerät entlang von natürlichen Körperöffnungen (Mund, Nase, Ohren) oder durch künstliche Zugänge (über kleine Hautinzisionen) eingesetzt.

Als eine der ersten Fachrichtungen etablierte die Hals-Nasen-Ohrenheilkunde endoskopische OP-Techniken als Behandlungsmethode : Gustav Kilian empfahl die Technik der Rhinoscopia media mit dem von ihm entwickelten Nasenspekulum und veröffentlichte eine Methode zur endonasalen Resektion des Processus uncinatus bei chronischer Sinusitis maxillaris (Behrbohm 2003). Heutzutage kommt im Fachgebiet der Hals-Nasen-Ohrenheilkunde das Endoskop bei der Diagnostik und Therapie von Erkrankungen der Nase, der Nasennebenhöhlen, des Naso-und Hypopharynx, des Larynx, der Trachea und des Ösophagus zum Einsatz. Hierbei werden für die Nase, die Nasennebenhöhlen und den Nasopharynx eher die starren Endoskope gewählt, wohingegen im Hypopharynx, Larynx, Ösophagus und in der Trachea die flexiblen Endoskope zum Einsatz kommen. Im Bereich der Nase wird die Endoskopie zum einen bei der Diagnostik von akuten oder chronischen Sinusitiden und zum anderen bei der Beurteilung des Behandlungserfolges 
benötigt. Sinuskopische Untersuchungen können ambulant erfolgen und gehen meist ohne große postoperative Beschwerden einher. Insofern hat sich die Sinuskopie als diagnostisches Instrument bei anderweitig nicht sicher diagnostizierbaren Kieferhöhlenerkrankungen bewährt (Fisher und Croft 1989). Darüber hinaus hat sich die Sinuskopie als Instrument zur unmittelbar präoperativen anatomischen Orientierung bei der Sinusbodenaugmentation als sinnvoll erwiesen (Engelke und Deckwer 1997).

Auch bei der Diagnostik und Therapie von Erkrankungen der Tränenwege kommt das Endoskop zum Einsatz. Beim Vorliegen einer Stenose im Bereich des Saccus lacrimalis oder des Ductus nasolacrimalis ist es durch den Gebrauch des Endoskops möglich, unter Schonung des Saug- und Pumpmechanismus der Tränenflüssigkeit von der Nase aus zu operieren.

Ein weiteres Einsatzgebiet des Endoskops stellt die Augenheilkunde dar. Hier wird das Endoskop bei Fremdkörperentfernungen (Splitterverletzungen) oder auch bei der Entfernung von Tumoren, die von der Augenhöhle aus dem Siebbein anliegen, benutzt. Bei intraorbitalen Druckerhöhungen, wie sie bei der endokrinen Orbitopathie oder nach traumatischen Blutungen in die Orbita auftreten, hat sich die endoskopische Dekompression der Augenhöhle bewährt. Als Hilfe hat sich das Endoskop bei der Behandlung von Epistaxis (Nasenbluten) erwiesen, da die Arteria sphenopalatina im Bereich des Foramen sphenopalatina aufgespürt und verkautert werden kann, wobei dem Patienten ein großer Eingriff oder eine Embolisierung erspart werden können. 


\subsection{Endoskopie und Zahnheilkunde}

Der Einsatz des Endoskops in der Parodontologie, Endodontie, Implantologie und Zahnerhaltung hat sich in den letzten Jahren als sehr vorteilhaft erwiesen, so dass in diesen Fachgebieten eine fortschreitende Tendenz zum regelmäßigen Gebrauch des Endoskops als diagnostisches und therapeutisches Hilfmittel zu beobachten ist. Die Anwendung der Endoskopie in den neueren Bereichen kann man als Odontoskopie, bzw. die Anwendungsverfahren als odontoskopische Verfahren bezeichnen (Engelke und Capobianco 2005a). Der Begriff Odontoskopie leitet sich ähnlich wie „Endoskopie“ aus dem Griechischen ab und setzt sich aus den Wörtern „odont“- (=Zahn) und „skopein“ (=sehen) zusammen.

Die Odontoskopie stellt eine Untersuchungsmethode dar, bei der die endoskopische Technik im Bereich des zahntragenden Kiefers zum Einsatz kommt und die durch Stützfunktion, Reinigungsfunktion und die Möglichkeit digitaler Bildverarbeitung und Dokumentation gekennzeichnet ist (Engelke und Capobianco 2004). Die Odontoskopie ist ein Oberbegriff, unter dem sich die unterschiedlichen odontoskopischen Verfahren wie die Apikoskopie, die Pulposkopie , die Parodontoskopie, die Osteoskopie, die Koronoskopie und die Alveoloskopie zusammenfassen lassen.

Der Gebrauch des Endoskops wird sowohl für endodontische Behandlungen als auch für endodontisch-chirurgische Maßnahmen empfohlen (Detsch et al. 1979, Marshall et al. 1981, Held et al. 1996, Bahcall et al. 1999, Bahcall und Brass 2003, Von Arx et al. 2003, Taschieri et al. 2006). Beim häufigsten Eingriff der Endochirurgie, der periradikulären Chirurgie, unterstützt das Endoskop insbesondere bei unübersichtlichen anatomischen Verhältnissen die Lokalisation der Wurzelspitze im Alveolarknochen (Engelke und Capobianco, 2005b). 
Das Endoskop kommt ferner zur Identifizierung von Wurzelkanälen (Nance et al. 2000; De Moor und Calberson 2005) und auch bei der retrograden Präparation von Wurzelkanalkavitäten nach Wurzelspitzenresektion (Held et al. 1996) zur Anwendung. Der Gebrauch des Endoskops in der konventionellen Endodontie kann als Pulposkopie bzw. als interne Koronoskopie bezeichnet werden (Engelke und Capobianco 2005b). In diesem Zusammenhang beschreibt von Arx das Auffinden von Wurzelkanalisthmen erster Molaren durch die endoskopische Inspektion während einer Wurzelspitzenresektion (Von Arx 2005).

Ferner wird das Endoskop nicht nur während der periradikulären Chirurgie (Filippi et al. 2006), sondern auch bei der Identifikation und chirurgischen Therapie von lateralen oder interradikulären Perforationen, Frakturen (Slaton et al. 2003) und bei Wurzelamputationen eingesetzt. Die endoskopische Untersuchung der Wurzelspitze im Rahmen der endodontischen Chirurgie kann als Apikoskopie bezeichnet werden (Engelke und Capobianco 2005b).

Im Bereich der maxillo-fazialen Chirurgie berichtet Troulis von der endoskopischen Mandibula-Osteotomie, bei der ein Distraktor eingesetzt wird (Troulis et al. 1999, Troulis et al. 2004). Lauer und Schmelzeisen beschreiben den Einsatz des Endoskops bei der Fixation von Gelenksfortsatzfrakturen des Unterkiefers (Lauer und Schmelzeisen 1999; Schon et al. 2002).

Ebenso kommt das Endoskop bei der Le-Fort-1-Osteotomie (Wiltfang et al. 2002; Rohner et al. 2001) und der plastischen Rekonstruktionschirurgie (Raurell et al. 2006) zur Anwendung.

Des Weiteren wird über den Einsatz der Endoskopie zur Diagnostik der Kieferhöhlen (Schmidseder und Lambrecht 1978, Lambrecht und Härle 1987, Fisher und Croft 1989, Wiltfang et al. 1999) sowie des Kiefergelenks berichtet (Carls et al. 1995). 
Schon beschreibt das extra- und intraoral assistierte Vorgehen bei CollumFrakturen (Schon et al. 2002).

Lee empfiehlt die Anwendung des Endoskops bei der Extraktion intranasaler Zähne (Lee 2001).

Komatsuzaki berichtet über den Gebrauch des Endoskops bei der Entfernung der submandibulären Speicheldrüsen (Komatsuzaki et al. 2003).

Suarez-Cunqueiro beschreibt die endoskop-assistierte Entfernung eines Fremdkörpers aus dem Condylarprocess (Suarez-Cunqueiro et al. 2004). Yura setzt das Endoskop zur Fremdkörperentfernung ( Entfernung eines Guttaperchapoints) aus dem Sinus maxillaris ein (Yura et al. 2007).

In der Parodontologie verwenden Ozawa und Stambaugh ebenso wie Kwan, Geisinger und Michaud optische Systeme zur Untersuchung des Sulcus gingivalis im Rahmen von Parodontalbehandlungen zur Konkremententfernung und zur Beobachtung der Wurzeloberfläche (Ozawa et al. 1999, Stambaugh et al. 2002, Kwan 2005, Geisinger et al. 2007, Michaud et al. 2007). Avradopoulos berichtet über den Gebrauch des Endoskops bei Patienten mit chronischer Parodontitis (Avradopoulos et al. 2004). Der Einsatz eines speziellen fiberoptischen Endoskops ermöglicht die Detektion von Wurzelkaries (Ozawa et al. 1999, Stambaugh et al. 2000a, Ozawa et al.2003), Wurzelperforationen und -frakturen, sowie subgingivalen Konkrementen (Ozawa et al. 1999, Ozawa et al. 2003). Der Einsatz des Endoskops in der Parodontologie wird als Parodontoskopie (Engelke und Capobianco 2005b) und im englischen Sprachraum als perioscopy (Stambaugh 2003) bezeichnet.

Auf dem Gebiet der Implantologie wird außerdem der Einsatz des Endoskops bei der Kontrolle nach Sinusbodenaugmentation beschrieben (Wiltfang et al.1999, Baumann und Ewers 1999). 
Engelke berichtet über eine gering invasive Form der Sinusbodenaugmentation, die SALSA-Technik (Engelke 2000). Des Weiteren wird das Endoskop zur Implantatfreilegung (Engelke und Capobianco 2005b), zur Beurteilung der Implantatstabilität direkt nach der Insertion (Engelke et al. 2004) und zur Therapie von Periimplantitiserkrankungen eingesetzt (Sennhenn-Kirchner und Engelke 2003).

Die Untersuchung des Kieferknochens mit dem Endoskop kann als Osteoskopie bezeichnet werden (Engelke und Capobianco 2005b). Hierbei wird zwischen externer Osteoskopie (die Beobachtung der Knochenoberfläche) und der internen Osteoskopie (die Beobachtung von artifiziell erzeugten Knochenhohlräumen) unterschieden (Engelke und Capobianco 2005b). Im Fachbereich der Zahnerhaltung kommt die Koronoskopie bei der Beurteilung von Zahnkronen zum Einsatz. Die endoskopische Betrachtung unterstützt das Auffinden von Karies an sonst schwer zugänglichen Stellen. Die Endoskopie erlaubt die Kontrolle von Kavitäten auf noch vorhandenes kariöses Dentin. Zusätzlich wird eine Inspektion pulpennaher Läsionen unter hoher Vergrößerung ermöglicht, die ggf. eine unbeabsichtigte Eröffnung einer vitalen Pulpa verhindert (Engelke und Capobianco 2005b).

Unterschieden werden die einfache Koronoskopie ohne Immersion und die unter Immersion stattfindende Koronoskopie. Ohne Immersion ähnelt die Koronoskopie dem Einsatz einer Intraoralkamera. Allerdings erfolgt hierbei eine Abstützung auf der Zahnkrone, so dass die durch freie Führung der Intraoralkamera anfallenden Schwierigkeiten wie das Auftreten von Bewegungsartefakten oder Focussierungsproblemen wegfallen. Bei der Koronoskopie mit Immersion muss eine Kavität vorliegen, die in geeigneter Weise abgedämmt werden kann, so dass ein Auffüllen der Kavität mit Flüssigkeit und eine Beobachtung unter Immersion erfolgen können (Engelke und Capobianco 2005b). 
Joudzbalys beschreibt den Einsatz des Endoskops bei der Vermessung von Extraktionalveolen (Joudzbalys et al. 2008). Ebenfalls mit der Stützimmersionsendoskopie können auch Wandstrukturen von Implantatkavitäten beobachtet werden (Engelke 2002a). Die Stützimmersionsendoskpie wird hierbei ergänzend zur röntgenologischen Untersuchung eingesetzt, die neben der Einteilung der Kavitätenwandstruktur in spongiöse und kortikale Abschnitte auch eine Beurteilung der Vaskularisierung des Knochens sowie die Darstellung von Verletzungen der Kavität im Sinne von Frakturen oder Dehiszenzen ermöglicht.

\subsubsection{Technische Durchführung der Alveoloskopie}

Der Begriff Alveoloskopie beschreibt den Einsatz des Endoskops bei der Detailbetrachtung einer Extraktionsalveole. Die Alveoloskopie erfolgt nach dem Prinzip der Stützimmersionsendoskopie (SIE), die von Engelke 2002 das erste Mal zur Untersuchung von Implantatkavitäten beschrieben wurde (Engelke 2002a). Das Endoskop wird hierbei mit einem Stütz-Spül-Schaft versehen, der das Endoskop um 2,5 mm überragt. Dadurch ist es möglich, unter Abstützung und kontinuierlicher Spülung die Extraktionsalveole zu untersuchen. Die Abstützung des Endoskops kann sowohl an den Kavitätenwänden als auch am Boden der Alveole erfolgen. Der gleich bleibende Abstand des in den Schaft integrierten Endoskops zum beobachteten Objekt (2,5mm) ermöglicht die exakte Fokussierung. Unmittelbar vor dem Endoskopfenster befindet sich eine Öffnung, durch die während der Untersuchung Spülflüssigkeit austritt. Ein angeschlossenes Spülsystem ermöglicht es, zwischen kontinuierlicher oder intermittierender Spülung zu wählen. Als Spülmedium kommt sterile Kochsalzlösung zum Einsatz. Während der Untersuchung wird die Alveole vollständig mit Flüssigkeit aufgefüllt und das Endoskop in die Spülflüssigkeit eingetaucht. Das vollständige Benetzen sowohl der Alveole als auch des 
Endoskops mit Spülflüssigkeit ermöglicht eine grenzflächenfreie Beobachtung der Alveole. Gleichzeitig verhindert die Spülung eine Kontamination des Sichtfensters durch spontan auftretende oder fortbestehende kapilläre Blutungen.

\subsection{Anatomie, Histologie und Physiologie der Extraktionsalveole}

Der Begriff „Parodont“ leitet sich ab von den griechischen Wörtern „para“, was soviel bedeutet wie bei, neben, entlang und „odont“, was mit Zahn zu übersetzen ist (Müller 2001). Neben dem Begriff Parodontium existieren in der Literatur verschiedene Synonyme: Parodont, Periodontium, Zahnhalteapparat und Paradentium. Die aus Weich-(Gingiva, Desmodont)und Hartgeweben (Wurzelzement und eigentlicher Alveolarknochen) bestehenden Bauelemente erfüllen in ihrer Eigenschaft als Parodont verschiedene Aufgaben:

Die Verankerung des Zahnes in seiner knöchernen Alveole, die Zusammenfassung der Zähne innerhalb eines Kiefers als Zahnreihe, die Anpassung an funktionelle und topographische Veränderungen, die Ermöglichung von Zahnstellungsänderungen, die Reparation der Auswirkungen traumatischer Insulte, die Gewährleistung der epithelialen Auskleidung der Mundhöhle, die Bereitstellung peripherer Abwehrmechanismen gegen Infektionen sowie die Schmerz- und Druckperzeption und das Tastempfinden (Müller 2001)

\subsubsection{Desmodont}

Das Desmodont, welches auch als Wurzelhaut oder Periodontium bezeichnet wird, ist ein sehr zell- und faserreiches, derbes Bindegewebe, das zwischen der Wurzeloberfläche des Zahnes und dem Alveolarknochen liegt und diesen mit 
dem Wurzelzement verbindet. Das desmodontale Gewebe besteht aus Zellen, Bindegewebsfasern, Grundsubstanz, Gefäßen und Nerven (Schroeder 2000). Am Alveolarknochenkamm geht das Desmodont kontinuierlich in das Bindegewebe der angewachsenen Gingiva über. Das Desmodont und die mit ihm entstehenden Hartgewebe (Wurzelzement und Alveolarknochen) stellen eine gelenkartige Verbindung zwischen Zahn und Knochen her, die auch als Syndesmose bezeichnet wurde (Fröhlich 1958). Aufgabe des Desmodonts ist zum einem, die bei Zahnkontakten entstehenden Kräfte auf den Alveolarfortsatz umzuleiten, damit diese dort abgefangen werden können. Zum anderen gestattet das Desmodont dem einzelnen Zahn eine eigene Beweglichkeit. Bei physiologischen oder kieferorthopädisch gesteuerten Zahnbewegungen wird der Faserapparat des Desmodonts mit Zug und Druck belastet, die nur in einem bestimmten Rahmen toleriert werden und Umbauvorgänge hervorrufen. Die Zahnbeweglichkeit ist im großen Maße durch die Breite, Höhe und Qualität des Desmodonts bestimmt (Schroeder 2000).

\subsubsection{Zellen}

Die Zellen des Desmodonts bilden eine sehr zahlreiche und funktionell sehr unterschiedliche Population. Zu ihren Aufgaben gehört das Remodellieren des Wurzelzementes und des Alveolarknochens, des Weiteren unterhalten sie alle physiologischen Prozesse im desmodontalen Gewebe. Die Gesamtpopulation desmodontaler Zellen setzt sich aus Fibroblasten, Ostoe- und Zementoprogenitorzellen, Osteoklasten und Osteoblasten, Zementoblasten und Dentoklasten, Epithelzellen und Leukozyten zusammen (Schroeder 2000). Der am weitesten verbreitete Zelltyp im Desmodont ist der Fibroblast, der für die im Vergleich zu anderen Geweben deutlich erhöhte Umsatzrate des desmodontalen Kollagens verantwortlich ist (Listgarten 1973, Ten Cate und 
Deporter 1974, Ten Cate und Deporter 1975, Ten Cate et al. 1976, Shore und Berkovitz 1979, Deporter und Ten Cate 1980, Melcher und Chan 1981, Schroeder 1986), wodurch das Desmodont ständig und relativ schnell auf entsprechende Reize mit Umbau und Adaptation reagieren kann (Plagmann 1998).

\subsubsection{Bindegewebsfasern}

Der größtenteils aus Kollagen und zu einem kleinen Anteil aus Oxytalan bestehende Faserapparat stellt den volumenmäßig größten Anteil des desmodontalen Gewebes dar. Der Faserapparat setzt sich aus den orientierten, vom Alveolarknochen zum Zement verlaufenden Faserbündeln, den so genannten primären Fasern (principal fibers) und einem mehrheitlich die Gefäße und Nervenstränge umspinnenden, losen und nicht gebündelten Faseranteil, den sekundären Fasern, zusammen (Sicher 1954).

Alle primären Faserbündel sind einerseits im Wurzelzement und andererseits im Alveolarknochen verankert. Der in diese Hartgewebe eingelassene Anteil wird als Sharpey'sche Faser bezeichnet. Sie sind oft nicht gradlinig zwischen beiden Hartgeweben ausgespannt, sondern erscheinen in ihrer Verlaufsrichtung eher gewellt. Die primären Fasern bilden den zahntragenden Faserapparat und werden deshalb auch desmodontale Fasern genannt. Zwischen den oxytalanen und den kollagenen Faserbündeln befinden sich die bindegewebige Grundsubstanz sowie Gefäße und Nerven. Sekundäre Fasern enthalten mehrheitlich kollagene Fasern, bestehen zum Teil aber auch aus elastischen Fasern (Hellwig et al. 1999, Schroeder 2000). Sie liegen lose und ungebündelt zwischen den Hauptfasergruppen und sind hauptsächlich in der Umgebung von Gefäßen und Nerven zu finden (Hellwig et al. 1999, Mutschelknauss 2000, Schroeder 2000). 


\subsubsection{Grundsubstanz}

Die Grundsubstanz stellt ein stark visköses Gel dar, das überwiegend aus Glykosaminoglykanen (Mukopolysacchariden), Glykoproteinen und Lipiden besteht (Melcher und Eastoe 1969, Pearson 1982). Diese Makromoleküle sind an der Steuerung von Zellfunktionen, Zellwachstum, Zelladhäsion und Zellwanderung beteiligt (Plagmann 1998). In die Grundsubstanz eingelagert sind die strukturellen Elemente des Desmodonts, wie Faserbündel, Zellen, Blutgefäße, Nervenfasern und Lymphgefäße.

\subsubsection{Gefäße und Nerven}

Blutgefäße: Im Vergleich zu anderen Bindegeweben ist das Desmodont sehr stark vaskularisiert. Dieser Unterschied hängt möglicherweise sowohl mit dem hohen Sauerstoffbedarf des so dicht gefaserten und zellreichen Desmodonts als auch mit der Notwendigkeit einer druckausgleichenden

Flüssigkeitsverschiebung zusammen (Birn 1966, Picton1969, Schroeder 1986). Das desmodontale Blutgefäßsystem ist netzartig aufgebaut und wird aus drei Quellen gespeist. Erstens zweigen Äste der ins Foramen apicale eintretenden A. dentalis im periapikalen Desmodont ab (Edwall 1982, Hayashi 1932, Schroeder 1986). Zweitens ziehen Äste der Aa. interalveolares und der Aa.

interradiculares, die innerhalb der Spongiosa der interradikulären und interdentalen Knochensepten verlaufen, durch die Volkmann-Kanäle (Foramina der Lamina cribriformis ) ins Desmodont (Birn 1966, Hayashi 1932, Schroeder 1986). Drittens treten supraperiostale Gefäßäste der Gingiva zum desmodontalen Gefäßsystem hinzu (Hayashi 1932, Schroeder 1986). Alle diese Gefäße sind Seitenäste der Aa. alveolares und der Aa. infraorbitales, Aa. linguales und Aa. mentales. Die Arteriolen und Venolen bilden ein mehrheitlich 
einschichtiges, die gesamte Zahnwurzel korbartig umgebendes Netz mit wechselnder Maschenweite, das etwa in der Mitte zwischen Knochen und Zement im desmodontalen Raum lokalisiert ist (Schroeder 2000).Die venösen Abflüsse aus diesem Korb folgen dem Verlauf der Arterien. Die Hauptgefäße des korbartigen Gefäßnetzes verlaufen palisanderartig in apikokoronaler Richtung (Castelli und Dempster 1965).Wedl entdeckte 1881 knäuelartige Gefäßschlingen, die Glomerula genannt werden. Diese stellen verzweigte Gefäßbündel des desmodontalen Gefäßnetzes, die zwischen den primären Faserbündeln im von losen Kollagenfasern umsponnenen Interstitium auftreten (Edwall 1982, Schroeder 1986).

\section{Nerven}

Das Desmodont wird von zwei Nervenfasergruppen innerviert, diejenigen, die dem sensorischen, und diejenigen, die dem autonomen System angehören (Byers und Holland 1977, Byers 1985, Hannam 1982). Das desmodontale Gewebe vermag zwei Arten von Empfindungen wahrnehmen: Schmerz und Druck. Die freien Nervenendigungen sensorischer Fasern, die überwiegend im zementnahen Desmodont anzutreffen sind, sind verantwortlich für die Schmerzrezeption, die Ruffini-artigen Endigungen als Mechanorezeptoren für die propiorezeptiven Reize (Druck). Die Empfindung von Druck ist überaus fein, selbst leichteste Zahnkontakte werden registriert. Diese Druckempfindungen werden über den N. trigeminus in das Mesenzephalon und die Medulla oblongata geleitet und lösen über Reflexbögen zu motorischen Neuronen eine die Kaumuskulatur sowie die Wangen-, Lippen- und Zungenmuskulatur aktivierende Reaktion aus (Hannam 1982) (=Kirschkernreflex).

Außer den sensorisch-afferenten Nervenfasern enthält das Desmodont autonome, wahrscheinlich sympathische Fasern, die meist marklos sind und korbartige Strukturen um die Blutgefäße bilden (Schroeder 2000). Diese Fasern 
sind für die Steuerung der glatten Muskelzellen sämtlicher desmodontaler Gefäße, das heißt für die lokale Blutgefäßregulation verantwortlich (Hannam 1982).

\section{Lymphgefäße}

Die Lymphe wird in sehr dünnwandigen Lymphkapillaren und stärkeren Lymphgefäßen abgeführt, die parallel mit den venösen Blutbahnen verlaufen (Bernick und Grant 1978, Box 1949, Edwall 1982, Schroeder 1986). Die Lymphgefäße verlassen das Desmodont über das gingivale Gewebe, die Alveolarschleimhaut sowie die Volkmannschen Kanäle des Alveolarknochens. Analog zu den Blutgefäßen bilden auch die Lymphgefäße des Desmodonts ein dichtes, korbartig geformtes Netz, das mit den Lymphgefäßen der Gingiva und der alveolären Knochensepten anastomosiert (Schroeder 1986).

\subsubsection{Kieferknochen}

Die knöchernen Anteile des Ober- und Unterkiefers, in denen die Zahnwurzeln in Funktion stehender Zähne eingelassen sind, werden Processus alveolaris (Maxilla, Oberkiefer) und Pars alveolaris (Mandibula, Unterkiefer) genannt oder als Alveolarfortsätze bezeichnet (Schroeder 2000). Diese Anteile sind zahnabhängige Strukturen. Sie entwickeln sich mit der Bildung und dem Durchbruch der Zähne und bilden sich nach ihrem Verlust wieder zurück (Kurihara und Enlow 1980, Landsberger 1923, Schroeder 1986). So kommt es bei Kindern mit einer angeborenen totalen Anodontie zu keiner Entwicklung der Alveolarfortsätze. In Abhängigkeit der unterschiedlichen Größe, der Form und der Stellung der Zähne im Kieferknochen ergeben sich Unterschiede in der Morphologie des Alveolarfortsatzes. Zur Funktion der Alveolarfortsätze gehört die Verankerung der Zähne in den Zahnfächern (Alveolen) und die Aufnahme und Verteilung jener Kräfte, die als Druck durch intermittierenden Zahnkontakt 
beim Kauen, Schlucken, Sprechen und bei parafunktionellem Stress (Knirschen, Pressen) ausgelöst werden (Schroeder 2000). Die Alveolarfortsätze der Maxilla und der Mandibula bestehen aus drei Anteilen. Einer äußeren, unterschiedlich dicken, von Periost bedeckten Knochenplatte, nämlich der äußeren Kortikalis. Des Weiteren aus einer inneren und sehr porösen Knochenplatte, der Lamina cribriformis oder auch innere Kortikalis. Und der zwischen beiden Knochenplatten und auch interradikulär und interdental zwischen zwei Laminae cribriformes liegenden Spongiosa. Am Eingang der Alveole, der als alveolärer Knochenkamm oder Limbus alveolaris bezeichnet wird, gehen die äußeren, kompakten Kortikalisschichten in die Lamina cribriformis über. Die Struktur der Kortikalis und der Knochenbälkchen der Spongiosa besteht aus Haversschen Systemen (Osteomen) und Lamellen (MacMillan 1924). Die Spongiosa besteht aus zarten, netzförmig angeordneten Knochenbälkchen, zwischen denen sich Knochenmarksräume befinden, die meist Fettmark enthalten (Schroeder 2000). Die Lamina cribriformis bildet die Alveolenwand und ähnelt einem feinlöchrigen Sieb, an welchem die Knochenbälkchen der Spongiosa befestigt sind. Die im koronalen und apikalen Bereich der Alveolen besonders zahlreichen Foramina dieser Knochenplatte, die als Volkmannsche Kanäle bezeichnet werden, verbinden das Desmodont und die Knochenmarksräume (Schroeder 2000). Sie werden von Blut- und Lymphgefäßen sowie von Nervenfasern durchzogen (Birn 1966, Hayashi 1932). 


\subsection{Parodontopathien und alveolärer Knochenverlust}

Unter dem Begriff Parodontopathien werden entzündlich bedingte und nicht entzündlich bedingte Erkrankungen der Mundschleimhaut und des Zahnhalteapparates verstanden. Bei der Untersuchung entzündlicher Parodontopathien wird zwischen zwei Ursachenkomplexen unterschieden. Der primäre Ursachenkomplex beschreibt die in der Plaque vorhandenen Pathogene und die plaquebedingten entzündlichen Reaktionen des Parodonts. Der sekundäre Ursachenkomplex umfasst lokale und systemische Faktoren, die den primären Ursachenkomplex beeinflussen können. Das Auftreten einer Parodontitis geht einher mit einer unterschiedlich schnellen und variabel tief reichenden Zerstörung des Zahnhalteapparates. Mit der Ausdehnung der supragingivalen bakteriellen Plaque nach subgingival beginnt die Bildung einer Zahnfleischtasche. Die Zahnfleischtasche ist mit zahnadhärenter Plaque besiedelt, die sich aus grampositiven aeroben, nichtmotilen Kokken und Stäbchen zusammensetzt. Das sauerstoffarme Milieu des Subgingivalraumes begünstigt die Entwicklung anaerober Keime. Es schließt sich eine Kolonisation der Zahnfleischtasche mit gramnegativen, fakultativ oder obligat anaeroben motilen Stäbchen und Kokken (Prevotella intermedia, Porphyromonas gingivalis, Actinobacillus actinomycetem comitans, Eicanella corrodens, Fusobacterium nucleatum) an, die sich zu einer sekundären losen Plaqueschicht formieren. Die Substratzufuhr der subgingivalen Plaque erfolgt überwiegend durch die Sulkusflüssigkeit. Die Menge an schwimmender Plaque nimmt mit zunehmender Zahnfleischtaschentiefe zu. Die Plaque ist umso parodontopathogener, je mehr bewegliche, gramnegative und anaerobe Erreger in ihr zu finden sind. Diese Plaquebakterien verfügen über unterschiedliche Virulenzfaktoren, die die Destruktion des Parodonts beschleunigen können. So lösen zum Beispiel die von den Mikroorganismen produzierten Enzyme die 
Interzellularsubstanz bzw. das kollagene Stützgerüst auf und erleichtern so das Eindringen der Mikroorganismen ins Gewebe. Zu diesen Enzymen gehören Kollagenasen (von Porphyromanas gingivalis produziert), Hyaluronidasen, Chondroitinsulfatasen, Neuraminidasen und unterschiedliche Proteasen und Peptidasen sowie alkalische und saure Phosphatasen. Das Resultat des Zusammenwirkens von subgingival gerichteter Plaqueausdehnung, bakterieller Proliferation und entzündlicher Exsudation ist die Bildung einer Knochentasche (Takata und Donath 1988). Hieraus resultieren Strukturveränderungen des Zahnhalteapparates. Bei der histologischen Untersuchung fällt eine Veränderung des am Zahn anhaftenden Saumepithels auf. Es kommt neben einer endgültigen Abtrennung koronaler Saumepithelanteile von der Zahnoberfläche zu einer Umwandlung des gelösten Saumepithels in ein Taschenepithel. Dieses Taschenepithel zeichnet sich durch die Proliferation von langen, dünnen Epithelleisten aus, die sich in das infiltrierte Bindegewebe erstrecken. Es kommt zu Mikroulzerationen zwischen den Epithelleisten. Das Taschenepithel zeigt weiterhin eine erhöhte Permeabilität für Moleküle jeder Art, so dass sich im kollagenfaserarmen Bindegewebe subepithelial entlang des Taschenepithels ein entzündliches Infiltrat bildet.

\subsection{Iatrogener alveolärer Knochenverlust}

Iatrogener alveolärer Knochenverlust kann unterschiedliche Ursachen haben. Im Bereich der Parodontalchirurgie kann es zur Schaffung einer günstigen Gingivamorphologie notwendig sein, eine modellierende Osteotomie durchzuführen. Die Resektion beinhaltet eine Ausformung dicker vestibulärer oder oraler Knochenränder, eine Resektion überstehender Septumanteile, eine Harmonisierung des girlandenförmigen marginalen Knochenrandes sowie eine 
Modellierung prominenter Wurzelanteile (Krekeler 1993). Wichtig hierbei ist, dass bei der Knochenmodellage niemals parodontal stützende Knochenstrukturen entfernt werden dürfen. Die modellierende Knochenchirurgie hilft, die nach einer Parodontitiserkrankung verbleibenden Knochenkrater zu verkleinern, Furkationseingänge zu minimieren, Knochenränder zu reduzieren und bewirkt eine Verringerung der parodontalen Taschentiefe. Für den Patienten von Vorteil sind die besseren Hygienemöglichkeiten. Allerdings kann im Anschluss an eine modellierende Knochenresektion ein Attachmentverlust auftreten. Weitere parodontalchirurgische Eingriffe, die mit einem iatrogenen Knochenverlust einher gehen, sind die Hemisektion und die Wurzelamputation.

Im Bereich der konservierenden Zahnheilkunde stellt die chirurgische Kronenverlängerung eine Maßnahme zum Zahnerhalt dar. Indikationen hierfür sind eine zirkulär auftretende Karies, massive Abrasionen, aufgetretene zervikale oder intraalveoläre Frakturen im kronennahen Bereich oder subgingivale Perforationen. Entscheidend für den Erhalt und die Verlängerung sind die Kronen-Wurzel-Relation, eine aussichtsreiche Position des Zahnes im Zahnbogen und der strategische Wert des Zahnes (Krekeler 1993). Weiterhin sind neben dem parodontalen Zustand des Zahnes auch ästhetische und phonetische Gesichtspunkte zu beachten. Ziel der chirurgischen Kronenverlängerung ist es, eine Wurzelhöhe von 3,5-4mm mit gesunder Zahnsubstanz zu schaffen, um eine ausreichende Retention zu erzielen. Wie auch bei der modellierenden Knochenresektion kommen bei der chirurgischen Kronenverlängerung rotierende Instrumente (Rosenbohrer, feinkörnige Diamanten) sowie Knochenmeißel und Küretten zum Einsatz. Am häufigsten tritt iatrogener Knochenverlust im Zusammenhang mit einer Zahnentfernung auf. Eine Ursache hierfür sind alveoläre Frakturen, bei denen in den meisten Fällen die vestibulären Alveolenanteile an der Zahnwurzel anhaften 
und mit dem Zahn entfernt werden. Im Oberkiefer kann es bei Hebelextraktionen der letzten Molaren zur Fraktur und zum Verlust des relativ spongiösen Tuberknochens, zum sogenannten Tuberabriss, kommen (Wagner 1989). Eine weitere Ursache für iatrogenen Knochenverlust stellen frakturierte Zahn -und Wurzelanteile sowie retinierte Zähne dar, deren Entfernung eine Osteotomie notwendig macht. Bei der Osteoetomie wird der den Wurzelrest oder retinierten Zahn bedeckende Kieferknochen von vestibulär mit kleinen Rosenbohrern oder Lindemann-Fräsen abgetragen.

Nach schonend durchgeführter Extraktion entsteht eine offene Riss-QuetschWunde im Schleimhautbereich mit knöcherner Exposition (so genannte Knochen-Weichteil-Wunde) (Krüger 1993). Ausgenommen hiervon ist der seltene Idealfall, dass die Sharpey'schen Fasern reißen und die knöcherne Alveole dann von einer dünnen Schicht lebenden Periosts überzogen ist. Wichtig für einen störungsfreien Knochenheilungsprozess ist die Schonung des inneren Saumepithels durch gewissenhaftes Lösen der Gingiva vom Zahn und Durchtrennung des Ligamentum circulare, da nach Meyer H(1935) und Krüger (1981) von den gebliebenen Wurzelhautanteilen und von den Schleimhauträndern junge Bindegewebszellen und Gefäßsprossen in das Koagulum einwachsen.

\subsection{Regeneration der Extraktionsalveole}

Jeder Wundheilungsprozess verkörpert eine Spezialform der Entzündung, innerhalb der die Exsudation und die Proliferation integrierende Bestandteile liefert (Büchs 1966). 
Nach Gabka und Harnisch (1973) kann man die Wundheilung nach

komplikationsloser Zahnextraktion in vier Stadien einteilen:

1. Stadium der Bildung des Blutkoagulums in der Alveole

2. Stadium der Schorfbildung

3. Stadium des Granulationsgewebes

4. Stadium der Epithelisierung.

Hahn und Lange (1966) bezeichnen jedoch die zweite Phase als Organisation des Koagulums, worauf dann die dritte Phase der Knochenneubildung und Umbildung folgt. Sie sehen hauptsächlich die Wundverkleinerung durch das Annähern der Gingivaränder als wichtigen Vorgang für die spätere Epithelisierung.

Direkt nach erfolgter Zahnentfernung beginnen die Regenerationsvorgänge der Extraktionsalveole. Zunächst füllt sich die Alveole vom Alveolenfundus her mit Blut, welches aus den durchtrennten umliegenden Gefäßen einströmt, auf. Die im Blut erhaltenen Proteine und Zellbestandteile aktivieren die Blutgerinnungskaskade. In deren Folge bildet sich in der Alveole ein Netz aus Fibrinfäden und Erythrozyten (Meyer W 1957, Amler et al. 1960). Häufig sind in den oberflächlichen Gebieten des Koagels die Erythrozyten durch den Speichel aus dem Fibrinnetz ausgewaschen (Meyer W 1957, Gergely und Bartha 1961). An das Fibrinnetz lagern sich Thrombozyten (Blutplättchen) an. Das sich dadurch bildende Blutkoagulum füllt die Alveole komplett aus. Der Prozess der Koagelbildung läuft innerhalb der ersten 24 Stunden nach Entfernung des Zahnes ab (Amler 1969).

Währenddessen nähern sich die Zahnfleischwundränder über dem Koagel an. Unterstützt wird das Koagel von der äußeren verhornten Schicht des gingivalen Saumepithels. Aus dem Bereich des inneren Saumepithels heraus erfolgt die Regeneration des Epithels, in deren Folge es nach 9-24 Tagen zur epithelialen Bedeckung des Koagels kommt (Meyer W 1957, Hahn und Lange 1966). 
Es folgt die Einwanderung von Abwehrzellen wie zum Beispiel neutrophiler Granulozyten und Makrophagen in die Wundregion. Diese beseitigen Bakterien und Zellreste und setzen Wachstumsfaktoren und Zytokine frei, die die Migration von Mesenchymzellen in die Alveole induzieren (Lin et al.1994). Es folgt die Organisation des Blutkoagulums mit dessen anschließender Retraktion durch Fibrinolyse. Zeitgleich wachsen von den Wundrändern, das heißt zum einen von den Schleimhauträndern, zum anderen von an den Alveolenwänden anhaftenden Wurzelhautteilen aus, mesenchymale Zellen und Gefäßsprossen (Endothelsprossen) in das Koagulum ein (Meyer H 1935, Krüger 1993). Dieser Prozess dauert 2-4 Tage (Araujo et al. 1997). Innerhalb einer Woche erfolgt dann die Ersetzung des Koagels durch Granulationsgewebe. Hieran schließt sich die Phase der Knochenneubildung und Knochenumbildung an. Erste Formationen von Knochentrabekeln lassen sich nach etwa 20 Tagen in der Alveole nachweisen (Amler et al.1960). Nach vier bis sechs Wochen ist die Alveole zum größten Teil mit kallusartigem Geflechtknochen gefüllt, der allmählich in lamellären Knochen umgewandelt wird, was immer mit einer gewissen Atrophie verbunden ist. Nach vier bis sechs Monaten ist die ursprüngliche Alveole mit Schichten von lamellärem Knochen verstärkt (Lin et al. 1994, Araujo et al. 1997, Cardaropoli et al. 2003). Obwohl die Knochenformation in der Alveole für mehrere Monate weiter abläuft, wird das knöcherne Niveau der Nachbarzähne nicht erreicht (Kingsmill 1999, Schropp et al. 2003). Meyer H (1935) sieht das Fehlen einer Kortikalis im Bereich des einstigen Alveolartrichters als Indiz für die noch später stattfindenden Knochenumbauprozesse. 


\subsection{Atrophie der Extraktionsalveole}

Die Atrophie des Alveolarknochens nach der Zahnextraktion ist eine multifaktorielle Erkrankung, bei der die Verfügbarkeit von lebensfähigen Knochenzellen (Osteoblasten und Osteoklasten) eine wichtige Rolle spielt. Lokale und systemische biochemische Faktoren sowie die physikalischen Belastungen des Kieferknochens beeinflussen dabei die Knochenzellen in ihrer Aktivität (Enlow 1963, Frost 1964, Frost 1973).

Zahnextraktionen führen zu einem Knochenremodeling, das äußere und innere Veränderungen im Bereich des Kieferkamms einschließt (Atwood 1971). Der Prozess der Remodellierung kann als eine chronische, progressive und irreversible Krankheit betrachtet werden (Atwood 1971).

Die Resorptionsvorgänge des Kieferkammes in vestibulo-oraler und koronoapikaler Richtung sind dabei von Bedeutung und werden mit dem Begriff „residual ridge resorption“ (RRR) beschrieben (Atwood 1971, Jahangiri et al.1998). In klinischen Studien wurde insbesondere in der Frontzahnregion post extractiomen ein mehr oder weniger ausgeprägter Verlust knöcherner Strukturen in Kombination mit einer Deformation des Alveolarkammes ermittelt (Carlsson et al. 1967, Atwood und Coy 1971, Tallgren 1972, Abrams et al. 1987, Atwood 2001). Es wurden dabei Resorptionsraten von 40-60 Volumenprozent ermittelt (Ashman et al. 1994).

Als Ursachen für den Resorptionsprozess werden entzündliche, anatomische, funktionelle, prothetische sowie systemische Faktoren gesehen (Atwood 1971, Mercier 1985, Fallschüssel 1986, Mercier 1988, Iizuka et al. 1992, Bodner et al. 1993, Devlin et al. 1996). Außerdem wird angenommen, dass für den Resorptionsprozess der erhöhte Zellturnover des Alveolarknochens im Vergleich zu anderen Knochen eine Rolle spielt (Baylink et al 1974). 
Das Ausmaß der Kieferkammresorption steht in engem Zusammenhang mit der seit der Extraktion vergangenen Zeit (Tallgren 1972, Humphries et al. 1989, Ulm et al. 1992, Araujo und Lindhe 2005).

In den ersten sechs Monaten ist die Resorptionsrate am höchsten (Lam 1960, Pietrokovski und Massler 1967, Johnson 1969). Mittels stereofotografischer Modellananalyse wurden Kammvolumenreduktionen von 10\% nach zwei Monaten und von 18\% nach zwölf Monaten nachgewiesen (Adams und Wilding 1985).

Eine Verringerung der Kammbreite nach der Zahnentfernung belegten Ostler und Kokich (1994) sowie Schropp et al (2003). Neben der Abnahme der Kammbreite wurden stets ausgeprägte Resorptionen in der vertikalen Dimension beobachtet (Adell et al. 1990, Isaksson et al. 1993). Cawood und Howell (1988) ermittelten in ihrer Studie an 300 mazerierten Unterkiefern und Oberkiefern ein deutlich unterschiedliches Muster des Knochenverlustes in anterioren und posterioren Kieferbereichen. Für die anterioren Anteile der Mandibula ergibt sich ein vertikaler und horizontaler Knochenverlust. Die posterioren Mandibulaanteile zeichnen sich durch einen vorwiegend vertikalen Knochenabbau aus.

Auffällig ist, dass die Resorptionsvorgänge im Unterkiefer deutlich ausgeprägter sind als im Oberkiefer. Tallgren (1972) wies eine viermal stärkere Resorption im anterioren Bereich der Mandibula gegenüber der Maxilla nach. Die geringere Resorptionsrate im Oberkiefer wird auf die Heilungstendenz der Maxilla im Vergleich zur Mandibula, bedingt durch eine bessere Durchblutung, zurückgeführt (Soehren und van Swol 1979).

Grundsätzlich verläuft die Kieferkammatrophie im Oberkiefer von vestibulär nach oral (zentripetal) und im Unterkiefer von oral nach vestibulär (zentrifugal). In Abhängigkeit des Atrophiestadiums entstehen somit charakteristische Kieferformen, die sich in sechs Resorptionsklassen (RKL) einteilen lassen (Atwood 1971). 
Resorptionsklassen nach Atwood (1971):

RKL 1: Bezahnte Pars alveolaris

RKL 2: Pars alveolaris post extractionem

RKL 3: Hohe, abgerundete Pars alveolaris

RKL 4: Messerschneidenartige Pars alveolaris

RKL 5: Flache Pars alveolaris

RKL 6: Konkave Pars alveolaris.

Lekholm und Zarb (1985) geben ein kombiniertes Klassifikationssystem an, bei dem fünf charakteristischen Kieferformen vier Knochenqualitäten zugeordnet werden. Somit ergeben sich zwanzig Kombinationsmöglichkeiten aus Kieferkontur und Kieferknochenqualität.

Einteilung der Kontur des zahnlosen Unterkiefers nach Lekholm und Zarb (1985):
A: Fast vollständig erhaltener Alveolarfortsatz
B: Geringfügige Resorption des Alveolarkamms
C: Fortgeschrittene Resorption des Alveolarkamms bis zum Basalbogen
D: Beginnende Resorption des Basalbogens
E: Extreme Resorption des Basalbogens.

\subsection{Bestimmung alveolärer Defektsituationen}

Vor einer Zahnextraktion oder einer Implantatinsertion ist es nötig, sich ein genaues Bild von den räumlichen Gegebenheiten des Kieferknochens zu machen. Das Darstellen der anatomischen Grenzbereiche, wie zum Beispiel der Verlauf des Nervus mandibularis im Unterkiefer, die Ausdehnung der Kieferhöhlen im Oberkiefer oder auch die Lokalisation der zu entfernenden 
Zahnwurzeln ermöglicht dem Operateur eine befundgetreue Planung und gibt ihm operative Sicherheit. Für die räumliche Darstellung und Vermessung der Kiefer kommen unterschiedliche Verfahren zum Einsatz.

\subsubsection{Direkte Vermessung}

Eine Möglichkeit, alveoläre Defekte direkt post extractionem darzustellen, ist die direkte Vermessung der Alveole mittels Mess-Sonde. Hierbei erfolgt die Vermessung des knöchernen Defekts direkt im Anschluss an die Zahnentfernung mit einer PA-Sonde. Hinsichtlich der Defektgröße kann bei dieser Methode allerdings nur eine ungefähre Aussage gemacht werden, da nur die Strecke vom Alveolenboden der Kavität bis zum Zahnfleischrand, also der Weichgewebsbegrenzung, ausgemessen werden kann. Eine Aussage über den Verlauf des knöchernen Limbus alveolaris ist durch die nach der Extraktion auftretende Blutung und die damit verbundene Sichtbehinderung nicht möglich. Joudzbalys et al. (2008) beschreiben in ihrer Studie die konventionelle Vermessung der Extraktionsalveole (CESE, Conventional Extraction Socket Evaluation), sowohl von Hart- als auch -Weichgewebe. Das Weichgewebe wurde in Hinblick auf Farbe, Konsistenz und Konturvariationen untersucht, und in mehrere Klassen von gut (rosé-farben, fest und von normaler Kontur) bis schlecht (rötliche Färbung, schwammig und unebene Kontur) eingeteilt. Die Vermessung des Hartgewebes beinhaltete die Ausdehnung des labialen Knochenschildes, die Breite des fazialen Knochens sowie die Schmelz-ZementGrenze der benachbarten Zähne. 


\subsubsection{Lupenbrille}

Anders als in anderen medizinischen Fachbereichen stellt der Gebrauch von vergrößernden Hilfsmitteln in der Zahnheilkunde noch eine relativ neue Entwicklung dar. Die Lupenbrille ist das in der Zahnmedizin am weitesten verbreitete Hilfsmittel zur optischen Vergrößerung (Tibbetts und Shanelec 1998). Grundlegend wird die Vergrößerung bei der Lupenbrille dadurch erzielt, dass mittels Zwischenschaltung eines Linsensystems zwischen Objekt und Auge das Objekt vergrößert auf der Netzhaut abgebildet wird (Burkhardt 1999). Die Lupenbrille kommt in allen Fachbereichen der Zahnheilkunde zur Anwendung. So zum Beispiel in der Zahnerhaltung zum Auffinden und der Therapie von kariösen Läsionen, in der Prothetik zur Kontrolle von Kronenrändern oder in der Parodontologie bei der Kontrolle nach Zahnsteinoder Konkremententfernung. Im Bereich der Endodontie leistet die Lupenbrille wertvolle Dienste beim Auffinden von akzessorischen Seitenkanälen. Das Arbeiten mit Lupenbrille ermöglicht ferner im Bereich der endodontischen Chirurgie, den Langzeiterfolg von Wuzelspitzenresektionen entscheidend zu verbessern.

Bei der Lupenbrille werden zwei Linsensysteme (binokulare Linsensysteme) (Burkhardt 1999) so nebeneinander angeordnet, dass die Linsen konvergieren und somit über beide Systeme dasselbe Objekt fokussiert wird (Tibbetts und Shanelec 1998). Der mit einer Lupenbrille erzielte Vergrößerungsfaktor variiert von 1,5- bis 10-fach, wobei eine Vergrößerung um das 4- bis 5-fache als Optimum angesehen wird (Tibbetts und Shanelec 1998). Bei starker Vergrößerung kann eine spezielle Lichtquelle zur optimalen Objektausleuchtung erforderlich sein (Tibbetts und Shanelec 1996, Tibbetts und Shanelec 1998, Burkhardt 1999).

Anders als bei der Arbeit mit einem Operationsmikroskop können bei der Arbeit mit Lupenbrille Änderungen des Blickwinkels oder das Fokussieren eines 
Objektes durch Stellungsänderungen des Behandlers durchgeführt werden. Der große Nachteil einer Lupenbrille ist, dass die Augen zur Bildbetrachtung konvergieren müssen, was zu deren Übermüdung führen kann (Tibbetts und Shanelec 1998).

\subsubsection{Operationsmikroskop}

In vielen Bereichen der Zahnheilkunde, wie der Endodontie, der Kieferchirurgie und der Parodontologie hat sich die Verwendung des Operationsmikroskops als Standardhilfsmittel etabliert. Zusätzlich findet es Anwendung in der Zahnerhaltung, Kieferorthopädie und der Prothetik.

In der Endochirurgie können mit dem Operationsmikroskop knöcherne Läsionen sichtbar gemacht und entsprechend therapiert werden (Velvart 1996). Durch die bis zu 40-facheVergrößerung wird das Auffinden der Wurzelspitze erleichtert, so dass die Ausdehnung der Osteotomie gering gehalten werden kann. Zusätzlich wird die Inspektion der Resektionsfläche ermöglicht, so dass anatomische Details wie z.B. apikale Mikrofrakturen oder undichte Guttaperchafüllungen identifiziert und therapiert werden können (Pecora und Andreana 1993, Kim 1997). Die durch die Vergrößerung ermöglichte bessere Sichtkontrolle erleichtert die Aufbereitung und Füllung des apikalen Wurzelanteils. Im Bereich der Endodontie findet das Operationsmikroskop bei der Kontrolle der Wurzelkanalaufbereitung Anwendung. Zusätzlich können bei stärkerer Vergrößerung akzessorische Kanäle identifiziert (Beer und Mayerhöfer 1995, Velvart 1996, Biselli 2001, Baldassari-Cruz et al. 2002) und anatomische Details wie Isthmusbildungen und sklerotische Kanäle oder iatrogen verursachte 
Probleme wie frakturierte Instrumente im Kanal, Stufenbildung und Verblockungen (Velvart 1996) dargestellt und korrigiert werden.

Im Bereich der Parodontologie wird das Operationsmikroskop bei der Behandlung von tiefen Zahnfleischtaschen eingesetzt. Dadurch entfällt eine für den Patienten belastende offene Kürettage.

In der Kronen- und Brückenprothetik sowie in der Zahnerhaltung wird das Operationsmikroskop bei der Beurteilung von Füllungs- und Kronenrändern verwendet. Des Weiteren kann es zur Beurteilung des Abdrucks (Perrin et al. 2000) sowie zur Kontrolle der Passgenauigkeit der fertigen Krone genutzt werden (Biselli 2001). In der Kieferorthopädie werden Mikroskope zur metrischen Kiefermodellanalyse angewandt.

Am bekanntesten ist das von Van der Linde verwendete OptokomMessmikroskop (Linden et al.1972).

Hierbei handelt es sich um ein Monookular mit einer 10 fachen Vergrößerung und einem Tiefenschärfebereich von $5 \mathrm{~mm}$.

Bei dem Operationsmikroskop beruht die Vergrößerung, ähnlich wie bei der Lupenbrille, auf der Zwischenschaltung eines Linsensystems zwischen Objekt und Auge. Hieraus resultiert eine vergrößerte Objektabbildung. Der mögliche Vergrößerungsfaktor bei der Arbeit mit einem Operationsmikroskop liegt bei 4bis 40-fach. Ein Bereich von 4-bis 10-fach hat sich in der Praxis bewährt, da bei stärkerer Vergrößerung die Tiefenschärfe verloren geht (Perrin et al. 2000). Die großen Vorteile eines Operationsmikroskops verglichen mit einer Lupenbrille sind die wählbare Vergrößerung, ausgezeichnete Ausleuchtung des Behandlungsfeldes durch eine ins Mikroskop integrierte Beleuchtungseinheit (Tibbetts und Shanelec 1998, Burkhardt 1999, Perrin et al. 2000). Des Weiteren kann das Operationsmikroskop mit einer Foto- oder Videokamera zu Dokumentationszwecken kombiniert werden (Velvart 1996, Tibbetts und Shanelec 1998, Biselli 2001). Über den Mitbeobachtertubus besteht des Weiteren die Möglichkeit, dass eine weitere Person den Eingriff mitverfolgen 
kann. Eine Überlastung der Augen wird durch die parallele Optik der Okulare verhindert (Tibbetts und Shanelec 1998). Als Nachteile des Arbeitens mit dem Mikroskop müssen die relativ hohen Anschaffungskosten sowie die lange Anlernphase genannt werden.

\subsubsection{Röntgenaufnahmen}

Die Röntgendiagnostik ist aus vielen medizinischen Disziplinen nicht mehr wegzudenken. So hat man stets das Bestreben gehabt, genauere und bessere Methoden zu entwickeln, und gleichzeitig die Strahlenbelastung für den Patienten zu verringern.

Die Herstellung einer Röntgenaufnahme stellt den Versuch dar, einen komplex gebauten Raum so abzubilden, dass alle einzelnen Bauelemente für sich in ihrer räumlichen Anordnung zueinander optimal sichtbar werden. Es wird also ein dreidimensionaler Raum auf einem zweidimensionalen Bild abgebildet. Die Schwierigkeit hierbei besteht in der Tatsache, dass bereits kleine Veränderungen des Aufnahmestandortes oder des Projektionswinkels zu einer Veränderung der Lage der einzelnen Bauelemente zueinander zur Folge hat.

Je nach Lage des Bildträgers kann man drei Aufnahmemöglichkeiten unterscheiden:

1. Intraorale Verfahren

2. Extraorale Verfahren

3. Panoramaverfahren.

Zu den intraoralen Verfahren zählen neben allen Einzelaufnahmen der Zähne auch die Flügelbissaufnahme und die Aufbissaufnahme. Bei intraoralen Aufnahmen sollte der Film möglichst ideal in Bezug zur Zahnachse gebracht werden, um das Objekt mittels Zentralstrahl korrekt abzubilden. Die in der zahnärztlichen Praxis am weitesten verbreitete Aufnahmetechnik ist die Halbwinkeltechnik. Der Zahn wird dann isometrisch abgebildet, wenn der 
Zentralstrahl durch den Apex des Zahns senkrecht auf die Winkelhalbierende fällt, die den Winkel zwischen Zahnachse und der Bildträgerebene teilt. Die Schwierigkeit hierbei besteht allerdings im Abschätzen des halben Winkels zwischen Zahnachse und Bildebene. Bei zu steiler Projektion wird der Zahn zu kurz, bei zu flacher Projektion zu lang abgebildet. Zu den extraoralen Verfahren gehören spezielle Aufbissaufnahmen und alle Schädel- oder Panoramaschichtaufnahmen. Die Panoramaverfahren werden je nach den gegebenen technischen Voraussetzungen als Panoramaschichtaufnahmen oder als Panoramavergrößerungsaufnahmen bezeichnet.

Aufnahmetechnik der Panoramaschichtaufnahme

Die Technik der Orthopantomographie wurde aus dem Prinzip der Tomographie entwickelt, wie sie sich Bocage 1921 patentieren ließ; die ersten erfolgreichen Aufnahmen wurden 1950 angefertigt (Paatero 1954). Er entwickelte die Technik weiter, bis sie die heute noch übliche Form hatte (Paatero 1961). Diese Aufnahmetechnik hat nach anfänglichen Schwierigkeiten zunehmend an Stellenwert gewonnen und ist nun zu einer Routineaufnahme bei der Beurteilung der Zähne und des alveolären Knochens geworden (Immenkamp 1972, Jung 1972, Pasler 1981, Rottke 1972, Sonnabend 1977, Sonnabend und Ring 1972). Mit der Panoramaschichtaufnahme ist es möglich, nicht nur die Zähne sondern auch die Kiefer mit den benachbarten Strukturen des Gesichtschädels darzustellen. Im Unterschied zu Zahnfilmaufnahmen, bei denen der Zentralstrahl und die Projektionsfläche auf das besagte Objekt ausgerichtet werden, wird bei der Orthopantomographie der Patient optimal in die vorgegebene FocusProjektionsfläche des Röntgengerätes eingeordnet. Bei einer Normprojektion kommt es zu einer Aufnahme, bei der die Kiefermitte bis zur Eckzahnregion als leicht gebogene Frontalansicht des Gesichtschädels abgebildet wird, ergänzt 
durch zwei leicht gebogene seitliche Ansichten des Gesichtschädels. Die intraoral liegenden Weichteile (Zunge) bewirken einen Additionseffekt, durch den die Kiefer verschattet werden können. Daneben kommt es durch die dreimal abgebildete Halswirbelsäule zu störenden Überlagerungen im Frontzahnbereich.

\subsubsection{Endoskop}

Das Endoskop ist ein optisches Instrument, das zur Untersuchung innerer Organe durch natürliche Körperöffnungen (z.B. Pharynx, Rektum) oder kleiner Hautinzisionen eingesetzt wird (Engelke und Capobianco 2005a).

Man kann zwischen zwei Arten von Endoskopen unterscheiden: Die starren und die flexiblen, die nach den physikalischen Eigenschaften ihrer Konstruktionsmaterialien benannt sind. Bei einem flexiblen Endoskop, auch Fiberskop genannt, werden Bündel von lichtleitenden Fasern präzise angeordnet, wohingegen bei einem starren Endoskop das Bild auf der Basis von Transmissionslinsen weitergeleitet wird.

Das in dieser Arbeit zur Anwendung gekommene starre Endoskop setzt sich wie folgt zusammen: Die Linsen des optischen Systems werden im inneren Hüllrohr geführt und mit Distanzhülsen auf Abstand gehalten. Der Raum zwischen den Linsen ist hierbei proportional zum Linsendurchmesser. Das innere Hüllrohr ist distal mit dem Ablenkprisma, das unter anderem die Blickrichtung bestimmt, und proximal mit dem Objektiv abgeschlossen. Es wird eingeschlossen von dem äußeren Hüllrohr, in dem sich neben dem Lichtleiter auch das Lichtleitkabel befindet. Distal wird dieses Teil von der Decklinse abgeschlossen, proximal ist die Okularabdeckung angebracht. Diese Komponente dient im wesentlichen dazu, die inneren Teile gegenüber eindringender Fremdstoffe abzudichten. Zusätzlich kann am Endoskop ein weiterer Kanal zur Spülung, Luftzufuhr oder für das Einbringen von Instrumenten existieren (Stambaugh et al. 2002). Ein 
Kameraanschluss, der über eine Kupplung mit dem Okular verbunden ist, ermöglicht es dem Behandler, das zu untersuchende Gebiet auf dem Monitor anstatt direkt durch das Okular zu betrachten. In Abhängigkeit des Abstandes des Objekts zum Endoskop ergibt sich ein unterschiedlich hoher Vergrößerungsfaktor. Je näher das Objekt ans Endoskop heranreicht, desto größer ist auch dessen Vergrößerung. Bei einer Distanz von $5 \mathrm{~mm}$ liegt der Vergrößerungsfaktor bei 3-fach, in $2 \mathrm{~mm}$ Abstand bei 6-fach (Engelke und Capobianco 2005a). Durch Kombination der endoskopischen Vergrößerung mit einem 2-bis 4-fachen Kamerazoom können somit Vergrößerungen in der Größenordnung eines Operationsmikroskops erzielt werden (Schubert 2005). Der Einsatz des Endoskops zur Diagnostik von Extraktionsalveolen wird als Alveoloskopie bezeichnet. Die Alveoloskopie erfolgt nach dem Prinzip der Stützimmersionsendoskopie (SIE), die von Engelke 2002 das erste Mal zur Untersuchung von Implantatkavitäten beschrieben wurde (Engelke 2002a). Mit Hilfe des Endoskops kann eine Betrachtung der Alveolenwände direkt nach der Zahnentfernung unter kontinuierlicher Flüssigkeitsspülung mit physiologischer Kochsalzlösung durchgeführt werden. Es können hierbei zum einen bereits bestehende oder während der Extraktion aufgetretene knöcherne Defekte diagnostiziert und gegebenenfalls auch therapiert werden. Zum anderen gibt die Alveoloskopie Aufschluss über möglicherweise apikal verbliebene Wurzelreste, in der Alveole vorhandene Fremdkörper (Reste von frakturierten Amalgamfüllungen, Wurzelfüllmaterial) oder auch das Vorliegen von entzündlichen Prozessen (apikale Granulome). Mit Hilfe eines Messinstrument (z. B. PA-Sonde) kann man des Weiteren das Ausmaß des knöchernen Defekts dreidimensional direkt nach der Extraktion bestimmen. Hierbei ist die Vermessung der Breite des labialen Knochens im Hinblick auf eine sofortige Implantation sehr wichtig (Joudzbalys et al. 2008). Eine dünne bukkale Knochenwand führt häufig zu einem partiellen oder kompletten Verlust des Knochens nach der Abheilung (Spray et al. 2000). 


\subsection{Ziel der Arbeit}

Ziel der vorliegenden Arbeit war, in vivo Extraktionsalveolen mit Hilfe der Stützimmersionsendoskopie darzustellen und zu vermessen. Hierbei sollten charakteristische Defektsituationen beschrieben werden. Des Weiteren sollte geklärt werden, ob es Defektsituationen in der Alveole gibt, die nicht auf der vor der Extraktion angefertigten Panoramaschichtaufnahme zu erkennen waren.

Dazu wurden folgende Methoden eingesetzt:

1) röntgenologische Untersuchung mittels Panoramaschichtaufnahme

2) endoskopische Untersuchung direkt post extractionem.

Die radiologische Untersuchung diente zur zweidimensionalen Bestimmung des Ausgangsbefundes mit den noch zu entfernenden Zähnen in situ. Als Ergänzung dazu dienten die post extractionem angefertigten endoskopischen Bilder, die eine dreidimensionale Beurteilung des knöchernen Defekts erlaubten.

Schwerpunkt in der endoskopischen Betrachtung waren Unterschiede zwischen dem oralen und vestibulären Knochenverlauf. 


\section{Material und Methode}

\subsection{Patienten}

Das Patientenkontingent dieser Studie setzte sich aus 26 Patienten des Zentrums für Zahn-, Mund- und Kieferheilkunde der Universitätsklinik Göttingen, 25 Patienten der zahnärztlichen Praxis Dr. Decco an der Universidad National de Entre Rios in Diamante, Argentinien sowie 3 Patienten der Gemeinschaftspraxis der Zahnärzte Hanf und Reindl in Hankensbüttel zusammen. Die Untersuchungen wurden in den Jahren 2003 bis 2006 durchgeführt. Es wurden 29 Frauen im Alter von 19 bis 66 Jahren mit einem Durchschnittsalter von 40,62 Jahren, und 25 Männer im Alter von 18 bis 73 Jahren mit einem Durchschnittsalter von 50,96 Jahren untersucht. Es wurden bei 54 Patienten insgesamt 132 Zähne durch reine Zahnextraktion (keine Osteotomien) entfernt.

In 24 Fällen (44,4\% des Patientenguts) wurde ein Zahn entfernt. Bei 28 Patienten (51,8\% des Patientenguts) wurden zwei bis fünf Zähne extrahiert, und bei zwei Patienten (3,7\% des Patientenguts) fand eine multiple Extraktion mit Entfernung von mehr als 5 Zähnen statt.

Bei den entfernten Zähnen handelte es sich um 16 Prämolaren des I.Quadranten und 25 Prämolaren des II. Quadranten sowie 40 Oberkiefer Frontzähne (regiones 13-23). Im Unterkiefer wurden 14 Prämolaren des III. Quadranten, 11 Prämolaren des IV. Quadranten sowie 26 Unterkieferfrontzähne (regiones 3343) entfernt. Die genaue Verteilung der entfernten Zähne in Bezug auf das gesamte Gebiss stellt sich in Abbildung 1 dar. 


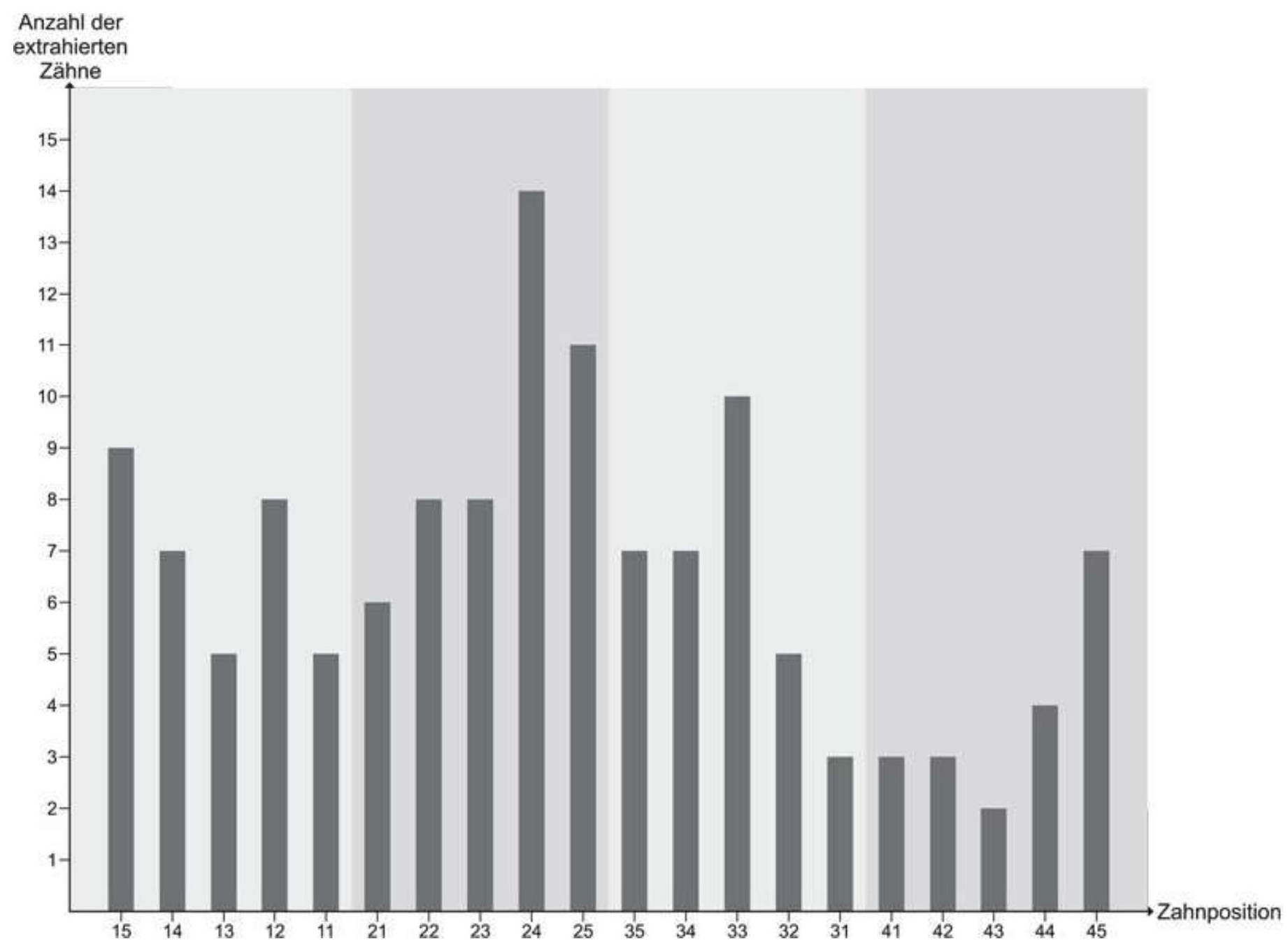

Abb. 1: Übersicht über die Verteilung der entfernten Zähne auf das Gesamtgebiss

\subsection{Befunderhebung und Aufklärung}

$\mathrm{Zu}$ Beginn wurde von allen Patienten die Anamnese erhoben, danach erfolgte die diagnostische Untersuchung mit Erhebung des intraoralen Zahnbefundes sowie die Röntgenuntersuchung. Anhand des erhobenen klinischen und röntgenologischen Befundes ergaben sich als Extraktionsindikationen ein ausgedehnter kariöser Zerstörungsgrad, fortgeschrittene parodontale Läsionen, weder konservativ noch operativ therapierbare apikale Läsionen sowie Platzmangel in Hinblick auf eine kieferorthopädische Behandlung. 
Die Patienten wurden mindestens 24 Stunden vor der Zahnentfernung über deren Notwendigkeit und Ablauf aufgeklärt sowie auf mögliche Komplikationen hingewiesen. Zu den möglichen Komplikationen zählten intraoperativ die Beschädigung der Nachbarzähne (Zahnlockerung, Lockerung von Kronen oder Füllungen, Beschädigungen von Verblendungen an VMK-Kronen), das Auftreten von Kieferfrakturen in Form von alveolären Frakturen oder eines Tuberabrisses bei der Hebelextraktion von oberen Molaren, die Kiefergelenksluxation bei der Entfernung von Unterkieferzähnen sowie die Verletzung des Nervus alveolaris inferior mit nachfolgenden Sensibilitätsstörungen im Versorgungsgebiet des Nervus mentalis. Weiterhin wurden die Patienten auf eine mögliche Mund-Antrum-Verbindung oder der Luxation von Zähnen oder Zahnteilen in die Kieferhöhle hingewiesen. Im Hinblick auf die postoperativen Komplikationen wurden die Patienten über mögliche Schwellungen, Wundheilungsstörungen mit zwei bis drei Tage nach der Operation auftretenden Schmerzen und gegebenenfalls Blutung durch Zerfall des Koagulums unterrichtet sowie das Auftreten von Nachblutungen informiert.

Neben der Aufklärung über den Operationsverlauf und die möglicherweise auftretenden Komplikationen wurden die Patienten ausführlich über den Nutzen und die Risiken einer Alveoloskopie unterrichtet. Hierbei wurde den Patienten erklärt, dass durch die endoskopische Kontrolle der Extraktionsalveole Wurzelreste, Fremdkörper und Entzündungsherde sicher entfernt und somit Zweiteingriffe vermieden werden können. Die endoskopische Vermessung der Alveole dient des Weiteren als diagnostische Hilfe bei der Beurteilung der Knochenqualität und -quantität im Hinblick auf eine später stattfindende Implantatinsertion. Die Patienten wurden auf den erhöhten Zeitbedarf der endoskopischen Messungen sowie die Risiken einer möglichen Aspiration von Spülflüssigkeit sowie eine durch die Wundspülung bedingte möglicherweise verzögerte Wundheilung hingewiesen. Nach der Patientenaufklärung wurde von 
allen Patienten eine Operationseinwilligung unterzeichnet. Mindestens einen Tag nach erfolgter Patientenaufklärung wurde die Zahnentfernung unter Lokalanästhesie durchgeführt.

Die Patientenselektion ergab sich durch die Lage der zu entfernenden Zähne, so wurden sowohl im Oberkiefer als auch im Unterkiefer ausschließlich Frontzähne und Prämolaren untersucht. Hierbei fand die endoskopische Vermessung von 132 Extraktionsalveolen statt.

\subsection{Radiologische Untersuchung}

Die präoperativ durchgeführte Röntgendiagnostik, die zur Verifikation der Extraktionsindikation diente, erfolgte bei allen Patienten mittels Orthopantomogramm.

Die Röntgenaufnahme wurden mit dem Philips Oralix FD bei 65-69 KV und $6 \mathrm{~mA}$ mit einer Aufnahmedauer von 19sec sowie dem Siemens Orthopantomograph 10 bei 70-75 KV und $8 \mathrm{~mA}$ mit einer Aufnahmedauer von $15 \mathrm{sec}$ durchgeführt.

Die Patientenpositionierung erfolgte mittels Einbisses.

Das verwendete Filmmaterial bestand aus dem Kodak T-Mat G/RA Dental Film im Format 12,7x30,5 cm für den Philips Oralix und dem Kodak T-Mat G/RA Dental Film 15x30cm für den Siemens Orthopantomograph. Die Filmkassetten waren mit Verstärkerfolie vom Typ Kodak Lanex regular screens bestückt. Entwickelt wurden die Orthopantomogramme mit dem Entwickler 3M XP 505. 
2.4 Durchführung der Zahnextraktion

Die Zahnextraktionen erfolgten alle unter Lokalanästhesie. Bei der Extraktion im Oberkiefer wurde vestibulär in der Umschlagfalte eine Infiltrationsanästhesie und palatinal eine Anästhesie am Foramen incisivum bei Frontzähnen oder am Foramen palatinum bei Seitenzähnen gesetzt. Die Schmerzausschaltung bei der Zahnentfernung im Unterkiefer erfolgte durch eine Leitungsanästhesie des Nervus alveolaris inferior. Zusätzlich erfolgte bei der Entfernung von Unterkieferfrontzähnen eine vestibuläre Infiltrationsanästhesie.

Als Anästhetikum kamen Ultracain D, Ultracain DS oder Ultracain DS forte (Wirkstoff Articain) zur Anwendung.

Die Zahnentfernung erfolgte bei allen Fällen mittels Extraktion. Hierbei wurde das marginale Ligament mit einem Bein’schen Hebel gelöst, und die Alveolenwände wurden durch die orovestibuläre Luxation oder Rotation des Zahnes mit Extraktionszangen geweitet. Anschließend erfolgte die Zahnentfernung durch extrusive Bewegung des Zahnes mit der Extraktionszange. Direkt nach der Zahnentfernung erfolgte die endoskopische Vermessung der Alveole.

Im Anschluss an die Vermessung der Alveole mit der Stützimmersionsendoskopie erfolgte die Säuberung der Alveole und die Wundversorgung. Hierbei wurde in der Wunde verbliebenes Weichgewebe mittels scharfen Löffels kürettiert. Eventuell vorhandene scharfe Knochenkanten wurden mit einer Knochenzange nach Luer geglättet. Die Wunde wurde im Anschluss bidigital komprimiert und auf der Wunde ein Aufbisstupfer bis zur Blutstillung und Bildung eines Blutkoagulums fixiert.

Die Patienten wurden nach erfolgter Wundversorgung ausgiebig über die postoperativen Verhaltensmaßnahmen unterrichtet. Es wurde ihnen eine Nahrungskarenz bis zum Abklingen der Anästhesie sowie eine feucht-kalte Wangenauflage zur Schwellungsprophylaxe angeraten. Des Weiteren wurde ein 
Verzicht auf Nikotin, Koffein und Alkohol für die ersten beiden Tage nach der Zahnentfernung sowie eine Vermeidung schwerer körperlicher Arbeit und ausgeprägter Hitze ( Saunabesuch, Sonnenbad) für den Tag des Eingriffs empfohlen. Diese Verhaltensmaßnahmen wurden den Patienten zusätzlich in Form eines Merkzettels mitgegeben.

\subsection{Endoskopisches Instrumentarium}

Da der Untersuchungsschwerpunkt der Kavitätenvermessung in der Nahbeobachtung der Alveolenwände lag, wurden alle Untersuchungen der Extraktionsalveolen mit einem Hopkins-Endoskop 1232 BA der Firma Storz (Durchmesser $1,9 \mathrm{~mm}, 30^{\circ}$ Vorausblick, Fa. Storz, Tuttlingen) durchgeführt. Das Endoskop wurde mit einem Lichtleitsystem ( Kaltlichtfontäne Storz halide 250-2 20123120, Fa. Storz, Tuttlingen) kombiniert, welches der Optik während der Bildaufnahme Licht von der Kaltlichtfontäne über ein Fiberglas-Lichtkabel (Fiberglas-Lichtkabel 495 NL, Firma Storz, Tuttlingen) zuführte.

Dem Endoskop wurde eine Videokette mit endoskopischer Videokameraeinheit und Bildverarbeitungseinheit angeschlossen. Die Bilderfassung erfolgte mit der Kamera. Die erfassten Bilddaten wurden mittels Bildverarbeitungseinheit auf eine Videokassette aufgenommen.

Zur Anwendung kam hierbei die endoskopische Videokamera KARL STORZ Endovision TELECAM DX C-Mount 20212034 PAL)(Abb.2).

Die endoskopische Videokamera wurde über einen Schnelladapter mit der Optik verbunden. Über ein eingebautes Bedienungselement in Form eines Rades konnte während der Bildaufnahme die manuelle Einstellung des Bildausschnittes und der Bildschärfe direkt an der Kamera vorgenommen werden. 


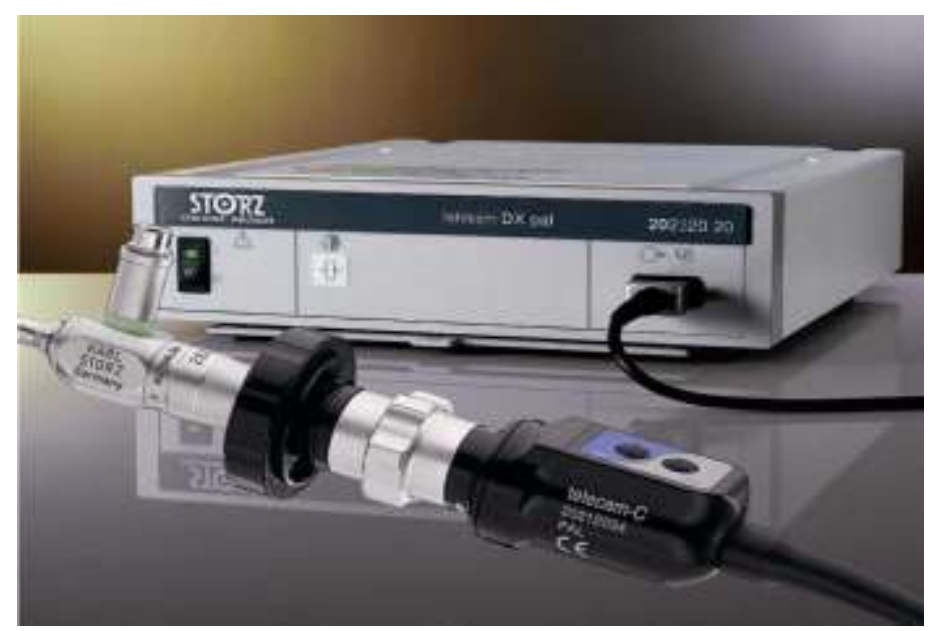

Abb.2 Endoskop, Kamera Telcam DX 20212034 C-Mount

An die endoskopische Videokamera war die Bildverarbeitungseinheit, bestehend aus einer Kamera-Kontrolleinheit und einem Videorekorder, angeschlossen. Zum Einsatz als Kamera-Kontrolleinheit kam hierbei die TELECAM SL PAL 20212020 der Firma Storz (Tuttlingen), welche über ein S-VHS-Kabel mit dem digitalen Video Cassette Recorder SVHS AG-7350 der Firma Panasonic verbunden war.

Mit Hilfe des Videorecorders wurden die von der endoskopischen Kamera aufgenommenen Bilddaten auf digitalen VHS-Kassetten gespeichert. Am S-VHS-Ausgang des Videorecorders war der Farbmonitor HR Triniton 100 $\mathrm{Hz}$ Double Scan (Firma Triniton) angeschlossen. Auf dem Farbmonitor wurde das von der Optik intraoperativ eingefangene Bild dargestellt. Postoperativ konnten die auf der VHS-Kassette abgespeicherten Bildsequenzen erneut auf dem Farbmonitor abgespielt und ausgewertet werden.

Zusätzlich zu den Bilddaten wurden intraoperativ Tonaufnahmen mit einem Mikrofon auf dem Videoband aufgezeichnet. Das Mikrofon war an der AudioEingangsbuchse des Videorekorders angeschlossen. Die Tonaufnahmen erwiesen sich gerade bei Reihenextraktionen als sehr hilfreich, um die Bildsequenzen den einzelnen Alveolen zuzuordnen. 
Das Endoskop wurde mit dem Stütz-Spül-Schaft 655002 der Firma Storz (Tuttlingen) kombiniert. Der Stütz-Spül-Schaft verfügt über einen LUER-LockSpülanschluss. Über diesen Spülanschluss wurde der Schaft mit einem SaugSpül-System (Endomat LC Set 203303001 der Firma Storz, Tuttlingen) zur Perfusion mit steriler physiologischer Kochsalzlösung verbunden.

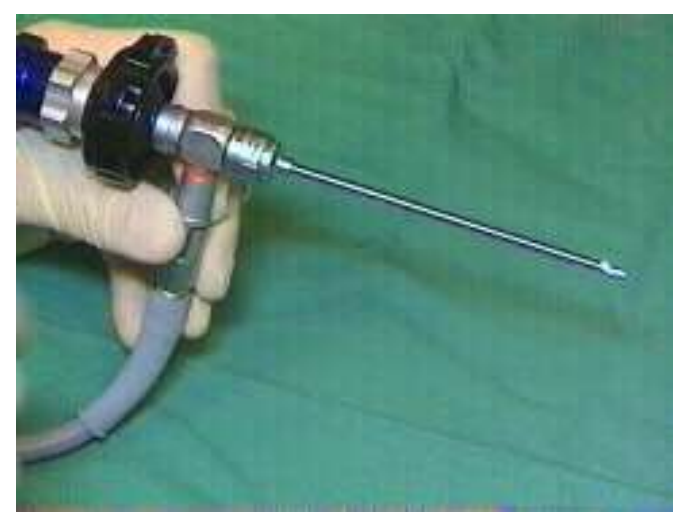

Abb.3 Endoskop, Lichtleiter, Stütz-Spül-Schaft

Um eine bessere Führung der Mess-Sonde zu erreichen, wurde eine Instrumentenführungsrinne, bestehend aus einem $3 \mathrm{~mm}$ langen Stück Metallkanüle, auf der Oberseite des Stütz-Spül-Schaftes aufgelasert. Das Set des Saug-Spül-Systems bestand aus dem Endomat LC 20330320 (Fa. Storz, Tuttlingen) zur Erzeugung eines kontinuierlichen Flüssigkeitsstroms mit physiologischer Kochsalzlösung und wurde durch ein Silikonschlauchset 20330340 (Firma Storz, Tuttlingen) für die permanente Zufuhr von Kochsalzlösung mit dem Stütz-Spül-Schaft verbunden. Für die Absaugung der verschmutzten Spüllösung wurde der Silikonschlauch 20330341 (Firma Storz, Tuttlingen) eingesetzt.

Für den Transport der Endoskopausrüstung sowie der angeschlossenen Videokette und Bildverarbeitungseinheit stand ein mehrere Etagen umfassender Rollwagen LC 29003 der Firma Storz zur Verfügung. Dieser ermöglichte die flexible Positionierung der Geräte im Behandlungsraum und erlaubte den Transport der Geräte in ein Büro zur Auswertung der gewonnenen Bilddaten. 
2.6 Durchführung der endoskopischen Messungen

Direkt im Anschluss an die Zahnentfernung wurde die endoskopische Untersuchung der Extraktionsalveole durchgeführt.

Hierbei wurde die Mess-Sonde entlang der Instrumentenführungsrinne mit dem Endoskop auf dem Boden der Extraktionsalveole platziert. Aufgrund der kontinuierlichen Spülung mit Kochsalzlösung war das Sichtfenster stets frei von Verschmutzung, so dass die Platzierung der Sonde auf dem Alveolenboden unter Sichtkontrolle stattfinden konnte.

Das so gewonnene Bild diente als Übersichtsaufnahme (Abb.4).

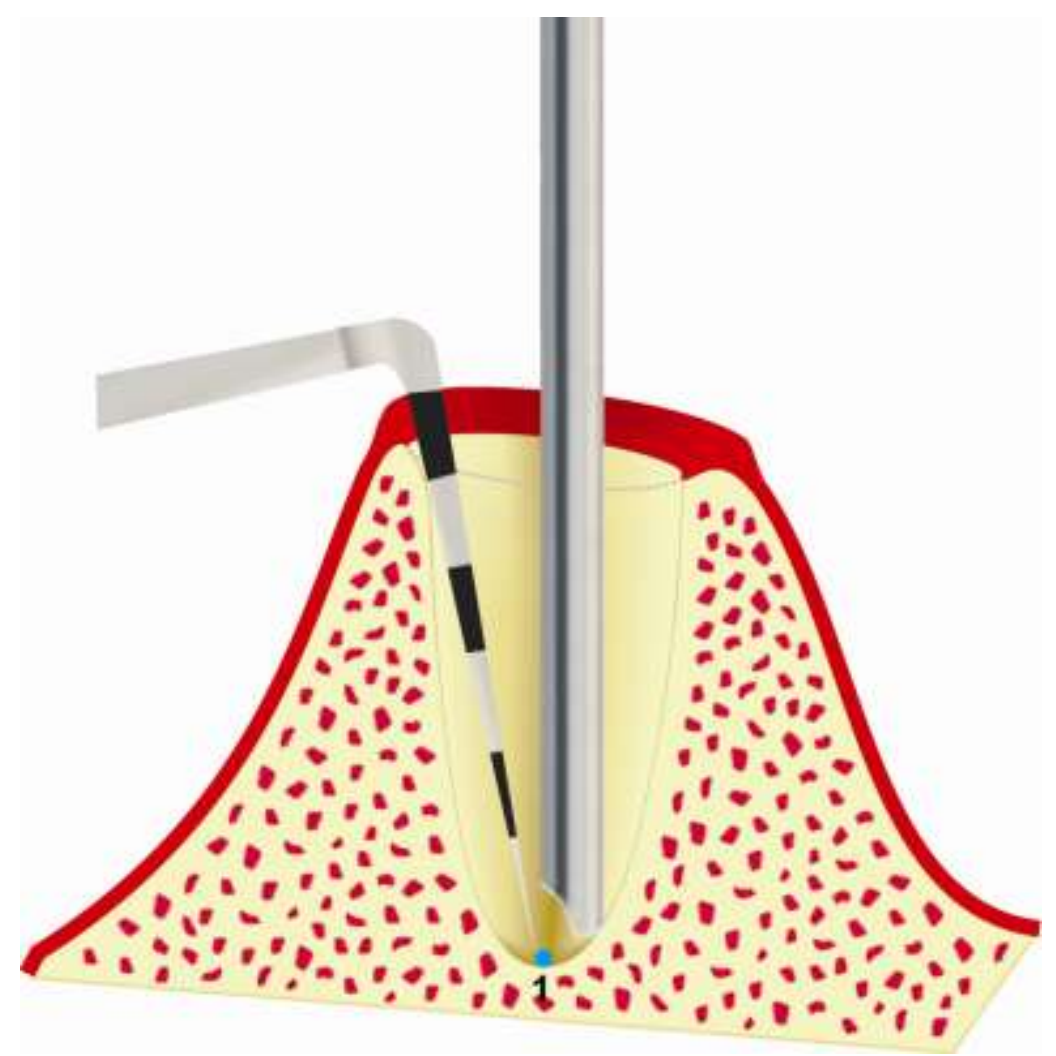

Abb.4 Schematische Darstellung: Sonde und Endoskop auf Alveolenboden (Punkt 1) 
Danach erfolgte die Vermessung der oralen Alveolenwand: Vom Alveolenboden (Punkt 1) fuhr das Endoskop entlang der Mess-Sonde bis zum knöchernen Limbus alveolaris oral (Punkt 2). Diese Strecke wurde als Strecke 1-2 bezeichnet. Die Mess-Sonde verblieb währenddessen auf dem Kavitätenboden. In gleicher Weise wurden danach die vestibuläre und die approximal-mesiale Alveolenwand ausgemessen (Abb.5)

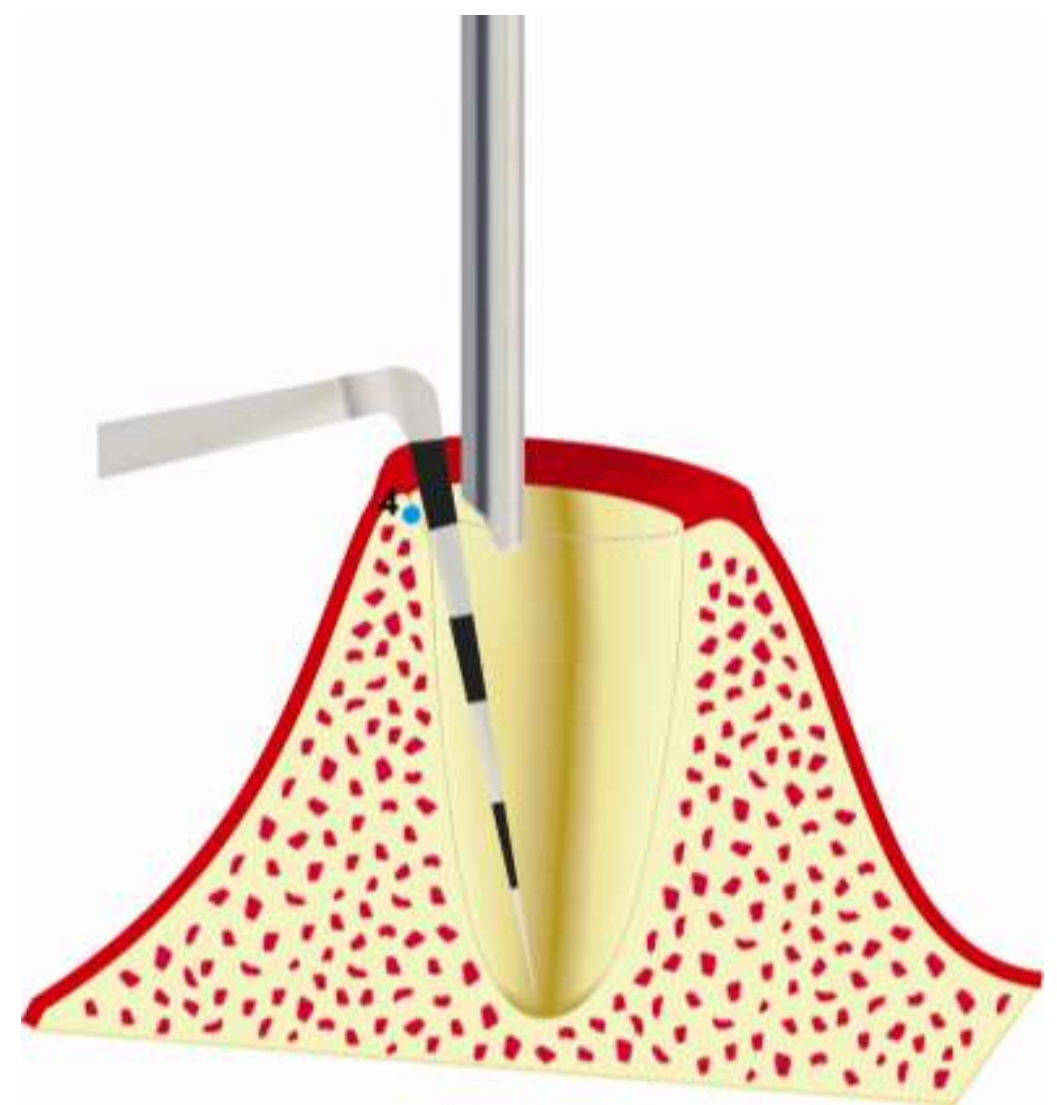

Abb.5 Schematische Darstellung: Sonde auf Alveolenboden, Endoskop am Limbus alveolaris mesial (Punkt 4)

Die vestibuläre Alveolenwand wurde vom knöchernen Alveolenboden (Punkt 1) bis zum knöchernen Limbus alveolaris vestibulär (Punkt 3) ausgemessen. Diese Strecke wurde als Strecke 1-3 bezeichnet.

Die Vermessung der mesialen Wand erfolgte vom Punkt 1 bis zum knöchernen Limbus alveolaris mesial (Punkt 4). Diese Messstrecke wurde Strecke 1-4 genannt . 


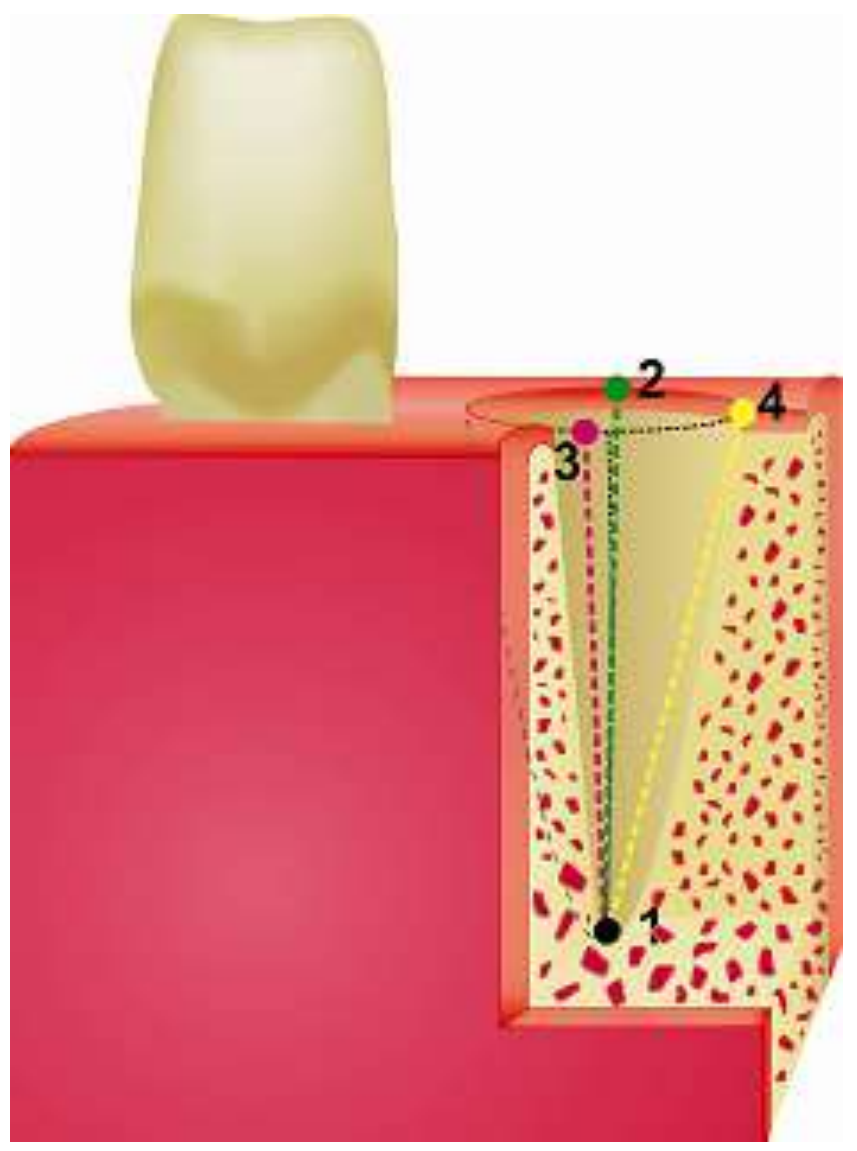

Abb.6 Schematische Zeichnung zur endoskopischen Vermessung der Alveole in oraler, vestibulärer und approximaler Richtung, Ansicht von frontal:

Alveolenboden (1), Limbus alveolaris oral (2), Limbus alveolaris vestibulär (3), Limbus alveolaris mesial (4)

2.7 Vermessung der Panoramaschichtaufnahmen

Die vor der Zahnentfernung angefertigten Panoramaschichtaufnahmen wurden in zentraler und approximal-mesialer Richtung vom Alveolenboden (Punkt 1) bis zum knöchernen Limbus alveolaris zentral (Punkt 2) bzw. bis zum knöchernen Limbus alveolaris mesial (Punkt 4) mit einem Lineal (mit Millimeterskalierung) ausgemessen. Der Abstand vom Alveolenboden bis zum Limbus alveolaris zentral wurde als Strecke rö1-2 bezeichnet, der Abstand vom Alveolenboden zum Limbus alveolaris mesial als Strecke rö1-4 (Abb. 7). 


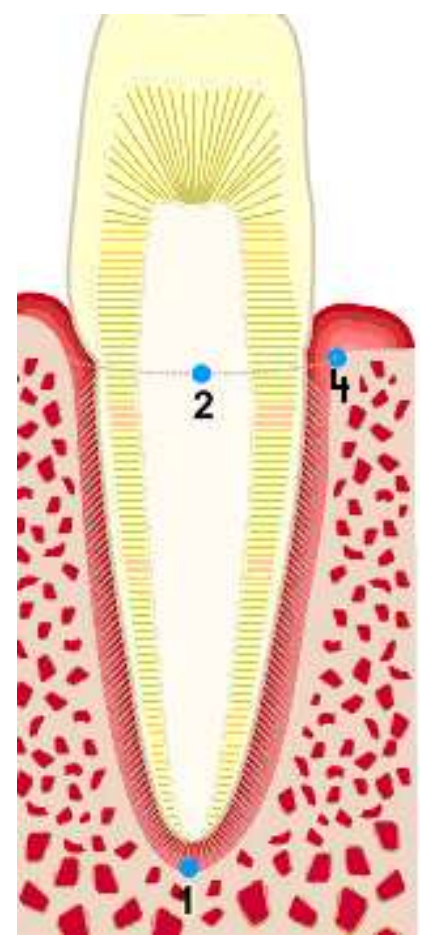

Abb. 7 Schematische Zeichnung zur Vermessung der Panoramaschichtaufnahme in zentraler Richtung: Strecke rö1-2 (Alveolenboden (1)-Limbus alveolaris zentral (2))

Vermessung der Panoramaschichtaufnahme in approximal-mesialer Richtung: Strecke rö1-4 (Alveolenboden (1)-Limbus alveolaris mesial (4))

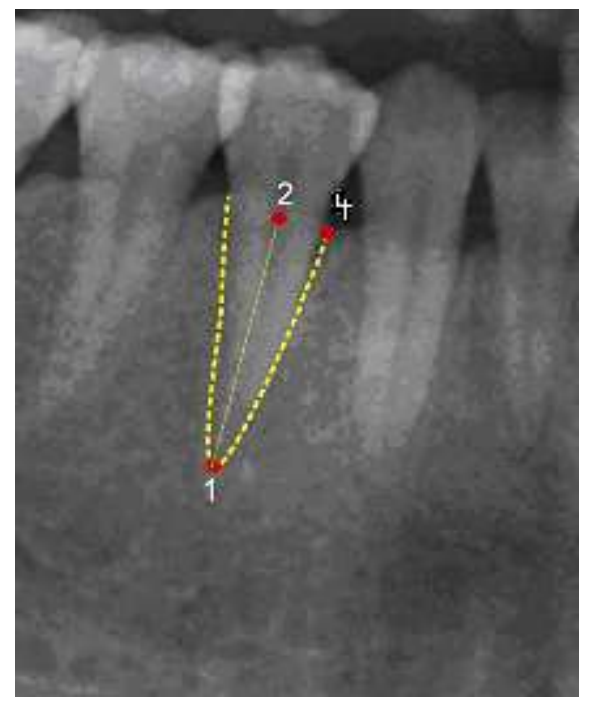

Abb.8 Vermessung der Panoramaschichtaufnahme in zentraler (Strecke rö1-2, Alveolenboden (1)-Limbus alveolaris zentral (2)) und approximal-mesialer Richtung (Strecke rö1-4 (Alveolenboden (1)- Limbus alveolaris mesial (4))

Um eine Beeinflussung bei der endoskopischen Befunderhebung zu vermeiden, wurden die Panoramaschichtaufnahmen erst nach der Alveolenendoskopie 
vermessen. Aufnahmetechnisch weisen alle Panoramaschichtaufnahmen einen Vergrößerungsfaktor von 25\% auf, der bei der Auswertung der Messwerte eingerechnet wurde.

2.8 Dokumentation der radiographischen und endoskopischen Bilder

Die Dokumentation sowohl der Panoramaschichtaufnahmen als auch der endoskopischen Bilder erfolgte zahnregionspezifisch mit dem ImPlanProgramm (Engelke und Hoch 2002). Die während der endoskopischen Untersuchung angefertigten Videomitschnitte wurden kontinuierlich in einem Programmfenster auf dem Computer angezeigt und wurden per Maus-Klick der entsprechenden Zahnregion zugeordnet. Pro Zahn wurden vier Bilder abgelegt, eine Übersichtsaufnahme und jeweils ein Bild vom oralen, vestibulären und mesialen Limbus alveolaris. (Abb.9)

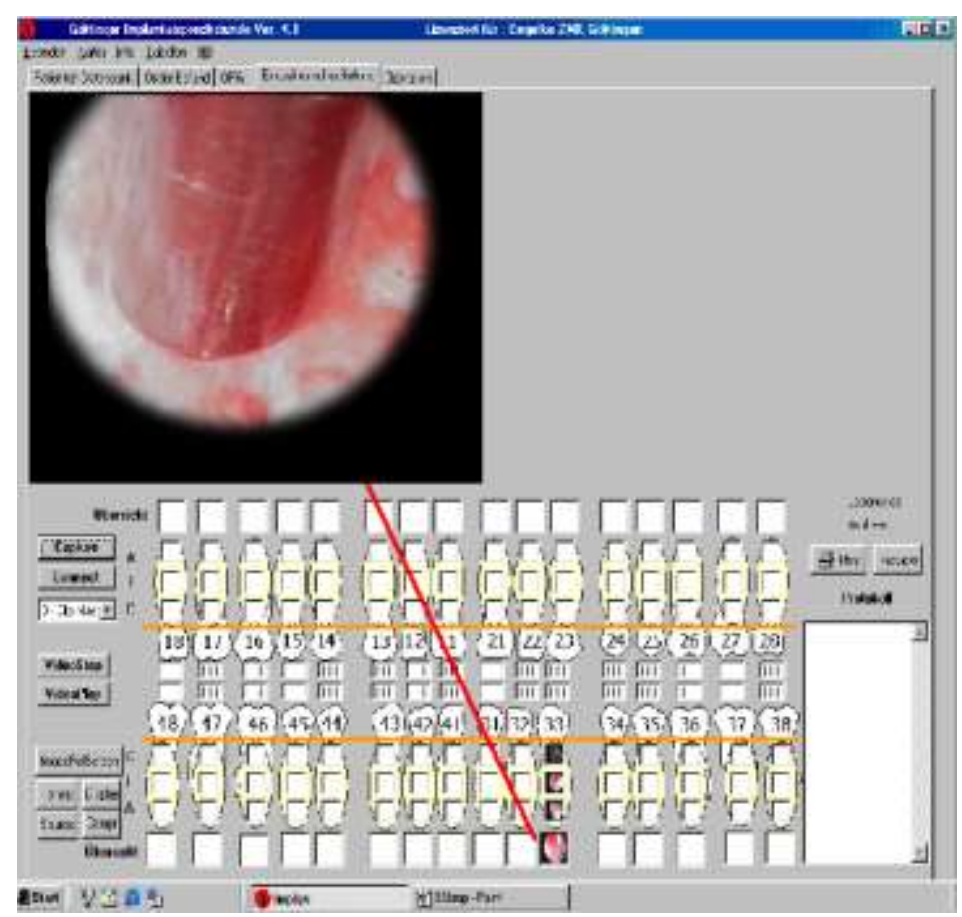

Abb.9 Computergestützte Archivierung der Röntgenbilder sowie der intra operationem gewonnenen endoskopischen Bilddaten zahnspezifisch, hier eine Übersichtsaufnahme von Zahn 33, mit dem ImPlan-Programm. 


\subsection{Auswertung}

Die Auswertung der erhobenen Bilddaten sollte eine Antwort auf die Fragen bringen, ob es knöcherne Defektsituationen nach Zahnentfernungen gibt, die durch die alleinige Betrachtung des Röntgenbildes nicht zu erkennen gewesen wären und ob zahnregionspezifische (hier im Frontzahn und Prämolarenbereich) Defektsituationen auftreten. Hierzu wurde, wie in der zahnärztlichen Praxis üblich, vor Behandlungsbeginn eine Panoramaschichtaufnahme angefertigt, welche mit den postoperativ angefertigten endoskopisch gewonnenen Bildern verglichen wurde. Die Ergebnisse sowohl der Vermessung der Röntgenbilder als auch der knöchernen Alveole wurden patientenspezifisch in einer mit dem Tabellenkalkulationsprogramm Microsoft Excel 2003 erstellten und auf dem Auswertungscomputer Toshiba Satellite gespeicherten Tabelle eingefügt. Die Auswahl der endoskopischen Bilddaten wurde nach den zuvor festgelegten Kriterien, eine Übersichtsaufnahme und je ein Bild des knöchernen Limbus alveolaris der oralen, vestibulären und mesialen Alveole, dokumentiert.

Die graphische Darstellung sowohl der endoskopisch als auch der röntgenologisch erhobenen Werte erfolgte in Form von Box-Plot-Diagrammen, auch Box-and-Whiskers-Diagramm nach TUKEY genannt.

Ein Box-Plot-Diagramm ist eine Darstellungsform, die Aussagen über die Medianwerte, die Quartile (25\%- und 75\%- Quartil), sowie die Lage der Extremwerte erlaubt.

Die Box enthält 50\% der Daten, die Whiskersbärte stellen das Streuungsmaß dar und geben Auskunft über die Lage der Extremwerte. 


\section{Ergebnisse}

\subsection{Auswertung der Vermessung der Alveolen}

Bei der Auswertung der Bilddaten wurden folgende Kriterien berücksichtigt:

Die endoskopische Vermessung der Extraktionsalveolen vom Alveolenboden bis zum Limbus alveolaris in oraler, vestibulärer und approximal-mesialer Richtung sowie die Vermessung der Panoramaschichtaufnahme in zentraler und mesialer Richtung vom Alveolenboden bis zum Limbus alveolaris.

Endoskopisch ausgewertet wurden 132 Extraktionsalveolen aus allen vier Quadranten. Es wurden ausschließlich Frontzahn- und Prämolarenextraktionsalveolen untersucht. Abb. 10 gibt eine Übersicht zur Verteilung der extrahierten Zähne auf das Gesamtgebiß.

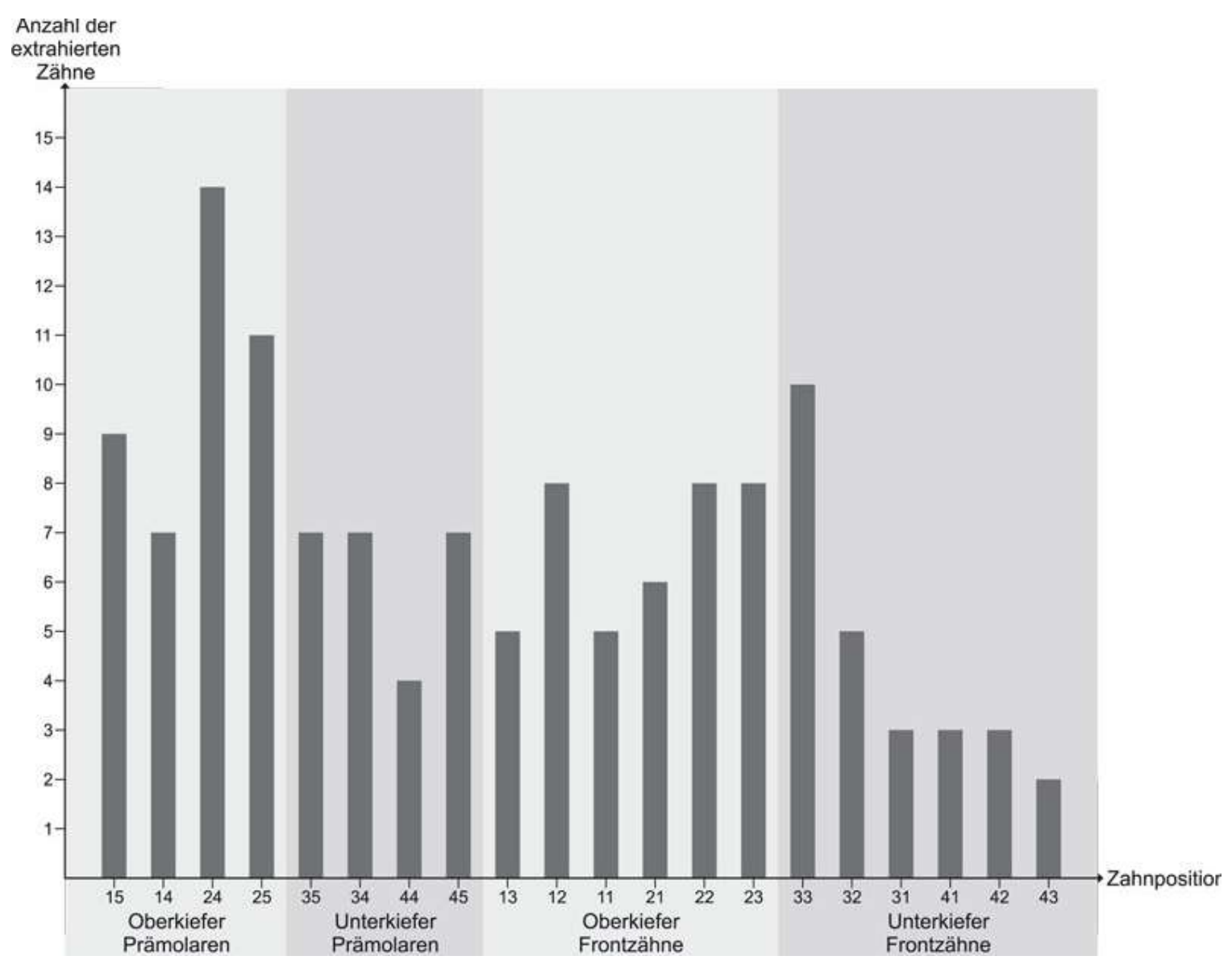

Abb.10 Verteilung der endoskopisch untersuchten Alveolen auf Ober- und Unterkiefer sowie auf Frontzähne und Prämolaren 
In der Gruppe der Oberkiefer Frontzähne (Regiones 13,12,11,21,22,23) wurden 40 Extraktionsalveolen endoskopisch untersucht.

Für die Strecke 1-2 (Alveolenboden-Limbus alveolaris oral) wurde mit dem Endoskop minimal $1 \mathrm{~mm}$ und maximal $15 \mathrm{~mm}$ gemessen.

Der Interquartilabstand erstreckt sich von $5,5 \mathrm{~mm}$ bis $12,5 \mathrm{~mm}$ bei einem Medianwert von $10 \mathrm{~mm}$.

Für die Strecke 1-3 (Alveolenboden-Limbus alveolaris vestibulär) ergibt sich minimal $0 \mathrm{~mm}$ und maximal $17 \mathrm{~mm}$.

Der Interquartilabstand erstreckt sich von 3,5 mm bis $12 \mathrm{~mm}$ bei einem Medianwert von $7 \mathrm{~mm}$ (Abb.11).
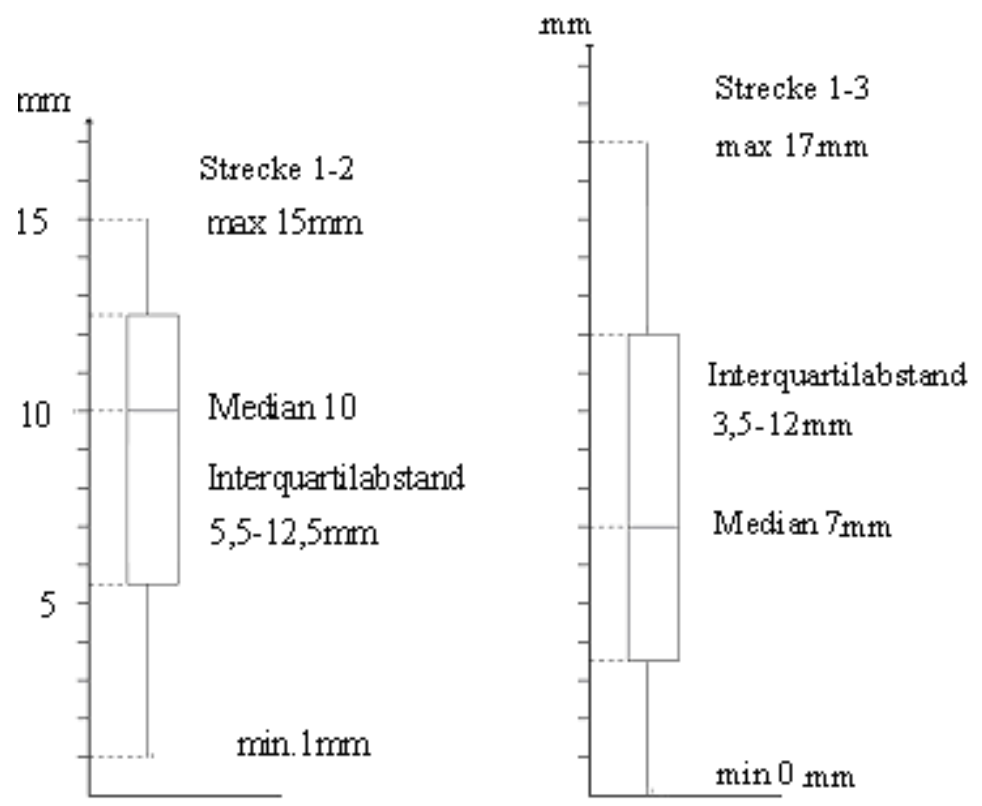

Abb.11 Box-Plot-Diagramm der endoskopisch erhobenen Messwerte der Strecken 1-2 und 1-3 der Oberkiefer- Frontzahnextraktionsalveolen

Approximal mesial beträgt der Abstand Alveolenboden-Limbus alveolaris (Strecke 1-4) minimal $2 \mathrm{~mm}$ und maximal $17 \mathrm{~mm}$.

Der Interquartilabstand erstreckt sich von $5,75 \mathrm{~mm}$ bis $13,25 \mathrm{~mm}$ bei einem Medianwert von 9,5 mm (Abb.12). 


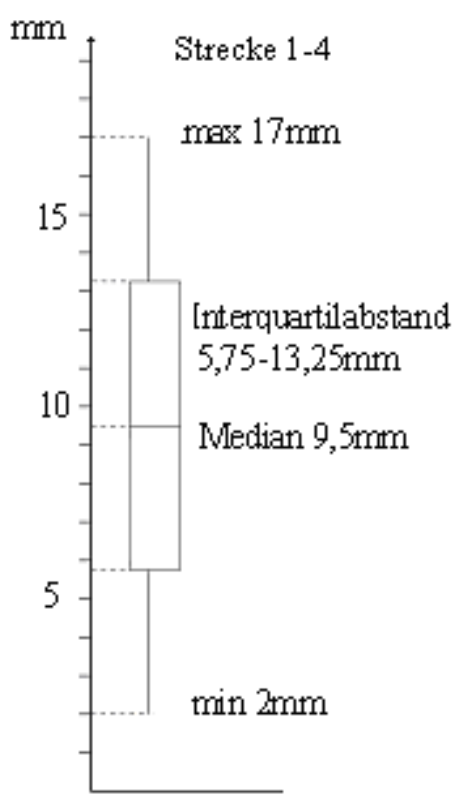

Abb 12 Box-Plot-Diagramm der endoskopisch erhobenen Werte der Strecke 1-4 der Oberkiefer-Frontzahnextraktionsalveolen

Im Bereich der Oberkiefer Frontzähne ergaben sich unterschiedliche Knochenhöhen im oralen und vestibulären Anteil der Extraktionsalveole (Abb.13).

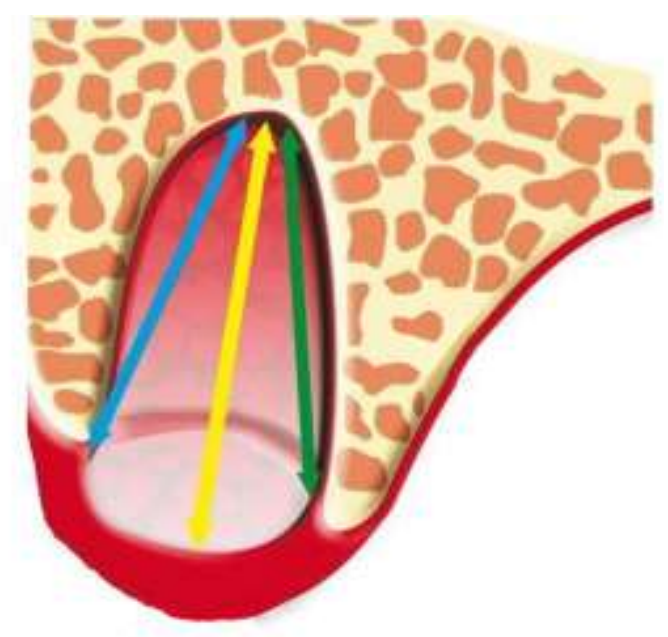

Abb.13 Graphische Darstellung der Oberkiefer-Frontzahnextraktionsalveole nach endoskopischer Vermessung, regio 13-23. Eingezeichnet sind die Strecke 1-3 (Alveolenboden-Limbus alveolaris vestibulär) als blauer Pfeil, die Strecke 1-4 (Alveolenboden-Limbus alveolaris mesial) als gelber Pfeil und die Strecke 1-2 (Alveolenboden-Limbus alveolaris oral) als grüner Pfeil. 
Die Auswertung der Panoramaschichtaufnahmen (für 33 Zähne) ergibt für die Strecke rö1-2 (Alveolenboden-Limbus alveolaris zentral) minimal $4 \mathrm{~mm}$ und maximal $17,6 \mathrm{~mm}$.

Der Interquartilabstand erstreckt sich von 7,2 $\mathrm{mm}$ bis $14 \mathrm{~mm}$ bei einem Medianwert von 10,4 mm.

Approximal mesial beträgt der Abstand Alveolenboden- Limbus alveolaris (Strecke rö1-4) minimal 2,4 mm und maximal 17,6 mm.

Der Interquartilabstand erstreckt sich von 5,6 $\mathrm{mm}$ bis 13,6 $\mathrm{mm}$ bei einem Medianwert von 9,6 mm (Abb.14).
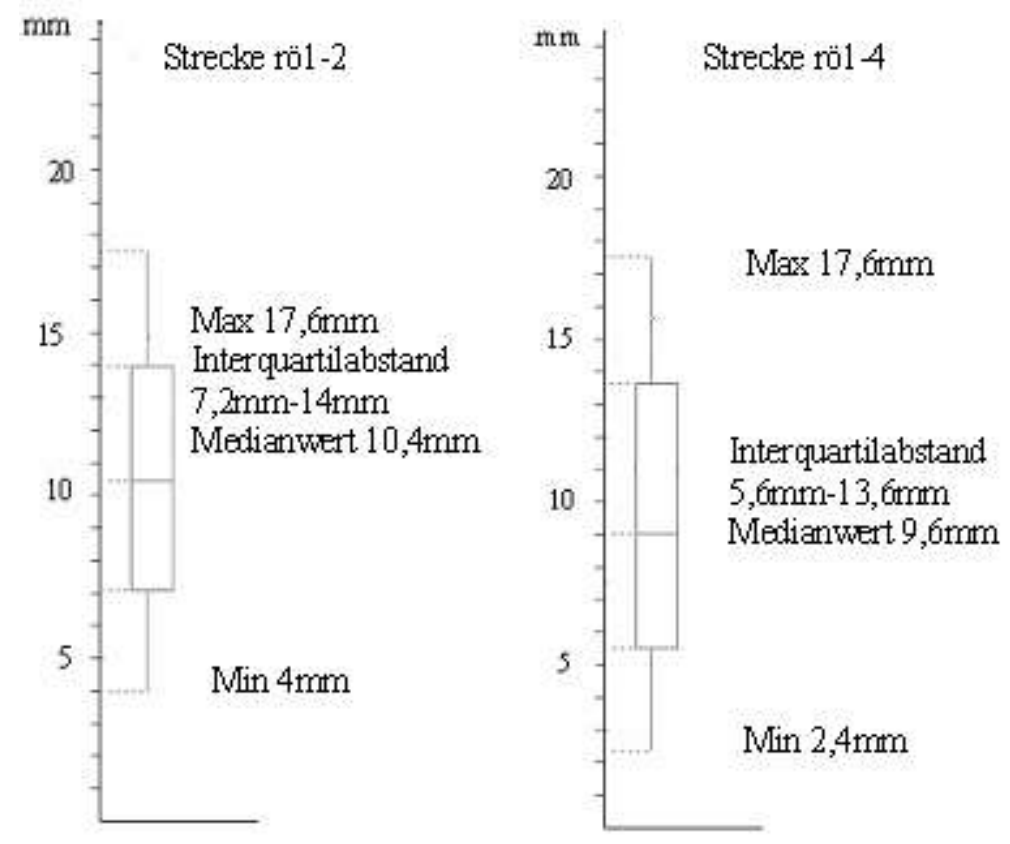

Abb.14 Box-Plot-Diagramm der röntgenologisch erhobenen Werte der Strecken rö1-2 und rö1-4 der Oberkiefer-Frontzähne

In der Gruppe der Oberkiefer-Prämolaren (Regiones 15, 14, 24,25) wurden 41 Extraktionsalveolen endoskopisch untersucht.

Die endoskopischen Messwerte der Strecke Alveolenboden-Limbus alveolaris oral (Strecke 1-2) betragen minimal $2 \mathrm{~mm}$ und maximal $15 \mathrm{~mm}$ bei einem Medianwert von $8 \mathrm{~mm}$.

Der Interquartilabstand erstreckt sich von $5 \mathrm{~mm}$ bis $11,5 \mathrm{~mm}$. 
Die endoskopisch erhobenen Messwerte der Strecke 1-3 (AlveolenbodenLimbus alveolaris vestibulär) betragen minimal $2 \mathrm{~mm}$ und maximal $15 \mathrm{~mm}$ bei einem Medianwert von $7 \mathrm{~mm}$.

Der Interquartilabstand erstreckt sich von 4,5 mm bis $11 \mathrm{~mm}$ (siehe Abb.15)
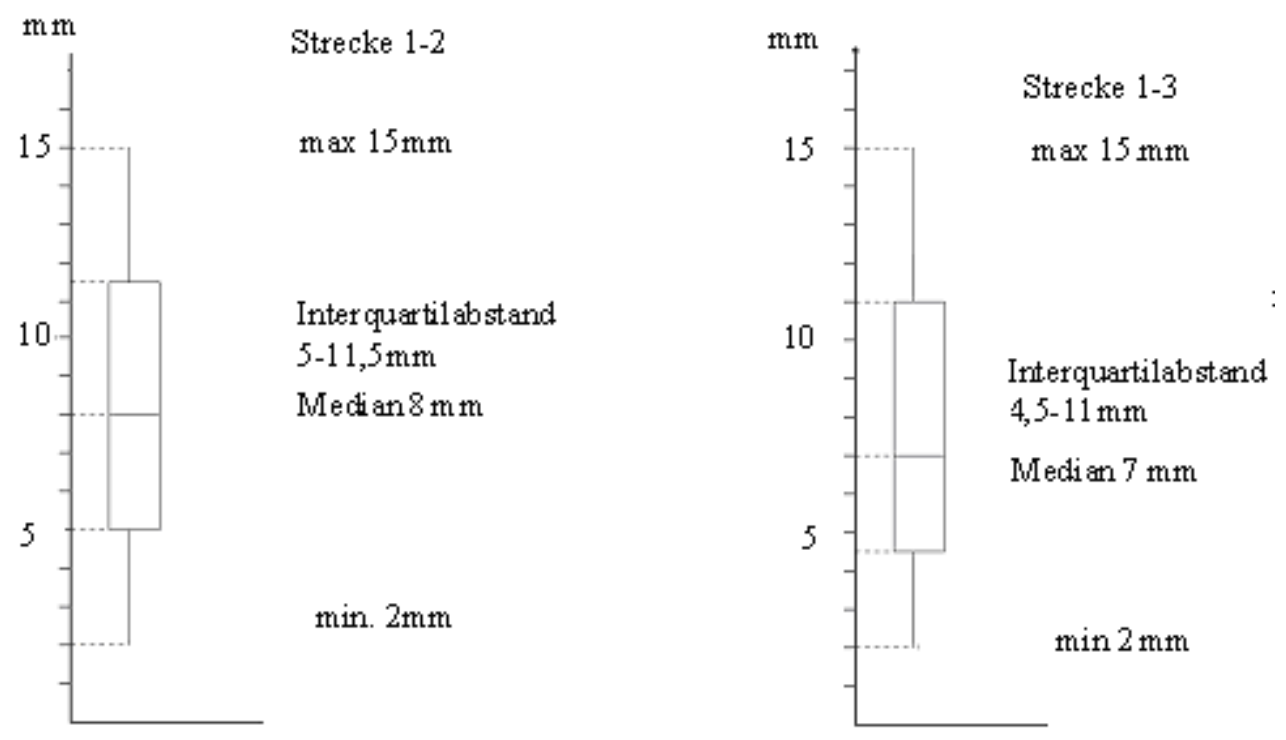

Abb. 15 Box-Plot-Diagramme der endoskopisch erhobenenMesswerte der Strecken 1-2 und 1-3 der Oberkiefer-Prämolarenextraktionsalveolen

Die endoskopisch erhobenen Messwerte für die Strecke 1-4 (AlveolenbodenLimbus alveolaris mesial) betragen minimal $0 \mathrm{~mm}$ und maximal $15 \mathrm{~mm}$. Der Interquartilabstand erstreckt sich von $5 \mathrm{~mm}$ bis $12,5 \mathrm{~mm}$ bei einem Medianwert von $10 \mathrm{~mm}$. 


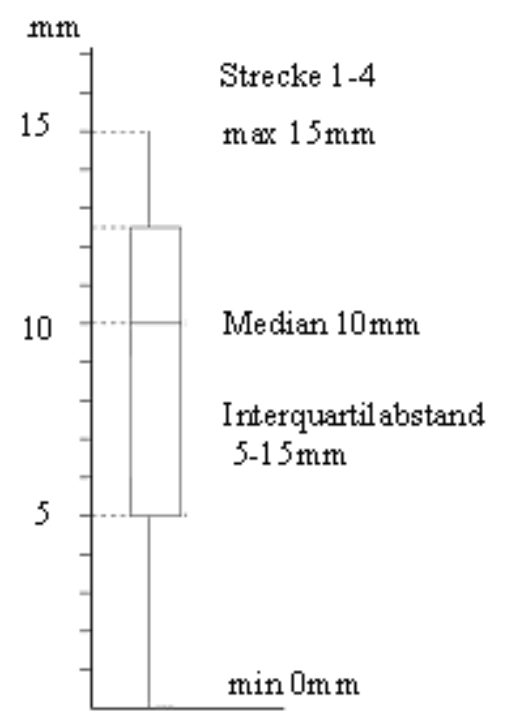

Abb. 16 Box-Plot-Diagramm der endoskopisch erhobenen Werte der Strecke 1-4 der Oberkiefer-Prämolarenextraktionsalveolen

Bei der Auswertung der endoskopisch erhobenen Messwerte für die Extraktionsalveolen der Prämolarenregion des I. und II. Quadranten ergaben sich in beiden Fällen unterschiedliche Knochenhöhen für den oralen und den vestibulären Anteil der Alveole (Abb.17, Abb.18).

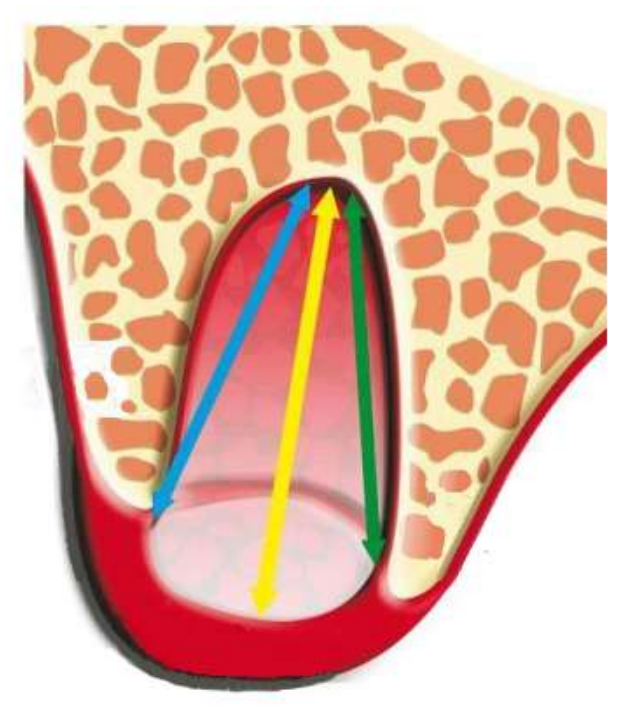

Abb.17 Graphische Darstellung der Oberkiefer-Prämolarenextraktionsalveole (Zähne 14, 15) im I.Quadrant, vermessen wurde die Strecke 1-3 (Alveolenboden-Limbus alveolaris vestibulär), hier als blauer Pfeil, die Strecke 1-4 (Alveolenboden-Limbus alveolaris mesial), hier als gelber Pfeil markiert, und die Strecke 1-2 (Alveolenboden-Limbus alveolaris oral) hier als grüner Pfeil 


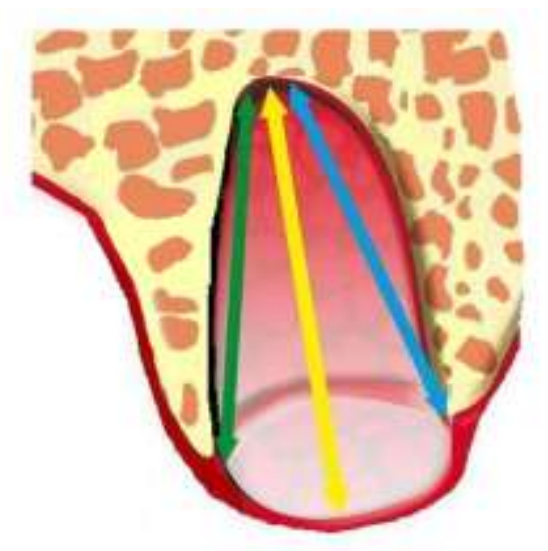

Abb. 18 Graphische Darstellung der Oberkiefer-Prämolarenextraktionsalveole (Zähne 24,25)

II. Quadrant. Vermessen wurde die Strecke 1-3 (Alveolenboden-Limbus alveolaris vestibulär), hier als blauer Pfeil, die Strecke 1-4 (Alveolenboden- Limbus alveolaris mesial) hier mit dem gelben Pfeil eingezeichnet und die Strecke 1-2 (Alveolenboden-Limbus alveolaris oral), hier als grüner Pfeil eingezeichnet.

Die Auswertung der Panoramaschichtaufnahme (bei 34 Zähnen) ergibt für die Strecke rö1-2 (Alveolenboden-Limbus alveolaris zentral) minimal $0 \mathrm{~mm}$ und maximal $16 \mathrm{~mm}$.

Der Interquartilabstand erstreckt sich von $4 \mathrm{~mm}$ bis $12 \mathrm{~mm}$ bei einem Medianwert von $8 \mathrm{~mm}$.

Die Strecke rö1-4 (Alveolenboden-Limbus alveolaris mesial) liegt bei minimal $0 \mathrm{~mm}$ und maximal 17,6 $\mathrm{mm}$.

Der Interquartilabstand erstreckt sich von $4 \mathrm{~mm}$ bis $12,8 \mathrm{~mm}$ bei einem Medianwert von 10,4 mm (Abb.19). 

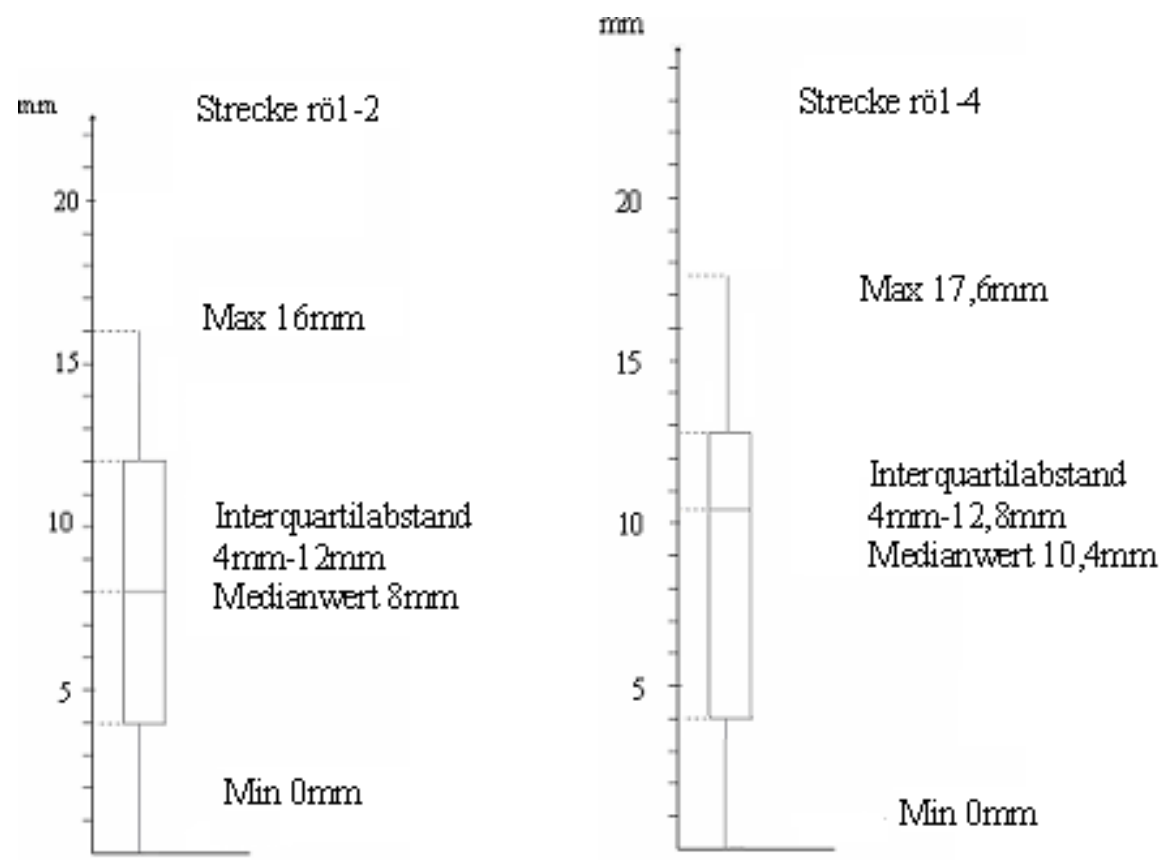

Abb.19 Box-Plot-Diagramm der röntgenologisch erhobenen Werte der Strecken rö1-2 und rö1-4 der Oberkiefer-Prämolaren

In der Gruppe der Unterkiefer-Frontzähne (Regiones 33,32,31,41,42,43) wurden 26 Extraktionsalveolen endoskopisch untersucht.

Für die Strecke 1-2 (Alveolenboden-Limbus alveolarris oral) wurden minimal $3 \mathrm{~mm}$ und maximal $14 \mathrm{~mm}$ gemessen.

Der Interquartilabstand erstreckt sich von $4 \mathrm{~mm}$ bis $9,5 \mathrm{~mm}$ bei einem Medianwert von $5 \mathrm{~mm}$.

Vestibulär beträgt der Abstand Alveolenboden-Limbus alveolaris vestibulär (Strecke 1-3) minimal $2 \mathrm{~mm}$ und maximal $16 \mathrm{~mm}$.

Der Interquartilabstand erstreckt sich von 3,5 mm bis 10,5 $\mathrm{mm}$ bei einem Medianwert von $5 \mathrm{~mm}$ (Abb.20). 


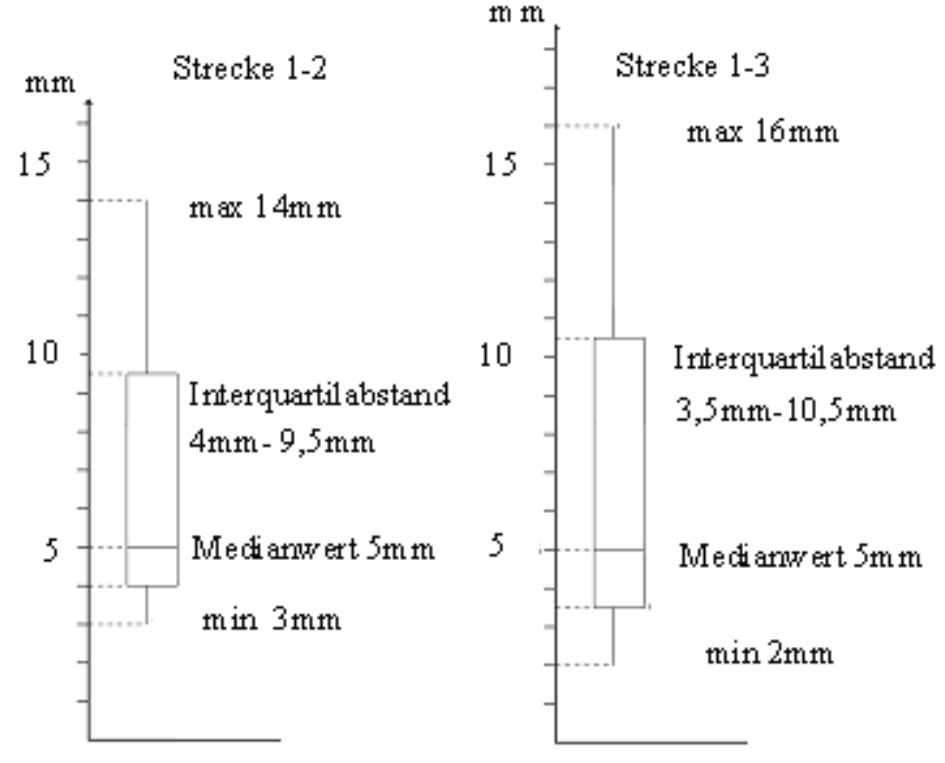

Abb.20 Box-Plot-Diagramm der endoskopisch erhobenen Werte für die Strecken 1-2 und 1-3 der Unterkiefer-Frontzahnextraktionsalveolen

Die Strecke Alveolenboden-Limbus alveolaris mesial (1-4) beträgt minimal $1 \mathrm{~mm}$ und maximal $16 \mathrm{~mm}$.

Der Interquartilabstand erstreckt sich von 3,5 mm bis $11 \mathrm{~mm}$ bei einem Medianwert von $6 \mathrm{~mm}$ (Abb.21).

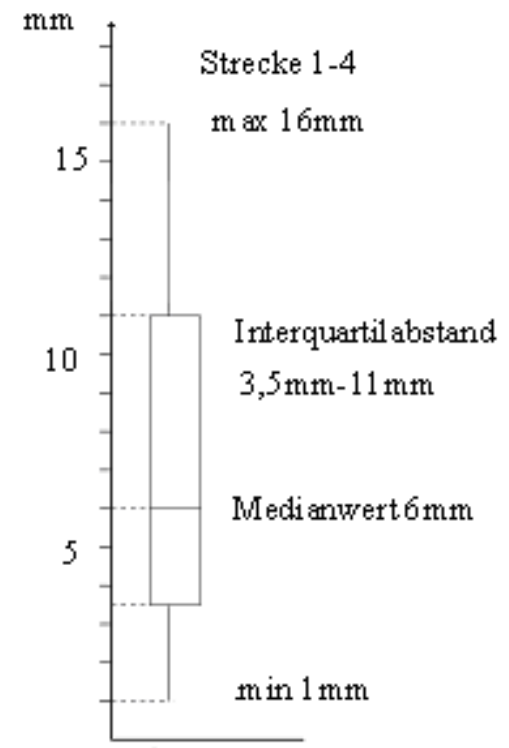

Abb.21 Box-Plot-Diagramm der endoskopisch erhobenen Werte für die Strecke1-4 der Unterkiefer-Frontzahnextraktionsalveolen 


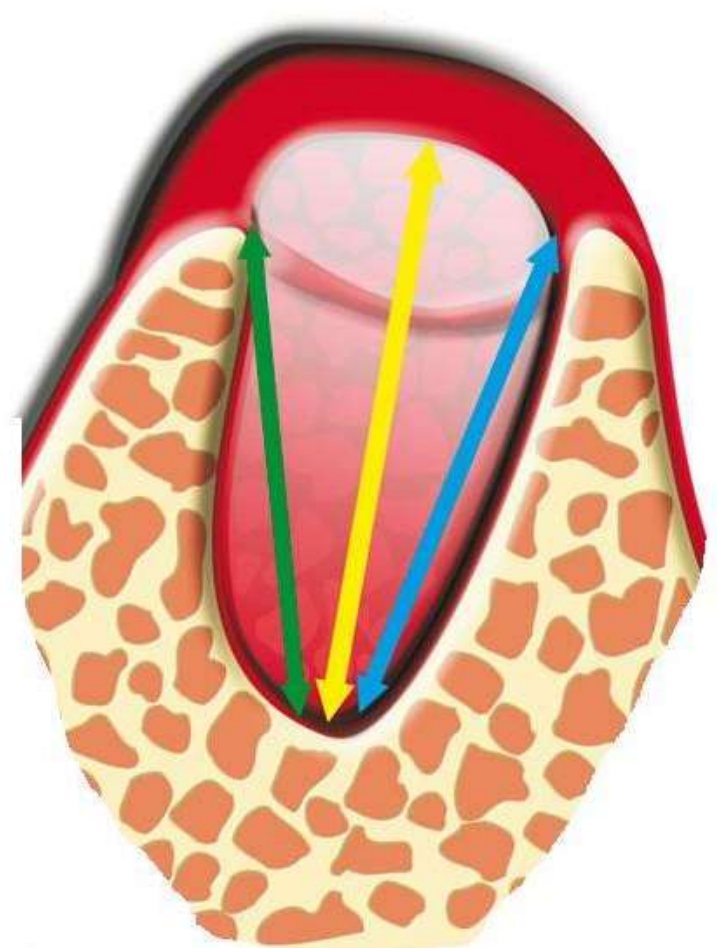

Abb.22 Graphische Darstellung der Unterkiefer-Frontzahnextraktionsalveole (regio 33-43) nach endoskopischer Vermessung. Eingezeichnet sind die Strecke 1-2 (AlveolenbodenLimbus alveolaris oral) als grüner Pfeil, die Strecke 1-4 (Alveolenboden-Limbus alveolaris mesial) als gelber Pfeil und die Strecke 1-3 (Alveolenboden-Limbus alveolaris vestibulär) als blauer Pfeil.

Bei der endoskopischen Vermessung der Unterkiefer-Frontzahnalveolen ergaben sich gleiche Werte für die Knochenhöhe oral und vestibulär.

Die Auswertung der Panoramaschichtaufnahme (bei 25 Zähnen) ergibt für den Abstand Alveolenboden-Limbus alveolaris zentral (Strecke rö1-2) minimal $4 \mathrm{~mm}$ und maximal $14,4 \mathrm{~mm}$.

Der Interquartilabstand erstreckt sich von $6 \mathrm{~mm}$ bis $11,2 \mathrm{~mm}$ bei einem Medianwert von $8 \mathrm{~mm}$.

Approximal mesial beträgt der Abstand Alveolenboden-Limbus alveolaris mesial (Strecke rö1-4) minimal $4 \mathrm{~mm}$ und maximal 14,4 mm. 
Der Interquartilabstand erstreckt sich von $5,6 \mathrm{~mm}$ bis $10,8 \mathrm{~mm}$ bei einem Medianwert von 7,2 mm (Abb.23).
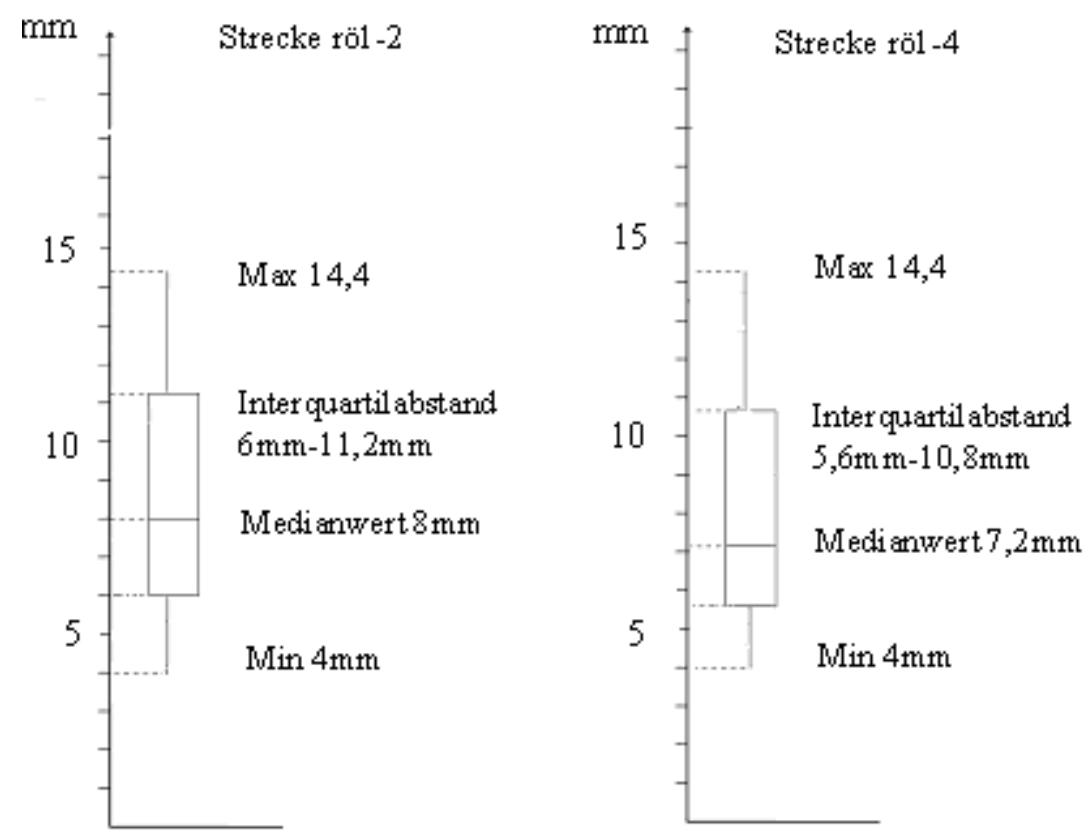

Abb.23 Box-Plot-Diagramm der röntgenologisch erhobenen Werte der Strecken rö1-2 und rö1-4 der Unterkiefer-Frontzähne

In der Gruppe der Unterkiefer Prämolaren (Regiones 34,35,44,45) wurden 25 Extraktionsalveolen endoskopisch untersucht.

Die Strecke 1-2 (Alveolenboden- Limbus alveolaris oral) erstreckt sich von minimal $4 \mathrm{~mm}$ bis maximal $15 \mathrm{~mm}$.

Der Interquartilabstand erstreckt sich von 5,5 $\mathrm{mm}$ bis $11 \mathrm{~mm}$ bei einem Medianwert von $7 \mathrm{~mm}$.

Vestibulär beträgt der Abstand Alveolenboden- Limbus alveolaris vestibulär (Strecke 1-3) minimal $2 \mathrm{~mm}$ und maximal $15 \mathrm{~mm}$.

Der Interquartilabstand erstreckt sich von $4 \mathrm{~mm}$ bis $10,5 \mathrm{~mm}$ bei einem Medianwert von $6 \mathrm{~mm}$. 

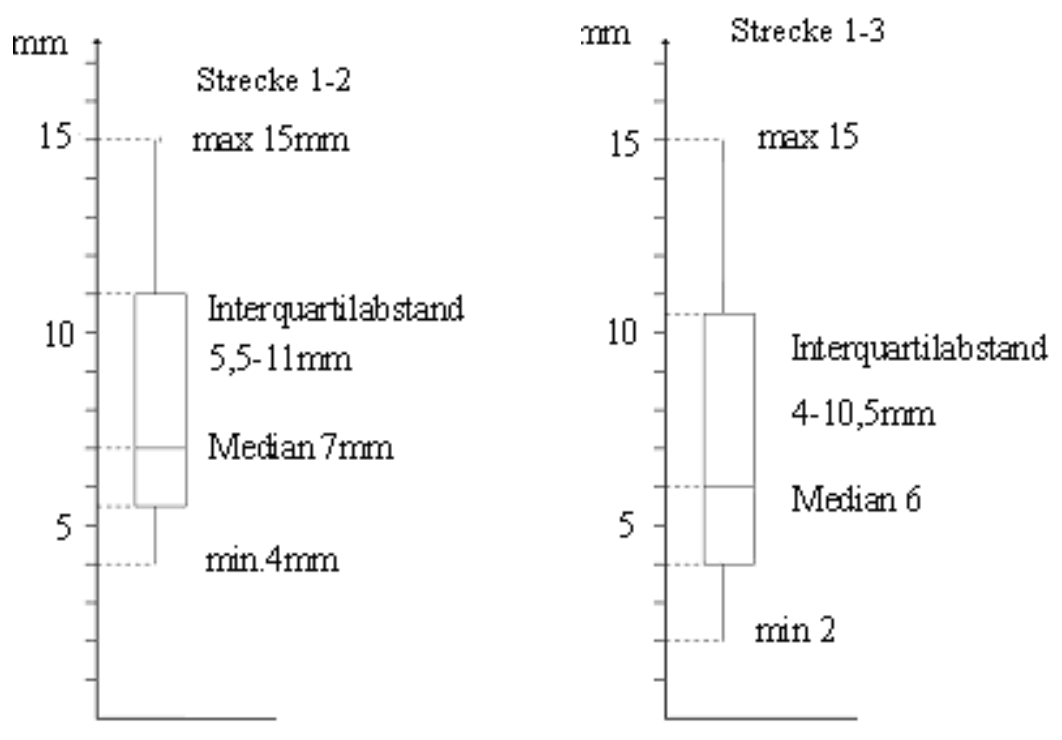

Abb.24 Box-Plot-Diagramme der endoskopisch erhobenen Werte für die Strecken 1-2 und 1-3 der Unterkiefer-Prämolarenextraktionsalveolen

Approximal mesial beträgt der Abstand Alveolenboden-Limbus alveolaris minimal $4 \mathrm{~mm}$ und maximal $16 \mathrm{~mm}$.

Der Interquartilabstand erstreckt sich von 5,5 $\mathrm{mm}$ bis $11,5 \mathrm{~mm}$ bei einem Medianwert von $7 \mathrm{~mm}$ (Abb.25).

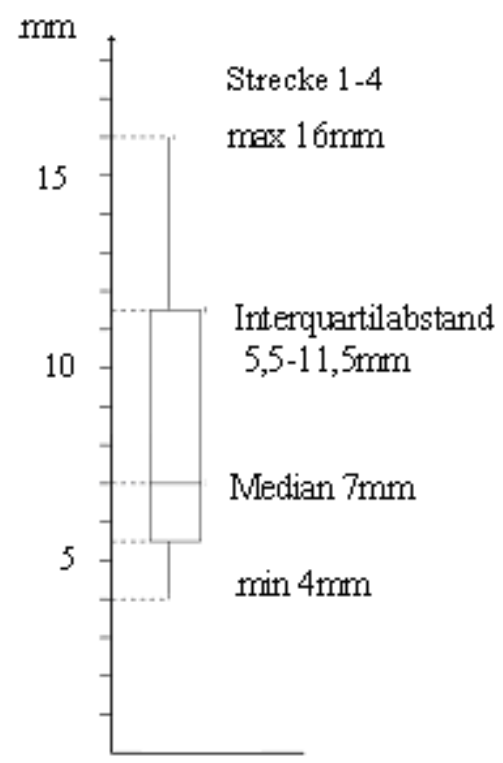

Abb 25 Box-Plot-Diagramm der endoskopisch erhobenen Werte für die Strecke 1-4 der Unterkiefer-Prämolarenextraktionsalveolen 

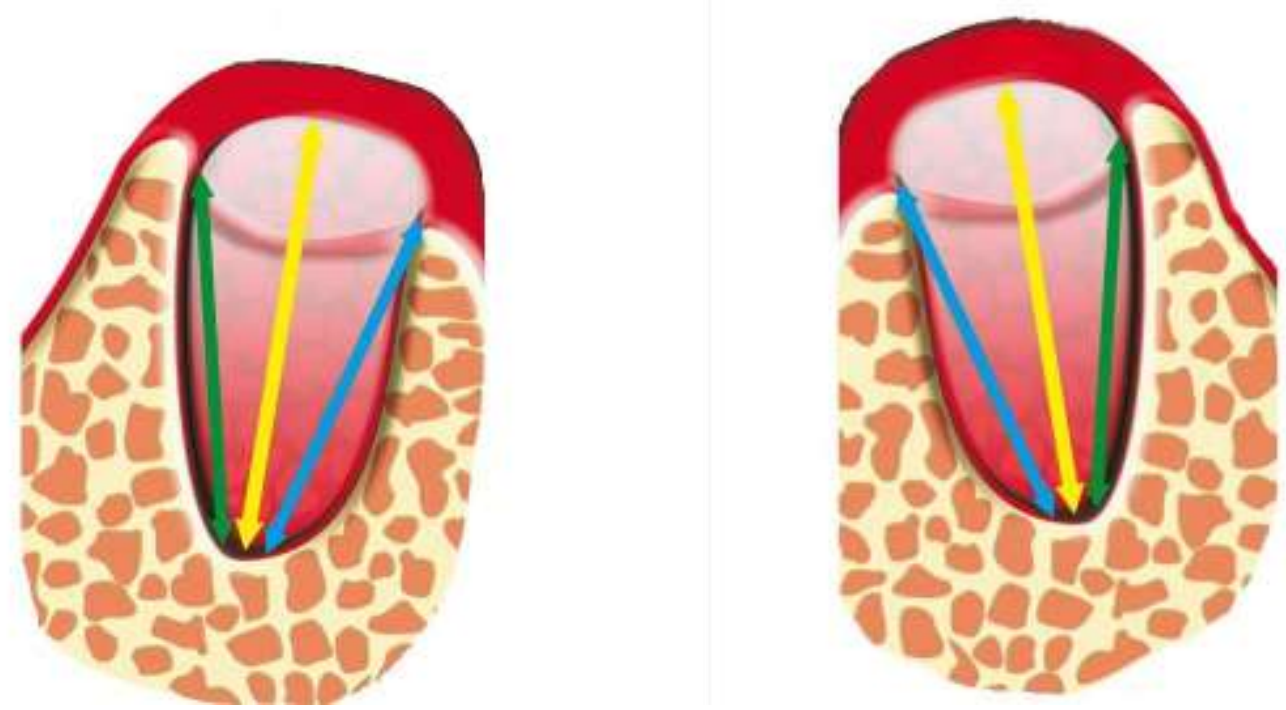

Abb 26 Graphische Darstellung der Unterkiefer-Prämolarenextraktionsalveolen im III. und IV. Quadranten nach endoskopischer Vermessung. Eingezeichnet sind die Strecke 1-2 (Alveolenboden-Limbus alveolaris oral) als grüner Pfeil, die Strecke 1-4 (AlveolenbodenLimbus alveolaris mesial) als gelber Pfeil und die Strecke 1-3 (Alveolenboden-Limbus alveolaris mesial) als blauer Pfeil.

Die Schemazeichnung zeigt sowohl für den III. als auch für den IV. Quadranten unterschiedliche Knochenhöhen im oralen und vestibulären Anteil der Alveole, sowie eine unterschiedlich große Knochenverteilung im Seitenvergleich. Die Auswertung der Panoramaschichtaufnahme (für 24 Zähne) ergab für die Strecke rö1-2 (Alveolenboden-Limbus alveolaris zentral) minimal $4 \mathrm{~mm}$ und maximal $14,4 \mathrm{~mm}$.

Der Interquartilabstand erstreckt sich von $6,4 \mathrm{~mm}$ bis $11,6 \mathrm{~mm}$ bei einem Medianwert von $8,8 \mathrm{~mm}$.

Appoximal mesial beträgt der Abstand Alveolenboden-Limbus alveolaris mesial (Strecke rö1-4) minimal 4,8 mm und maximal 14,4 mm.

Der Interquartilabstand erstreckt sich von $6,4 \mathrm{~mm}$ bis $11,2 \mathrm{~mm}$ bei einem Medianwert von $8 \mathrm{~mm}$. 


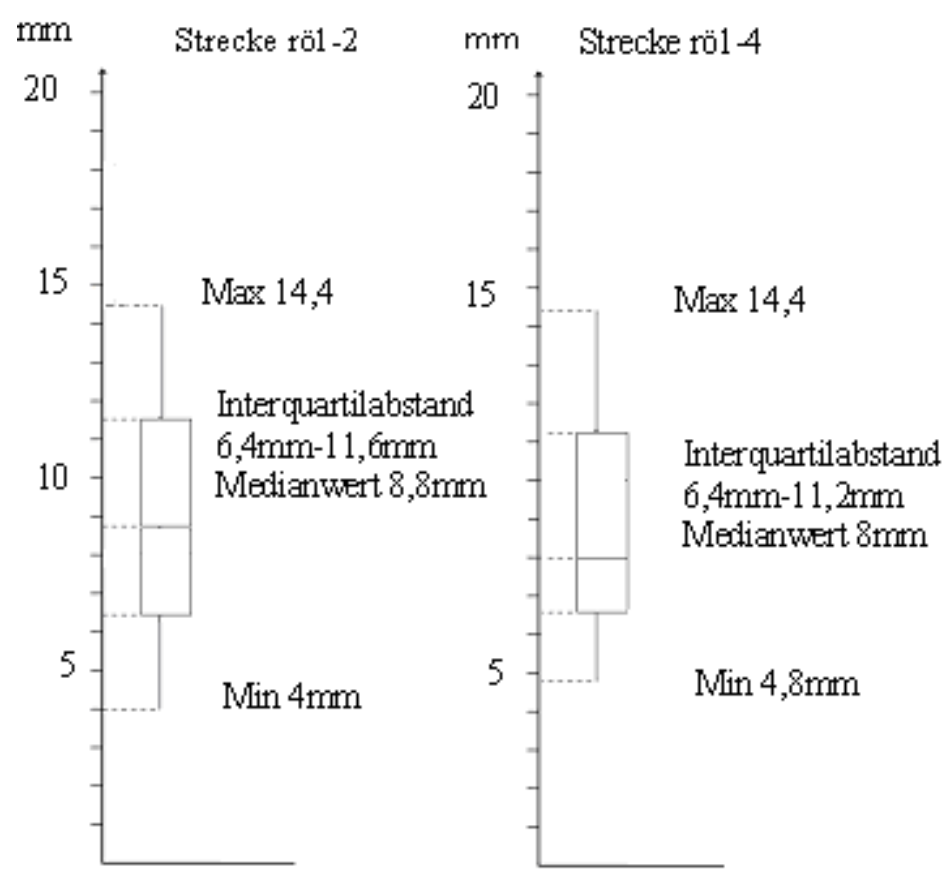

Abb.27 Box-Plot-Diagramm der röntgenologisch erhobenen Werte der Strecken rö1-2 und rö1-4, Unterkiefer-Prämolaren (Zähne 34,35,44,45 )

3.2 Vergleich der endoskopisch erhobenen Messwerte mit den röntgenologischen Messwerten bezogen auf die Strecke Alveolenboden-Limbus alveolaris mesial

Alle angefertigten Panoramaschichtaufnahmen weisen einen aufnahmetechnisch bedingten Vergrößerungsfaktor von $25 \%$ bezogen auf die tatsächliche Zahnlänge auf. Nach Abzug dieses Vergrößerungsfaktors (nach der Berechnung: Vermessene Zahnlänge auf der Panoramaschichtaufnahme dividiert durch 125, multipliziert mit 100) ergaben sich folgende Zusammenhänge zwischen den endoskopisch erhobenen Messwerten und den röntgenologisch erhaltenen Messwerten für die Strecken 1-4 und rö1-4. 


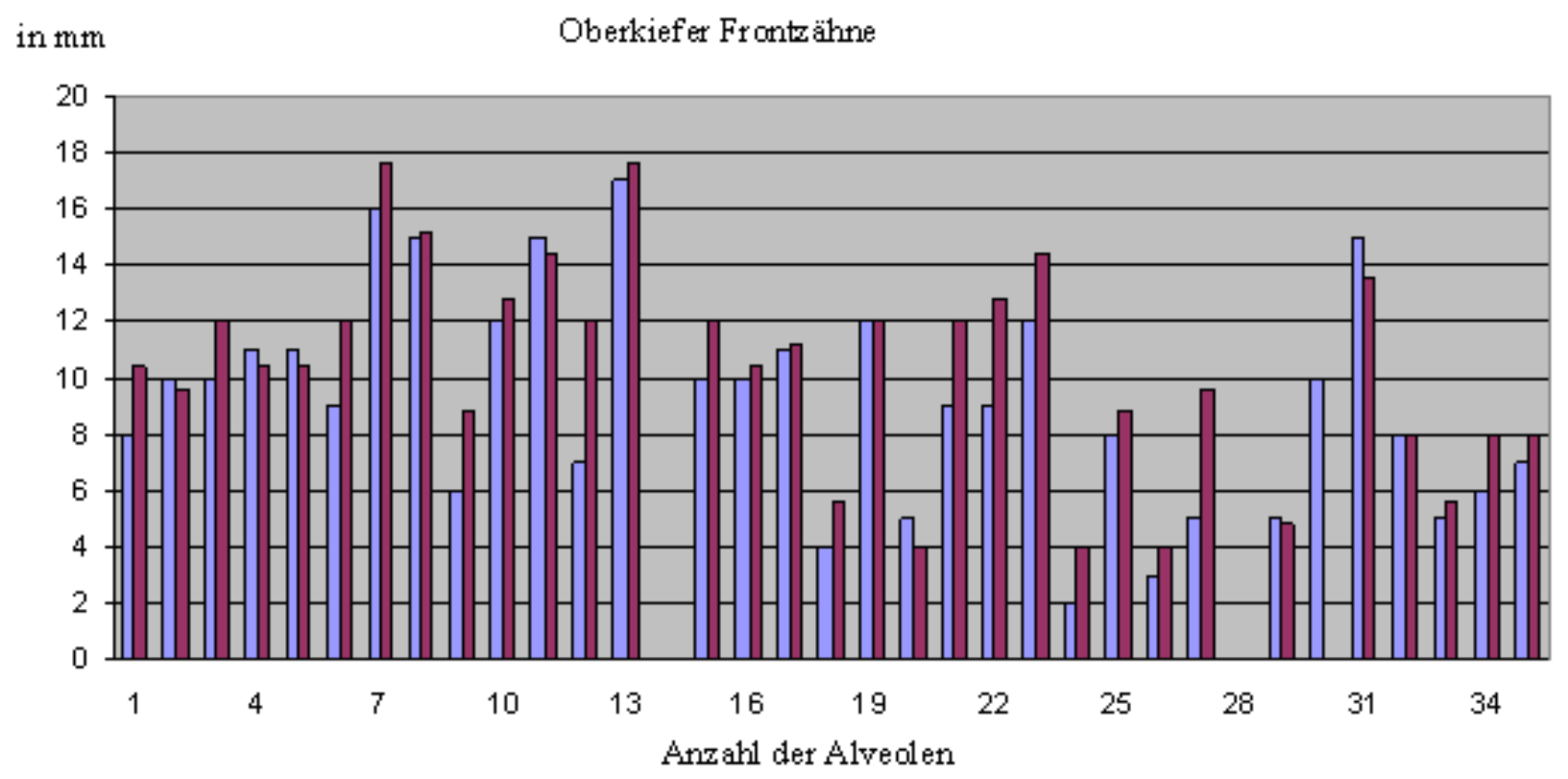

Abb.28 Vergleich der endoskopisch erhaltenen Messwerte mit den korrigierten röntgenologischen Messwerten für die Strecken 1-4 und rö1-4 (Alveolenboden-Limbus alveolaris mesial) im Bereich der Oberkiefer-Frontzähne

Es ergeben sich beim Vergleich der endoskopischen und röntgenologisch erhobenen Werte für die Messstrecken 1-4 und rö1-4 (Alveolenboden-Limbus alveolaris mesial) im Bereich der Oberkiefer-Frontzähne in 8 Fällen höhere Messwerte bei der endoskopischen Vermessung. In 2 Fällen lag eine Übereinstimmung vor und in 23 Fällen ergab die Vermessung des Röntgenbildes einen größeren Wert. 


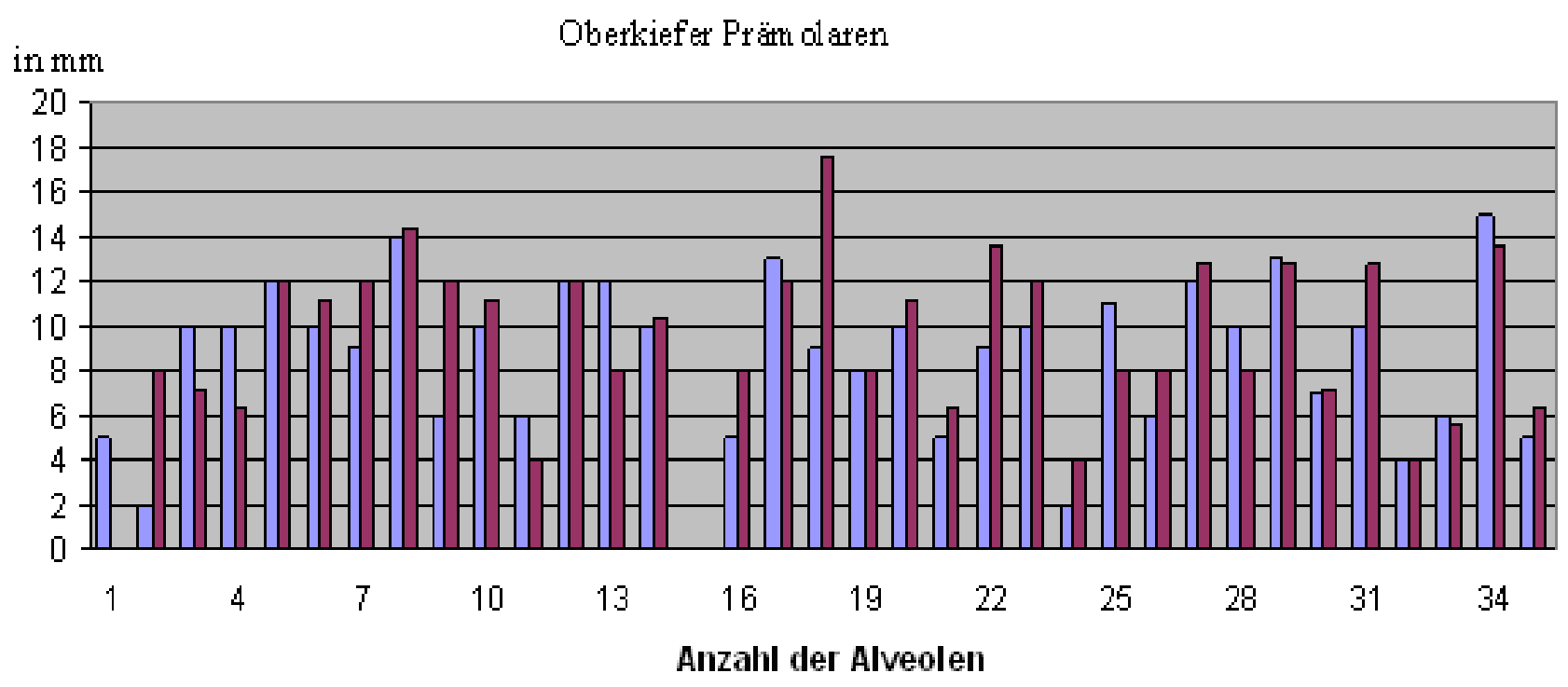

Abb.29 Vergleich der endoskopisch erhaltenen Messwerte mit den korrigierten röntgenologischen Messwerten für die Strecken 1-4 und rö1-4 (Alveolenboden-Limbus alveolaris mesial), im Bereich der Oberkiefer-Prämolaren.

Es ergeben sich beim Vergleich der endoskopischen und röntgenologisch erhobenen Werte für die Messstrecken 1-4 und rö1-4 (Alveolenboden-Limbus alveolaris mesial) im Bereich der Oberkiefer-Prämolaren in 11 Fällen höhere Messwerte bei der endoskopischen Vermessung. In 3 Fällen lag eine Übereinstimmung vor und in 19 Fällen ergab die Vermessung des Röntgenbildes einen größeren Wert. 


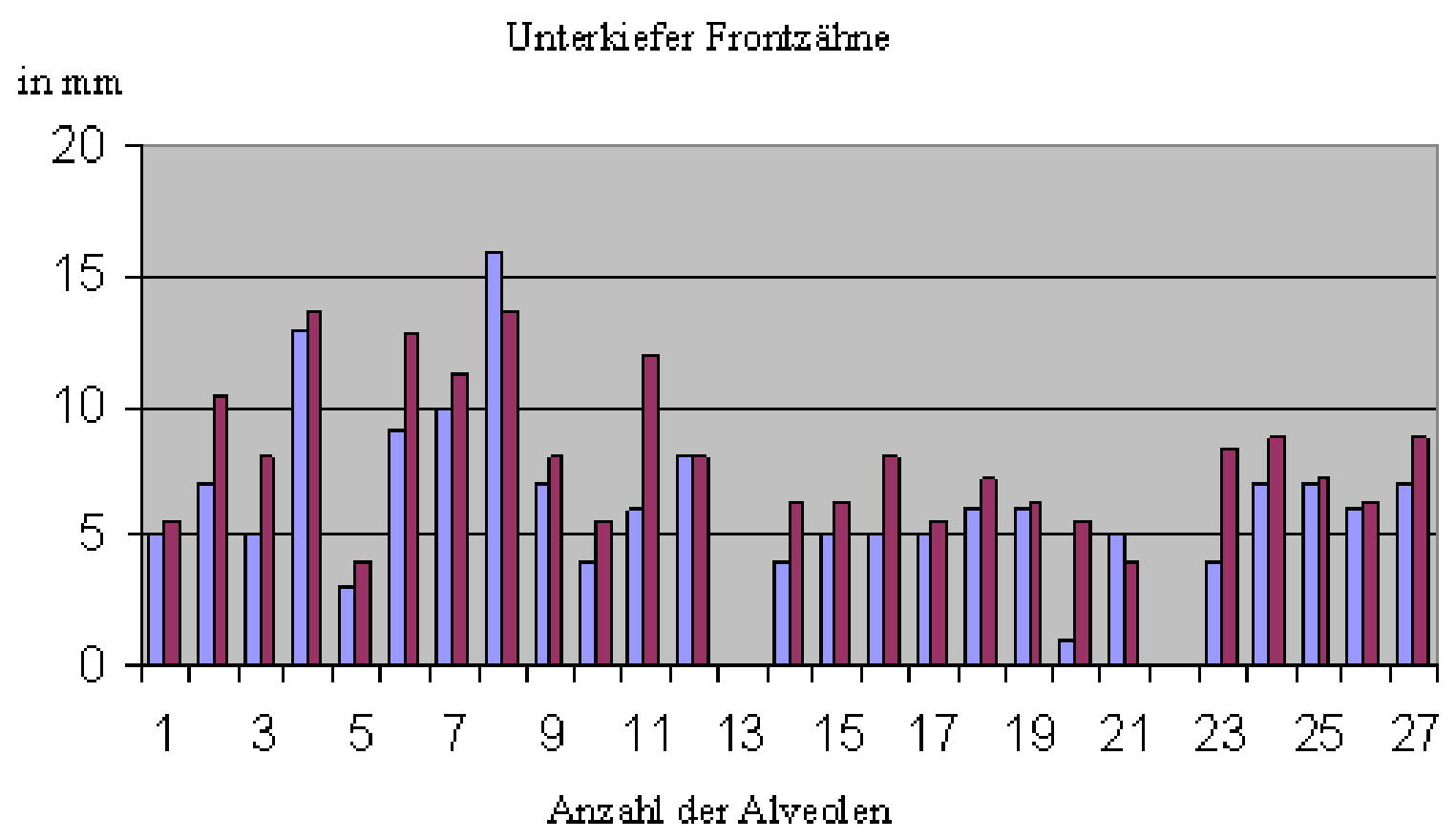

Abb.30 Vergleich der endoskopischen(blau) und korrigierten röntgenologischen (lila) Messwerte für die Strecken 1-4 und rö1-4 im Bereich der Unterkiefer-Frontzähne

Beim Vergleich der endoskopischen und röntgenologisch erhobenen Werte für die Messstrecken 1-4 bzw. rö1-4 (Alveolenboden-Limbus alveolaris mesial) im Bereich der Unterkiefer-Frontzähne lagen in 2 Fällen höhere Messwerte bei der endoskopischen Vermessung und in einem Fall eine Übereinstimmung der Messwerte vor. In 22 Fällen ergab die Vermessung des Röntgenbildes einen größeren Wert. 
in $\mathrm{mm}$

Unterkiefer Prämolaren

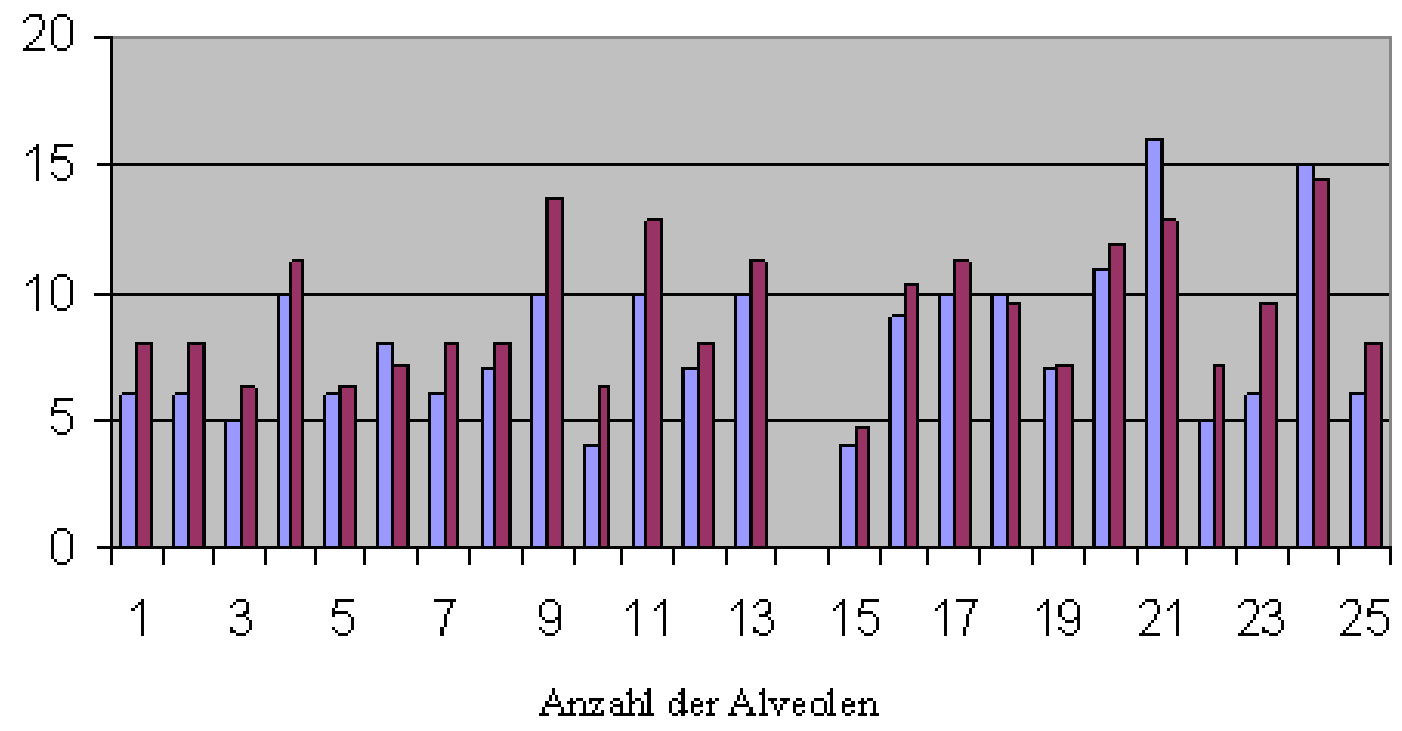

Abb.31 Vergleich der endoskopischen(blau) und korrigierten röntgenologischen (lila) Messwerte für die Strecken 1-4 und rö1-4 im Bereich der Unterkiefer-Prämolaren

Beim Vergleich der endoskopischen und röntgenologisch erhobenen Werte für die Messstrecken 1-4 und rö1-4 (Alveolenboden-Limbus alveolaris mesial) im Bereich der Unterkiefer-Frontzähne lagen in 4 Fällen höhere Messwerte bei der endoskopischen Vermessung und in keinem Fall eine Übereinstimmung der Messwerte vor. In 20 Fällen ergab die Vermessung des Röntgenbildes einen größeren Wert. 


\section{Diskussion}

4.1 Methodische Aspekte der Defektbestimmung von Alveolen

In der Zahnheilkunde ist dem Gebrauch von vergrößernden Hilfsmitteln, wie der Lupenbrille, dem Operationsmikroskop und dem Endoskop in den letzten Jahren eine immer größer werdende Bedeutung zugekommen. Am häufigsten wird hierbei die Lupenbrille zum Einsatz gebracht. Im Gegensatz zu anderen Hilfsmitteln sind die Anschaffungskosten relativ niedrig und die Einarbeitungszeit ist gering. Lupenbrillen sind handlich im Gebrauch und gewährleisten eine ergonomische Arbeitshaltung. Änderungen des Blickwinkels und das Fokussieren eines Objekts können bei der Lupenbrille durch Stellungsänderungen des Behandlers vollzogen werden (Perrin et al. 2000). In diesem Punkt ist die Lupenbrille dem Operationsmikroskop klar überlegen. Als Nachteil ist aber zu vermerken, dass die Augen zur Bildbetrachtung konvergieren müssen, was deren Übermüdung fördert. Der Vergrößerungsfaktor bei der Lupenbrille ist nicht variabel, sondern steht bei Erwerb der Brille fest. Bei starker Vergrößerung kann eine spezielle Lichtquelle zur optischen Objektausleuchtung erforderlich sein (Tibbetts und Shanelec 1996, Tibbetts und Shanelec 1998, Burkhardt 1999). Das Operationsmikroskop hat im Vergleich mit der Lupenbrille den Vorteil, dass die Vergrößerung wählbar ist (zwischen 4bis 40-fach), und das Operationsfeld durch eine integrierte Lampe stets perfekt ausgeleuchtet ist. Für Dokumentationszwecke kann das Operationsmikroskop mit einer Foto- oder Videokamera verbunden werden. Über den Mitbeobachtertubus hat die Assistenz die Möglichkeit, das gleiche Bild wie der Operateur zu sehen und kann effizienter assistieren. Die parallele Optik der Okulare vermindert darüber hinaus die Ermüdung der Augen. Ein Nachteil des Mikroskopierens ist, dass dieses in der Lernphase mit hohem Zeitaufwand verbunden ist (Burkhardt 1999). Im Vergleich zur Lupenbrille liegen die 
Anschaffungskosten sowohl für das Mikroskop als auch für das erforderliche mikrochirurgische Instrumentarium um ein Vielfaches höher. Beide, sowohl Lupenbrille als auch Operationsmikroskop, eignen sich nur bedingt für die Betrachtung knöcherner Defektsituationen, da sie jeweils nur den direkten Blick auf, aber nicht ins Innere des Knochens ermöglichen. Es ist häufig schwierig, die Gegebenheiten in der Alveole darzustellen, ohne einen mukoperiostalen Lappen zu präparieren (Joudzbalys et al. 2008). Des Weiteren wird die Sicht durch auftretende Blutungen stark behindert. Mikroskope und Lupenbrillen weisen nur eine geringe Tiefenschärfe auf und sind somit auf einen konstanten Arbeitsabstand und eine bestimmte Vergrößerung festgelegt.

Eine weitere Möglichkeit, knöcherne Defektsituationen darzustellen, ist die Anfertigung eines Röntgenbildes. Auch diese Darstellungsart bietet zahlreiche Fehlerquellen bei der Abbildung des Kieferknochens. So kann es bei intraoralen Zahnfilmaufnahmen durch Biegen des Röntgenfilms oder der Speicherfolie zu Verzerrungen des Bildes kommen. Auch das freihändige Einstellen des Strahlenbündels trägt dazu bei, dass die gemessenen Defekte in ihrer Ausdehnung mitunter stark variieren. So erschienen Zähne in einer zu steil eingestellten Aufnahme verkürzt, oder es kommt durch das Anpressen des Film mit dem Finger zum Verbiegen. Auch bei extraoralen Projektionen wie der Panoramaschichtaufnahme kann die Streubreite bei der Bestimmung von knöchernen Defekten groß sein, wenn es zu feinen Schwankungen bei der Positionierung des Patienten im Röntgengerät kommt. In situ erscheint der Zahn bei allen intra- und extraoralen Aufnahmen mitsamt seiner Umgebung im Röntgenbild, das heißt, man muss mit Summationseffekten rechnen (Pasler 1995). So kann es unter Umständen möglich sein, dass eine zarte Wurzel eines oberen Prämolaren von oral dicken Knochenanteilen derart überlagert ist, dass sie kaum oder gar nicht zu erkennen ist. Der Limbus alveolaris ist am besten zwischen den einzelnen Zähnen als sog. „Septumspitze“ erkennbar (Pasler 1995). In Folge von parodontalen Entzündungen, aber auch bei einer zu steil 
eingestellten Projektion oder Überbelichtung kann es zu einer Zerstörung der

Septumspitze, und damit zum Fehlen der kortikalen Begrenzungslinie kommen.

Die genaue Vermessung des Röntgenbildes ist dadurch beeinträchtigt.

Im Frontzahnbereich des Ober- und Unterkiefers kommt es des Weiteren zu starken Überlagerungen mit der Halswirbelsäule, was die genaue Bestimmung von Knochendefekten erschwert.

Studien von Thanyakarn et al. (1992) kamen zu dem Ergebnis, dass bei der direkten Vermessung der extrahierten Zähne im Vergleich zur post extractionem angefertigten Panoramaschichtaufnahme es zu unterschiedlich großen Abweichungen in der Länge der Zähne kam. So wurden die Unterkieferprämolaren mit einer Vergrößerung von 13-15\% und die zweiten Oberkieferprämolaren mit einer Vergrößerung von 17-28\% auf dem Röntgenbild abgebildet. Es kommt folglich innerhalb der Panoramaschichtaufnahme in Abhängigkeit von der betrachteten Zahnregion zu unterschiedlichen Vergrößerungsfaktoren.

In der hier vorliegenden Arbeit wurden prae extractione Panoramaschichtaufnahmen angefertigt und vermessen und diese mit den intra operationem gewonnenen endoskopischen Messwerten verglichen. Hierbei wurden ebenfalls in Abhängigkeit von der untersuchten Zahnregion unterschiedlich starke Abweichungen von radiographischen und endoskopischen Ergebnissen erhalten.

Korrespondierend mit den Untersuchungen von Thanyakarn et al. (1992) wurden auch hier unterschiedlich starke Vergrößerungsfaktoren für die unterschiedlichen Zahnregionen gefunden. In der hier vorliegenden Arbeit kam es allerdings zu den größten Abweichungen zwischen endoskopischen und radiographischen Befund in der Region der Unterkieferfrontzähne sowie der Unterkiefer Prämolaren. Im Bereich der Oberkieferfrontzähne und der Oberkiefer Prämolaren lag der Vergrößerungsfaktor zwischen 20 und $30 \%$. 
Im Gegensatz zu den genannten Möglichkeiten steht das Endoskop. Endoskope weisen eine hohe Tiefenschärfe auf, die es ermöglicht, ohne nachzujustieren zwischen Nah- und-Fernbeobachtung zu springen. Der Vergrößerungsfaktor ist hierbei proportional zum Abstand von Objekt und Endoskop (je näher das Objekt am Endoskop, desto höher ist die Vergrößerung). Gegenüber einem Operationsmikroskop ist auch die bessere Hyginefähigkeit durch Sterilisierbarkeit von Teleskop und Lichtleiterkabel zu nennen (Bahcall et al. 1999).

Anders als im Röntgenbild konnte mit den endoskopischen Untersuchungen der Extraktionsalveole nachgewiesen werden, dass es unterschiedliche Knochenhöhen im oralen und vestibulären Anteil der Alveole gibt. Joudzbalys et al. (2008) empfehlen für die Untersuchung von Extraktionsalveolen die Stützimmersionsendoskopie, die sowohl für die Vermessung als auch für die Untersuchung der Morphologie und der Knochenqualität in der Alveole ohne Lappenbildung möglich ist.

Bei der endoskopischen Betrachtung von Extraktionsalveolen kann es sowohl zu technischen als auch patienten- und behandlerbedingten Schwierigkeiten kommen.

Die Focussierung wird dabei als zentrales Problem gesehen (Stambaugh et al.2002). So können sich beim rein handgeführten, nicht abgestützten Endoskopieren durch leichte Bewegungen des Endoskops die betrachteten Regionen scheinbar hin und her bewegen, während der Behandler den Eindruck hat, das Endoskop sei in seiner Position starr verankert. Sowohl die räumliche Orientierung als auch der Focus gehen dadurch leicht verloren.

Durch den Einsatz der Stützimmersionsendoskopie konnte dieses Problem behoben werden. Die Stützimmersionsendoskopie ermöglicht durch die sichere Abstützung an den knöchernen Alveolenwänden eine exakte Fokussierung der relevanten Strukturen, da das Bild während der Betrachtung unbewegt bleibt. Neben Komplikationen bei der Fokussierung wird die 
Verschmutzungsproblematik beim Einsatz des Endoskops in einem halboffenen System (Extraktionsalveole, Implantatkavität), d.h. in einem Raum, in dem flüssige und feste Partikel einströmen und die Sicht auf die Hauptstrukturen einschränken können, als technisches Problem gesehen (Ozawa et al. 1999, Stambaugh et al.2002, Bahcall und Barrs 2003).

In der hier vorliegenden Arbeit wurde dieses Problem durch die permanente Verwendung der Immersionstechnik umgangen. So wurde bei Eintrübung des Bildes durch Blutungen oder Schmutzpartikel die im Endoskop integrierte laminäre Strömung aktiviert, die die Verschmutzungen umgehend entfernte. Dadurch war auch eine Betrachtung von Extraktionsalveolen möglich, bei denen eine kapilläre Blutung während der Betrachtung fortbestand.

Eine zusätzliche technische Schwierigkeit der Endoskopie stellt die Bildung einer reflektierenden Grenzfläche zwischen zwei Medien der Mundhöhle (z.B. Sekret und Spülflüssigkeit) dar (Engelke 2002a). Diese Reflektionen treten auf, sobald die Endoskopspitze nicht vollständig ins Spülmedium eingetaucht ist. Dieses Problem wurde in der hier vorliegenden Arbeit durch Erzielung einer kompletten Immersion umgangen.

Die untersuchten Kavitäten wurden hierbei vollständig mit Spülflüssigkeit gefüllt und das Endoskop in diese eingetaucht, ohne dass es durch eine Grenze zwischen zwei Medien geführt werden musste. Bei der Untersuchung von Oberkieferalveolen wurde zusätzlich der Eingang der Kavität partiell mit einem Gazetupfer abgedeckt.

Neben technischen Problemen bei der Darstellung der Strukturen des Zahnhalteapparates können auch Probleme im Hinblick auf die Interpretation der gewonnen Bilder auftreten.

Bei den hier durchgeführten Untersuchungen lag das Interesse auf der Darstellung des knöchernen Limbus alveolaris, also der Abgrenzung zwischen Hart- und Weichgewebe. 
Diese Grenze zwischen Knochen und Weichgewebe wird bereits aus der unterschiedlichen Farbe beider Gewebe ersichtlich: So stellt sich Knochen als glatte, weiße Oberfläche ohne Strukturierung dar (Engelke 2002a,2002b), im Gegensatz dazu erscheint Weichgewebe in roter Farbe.

Ozawa et al. (2003) stellen Weichgewebe als fleckige Struktur, die sich im Flüssigkeitsstrom der Spülung bewegte, dar.

Als ein schwerwiegendes Problem erwiesen sich allerdings anatomische Besonderheiten. So bereitete die Endoskopie von sehr schmalen Unterkieferfrontzahnalveolen große Probleme, da diese Alveolen in mesiodistaler Ausdehnung den Einsatz des 1,9mm dicken Endoskops nebst StützSpülschaft nicht erlaubten. Ebenso bereitete die Endoskopie von Molarenalveolen große Probleme, hierbei stellte die Mundöffnung des Patienten den limitierenden Faktor dar. In der Molarenregion wäre somit der Gebrauch einer $70^{\circ}$-Optik zu empfehlen. Bei den hier durchgeführten Untersuchungen galt daher das Interesse den Frontzahn- und Prämolarenalveolen.

\subsection{Risiken für den Patienten}

Neben den im Rahmen eines chirurgischen Eingriffs möglicherweise auftretenden Komplikationen wie der Beschädigung von Nachbarzähnen, Kieferfrakturen (zum Beispiel im Sinne eines Tuberabrisses bei einer Extraktion im Oberkiefer) oder Nervschädigungen am Nervus alveolaris inferior birgt die endoskopische Untersuchung für den Patienten zusätzliche Risiken.

In erster Linie ist hierbei die durch die permanente Spülung der Alveole mit physiologischer Kochsalzlösung mögliche Aspiration von Spülflüssigkeit, gerade bei Eingriffen im Oberkiefer, zu nennen.

Ein anderer Aspekt stellt die durch die permanente Spülung der Alveole mit physiologischer Kochsalzlösung möglicherweise behinderte intraalveoläre Ausbildung eines Blutkoagels dar. 
Durch unzureichende Stabilisierung des Blutkoagulums in der

Extraktionsalveole könnte es in der Spätfolge zu einer verzögerten Wundheilung mit Ausbildung einer trockenen Alveole (dry socket) sowie den dann nötigen Nachbehandlungen kommen. Bei den hier untersuchten Extraktionsalveolen traten jedoch keine Komplikationen dieser Form auf.

Als Nachteil für den Patienten kann jedoch der vermehrte Zeitbedarf bei der endoskopischen Untersuchung der Extraktionsalveole im Vergleich zur röntgenologischen Untersuchung angesehen werden.

4.3 Darstellung anatomischer Strukturen in der Extraktionsalveole

Erkenntnisse über die knöcherne Defektsituation nach Zahnentfernung stützen sich bisher hauptsächlich auf die Auswertung von Röntgenbildern, wie dem Zahnfilm, der Panoramaschichtaufnahme und dem Computertomogramm. In der hier vorliegenden Arbeit wurde die Stützimmersionsendoskopie als ein neues Verfahren zur Darstellung von Extraktionsalveolen vorgestellt, das als Ergänzung zur Röntgenaufnahme eine dreidimensionale Darstellung des knöchernen Defekts nach erfolgter Zahnentfernung ermöglicht.

Die hieraus gewonnenen Erkenntnisse liefern wichtige Informationen hinsichtlich der Qualität und Quantität des Kieferknochens und ermöglichen die detailgetreue Darstellung der Extraktionsalveole.

Im Bereich der Zahnheilkunde wird das Endoskop bereits in vielen Fachbereichen routinemäßig sowohl zur Diagnostik als auch zur Therapie eingesetzt.

In der Endodontie benutzten Filippi et al. (2006) und von Arx et al. (2001) das Endoskop bei der periradikulären Chirurgie zur Darstellung von zu 
resezierenden Wurzelspitzen. Ebenso kam das Endoskop bei der Therapie von lateralen oder interradikulären Perforationen und bei Wurzelamputationen zum Einsatz. Beide Autoren kommen hierbei zu der Erkenntnis, dass der Gebrauch des Endoskops in der periradikulären Chirurgie höhere Erfolgsraten mit sich zieht als das konventionelle Vorgehen ohne endoskopische Kontrolle. Zudem ist die eindeutige Differenzierung von Hart- und Weichgewebe möglich, es grenzen sich hartgewebige Wurzelsubstanz (von Arx et al. 2001) und hartgewebige Knochensubstanz (Engelke 2002a) vom Weichgewebe des Parodontiums ab. Engelke (2002a) bildet Knochengewebe als glatte, weiße Oberfläche ohne Strukturierung ab, auf der er angeschnittene Gefäße mit florider Blutung sichtbar machte. Ebenso ermöglicht die Betrachtung der Kavitätenwandstrukturen mit den dort vorkommenden Gefäßen Rückschlüsse auf den Grad der Vaskularisierung und damit auch auf den Grad der Vitalität des Knochens zu ziehen. Bei der hier vorliegenden Arbeit konnte bei der Untersuchung der Extraktionsalveolen mit Hilfe der Stützimmersionsendoskopie belegt werden, dass die genaue Unterscheidung zwischen Hart- und Weichgewebe im endoskopische Bild möglich ist. Des Weiteren wird eine Darstellung von eventuell auftretenden knöchernen Kavitätenwanddefekte, wie zum Beispiel Frakturen oder Dehiszenzen, sowie Perforationen zum Subantralraum (im Sinne einer Mund-Antrum-Verbindung) oder Mundboden ermöglicht. Korrespondierend mit den Untersuchungen von Engelke und Capobianco (Engelke 2002a, Engelke 2002b, Engelke und Capobianco 2004) konnte in den durchgeführten Untersuchungen mit Hilfe der Stützimmersionsendoskopie das Vorkommen dieser knöchernen Kavitätenwanddefekten in Form von Knochenperforationen (zumeist im vestibulären Anteil der Alveole) nachgewiesen werden. In Übereinstimmung mit anderen vorliegenden Untersuchungen stellten sich die intraalveolär verbliebenen Wurzelrestfragmente als kompakte, im Flüssigkeitsstrom der Spülung nicht bewegliche Strukturen dar, die sich von 
dem umliegenden unscharf begrenzten im Flüssigkeitsstrom beweglichen Weichgewebsanteilen abhoben.An den Alveolenwänden wurden ebenso wie an Implantatkavitätenwänden in den Untersuchungen von Engelke (2002a, 2002b) kompakte Wandabschnitte mit einer gleichmäßigen Knochenstruktur und spongiösen Wandabschnitten mit Knochentrabekeln und bindegewebsreichen Markräumen nachgewiesen. Ähnlich wie bei den Untersuchungen von Engelke und Capobianco (2004) können auf der Oberfläche des kompakten Knochens weiße, strichartige Auflagerungen abgebildet werden, die als desmodontale Fasern identifiziert werden konnten.

Neben diesen histologischen und anatomischen Strukturen ist mit der Endoskopie ebenso eine Detektion von iatrogen in die Wunde eingebrachten Fremdkörpern, wie zum Beispiel Baumwollfasern eines Gazetupfers, Amalgamfüllungsreste oder Abriebpartikel rotierender Instrumente, möglich. Konkremente als eine Art „physiologischer Fremdkörper“ zeigen Stambaugh et al. (2000a, 2002) als Auflagerungen auf endoskopisch untersuchten Wurzeloberflächen.

In diesem Zusammenhang konnten in dieser Arbeit in einigen Extraktionen grau-gelbliche, kompakte Bruchstücke detektiert werden, die als subgingivaler Zahnstein identifiziert wurden.

Auf dem Gebiet der Parodontologie beschreiben Stambaugh et al. (2000b) und Ozawa et al. (1999) ebenso wie Kwan (2005), Geisinger et al. (2007), Michaud et al. (2007) und Avradopoulos et al. (2004) den Gebrauch des Endoskops bei der Parodontalbehandlung, zur Konkremententfernung und zur Beobachtung der Wurzeloberfläche, um Wurzelkaries zu detektieren. 
4.4 Kieferkammerhalt und mikrochirurgische Maßnahmen mit der Endoskopie

In der gegenwärtigen Literatur werden zahlreiche Möglichkeiten beschrieben, die den Erhalt der knöchernen und weichgewebigen Strukturen durch direkt nach der Extraktion erfolgende unterstützende Maßnahmen gewährleisten sollen. Eine der häufigsten Methoden ist die Sofortimplantation. Die sich sofort an die Zahnentfernung anschließende Implantation reduziert die Gesamtbehandlungsdauer und erlaubt eine bessere prothetische Rehabilitation, da durch die Alveole die Ausrichtung des Implantats erleichtert wird (Denissen und Kalk 1991, Werbitt und Goldberg 1992, Wheeler et al. 2000, Becker et al. 2002).

Mehrere neue Studien belegen jedoch, dass durch die Sofortimplantation der Atrophiegrad des Kieferkammes gegenüber der konventionellen Spätimplantation nicht geringer ist (Nemcovsky und Artzi 2002, Nemcovsky et al.2002, Araujo et al.2005, Araujo et al.2006, Botticelli et al.2006). Dennoch wird die Sofortimplantation als klinisch erfolgreiche Therapiemethode zum Erhalt der knöchernen und weichgewebigen Strukturen nach einer Extraktion angesehen (Werbitt und Goldberg 1992, Lang et al. 1994, Brägger et al. 1996, Schwartz-Arad und Chaushu 1998, Garber et al. 2001, Saadoun 2002, Barone et al. 2006, Zeren 2006, Covani et al.2007).

Wie in der Literatur dokumentiert, schließt sich an die Zahnentfernung eine durchschnittliche Resorption von 2 bis $2,5 \mathrm{~mm}$ in der Horizontalen und $1 \mathrm{~mm}$ in der Vertikalen an (Schropp et al. 2003, Botticelli et al. 2006). Diese Art der Resorption tritt in den ersten 3-6 Monaten nach der Zahnentfernung auf (Botticelli et al. 2006).

In vielen Fällen wird parallel zu einer Sofortimplantation Knochenersatzmaterial zur Knochenaugmentation eingebracht. Das Knochenersatzmaterial füllt hierbei den durch die Inkongruenz zwischen Zahnwurzel- und Implantatquerschnitt 
bedingten Spaltraum zwischen Implantat und Alveolenwand aus. Hierdurch soll eine Stabilisierung des Implantates erreicht werden. Aktuelle Studien kommen zu dem Schluss, dass eine erfolgreiche Implantateinheilung auch ohne das Auffüllen des Spaltraums erfolgt (Paolantonio et al. 2001, Covani et al. 2004).

Eine weitere Methode stellt das Einsetzen von Wurzelreplikaten direkt nach der Extraktion in die Alveolen dar. Hierbei kommen zum einen resorbierbare, wurzelanaloge Implantate und zum anderen nichtresorbierbare, solide semianaloge alloplastische Implantate zur Anwendung. Yilmaz et al. (1998) erzielten positive Ergebnisse bei der Kieferkammresorptionsprophylaxe durch die Verwendung von nicht resorbierbaren Wurzelreplikaten bestehend aus standardisierten Kegeln aus Bioglas.

Klinische Studien von Suhonen und Meyer (1996), Serino et al.(2003) und Rothamel et al.(2007) konnten den Erhalt der Kieferkammkontur durch defektorientiertes Auffüllen der Alveole mit resorbierbaren Implantaten belegen. Hierbei verwendeten Suhonen und Meyer (1996) als resorbierbare Implantate polyglykolide Wurzelreplikate, wo hingegen Serino et al. (2003) Polylactid.und Polyglykolidschwämme und Rothamel et al. (2007) polylactidvernetzte BTCP Wurzelreplikate in die Alveole einbrachten.

Die am häufigsten zur Kiefekammprophylaxe kommende Behandlungsmethode stellt das Auffüllen der Alveole mit Füllmaterial dar. Hierbei soll das in die Alveole eingebrachte Material im Sinne einer ,guided bone regeneration“ die Ausheilung der Alveole unterstützen. Oftmals wird zusätzlich die Alveole mit einer Membran abgedeckt, um das eingebrachte Füllmaterial vor äußeren Einflüssen zu schützen. Als Füllmaterial steht eine Vielzahl an Materialien zur Verfügung. Hierbei werden grundsätzlich autogene (homologe), also vom gleichen Individuum stammende, allogene, d.h. von der gleichen Spezies, aber von einem anderen Individuum gewonnene, xenogene, also von einer anderen 
Spezies stammende und alloplastische, d.h. synthetische Materialien unterschieden. Autogenes Knochenmaterial wird dem Patienten meist aus dem Bereich des Kieferwinkels oder aus dem Hüftknochen entnommen. Bei allogenen Knochenmaterial kommt meist gefriergetrockneter mineralisierter oder demineralisierter Knochen zum Einsatz. Als xenogene Materialien kommen hauptsächlich Rinderknochen (bovine) zum Einsatz. Synthetische Materialien bestehen meist aus bioaktiven Gläsern, Hydroxylapatiten und Tricalciumphosphaten (TCP). Beim Einsatz dieser Füllmaterialien mit oder ohne die Kombination mit einer Membrantechnik konnte in vielen histomorphometrischen Studien eindeutig gezeigt werden, dass mehr vitaler Knochen gebildet wird als auf der Kontrollseite (Smukler et al.1999, Artzi et al. 2000, Carmargo et al. 2000, Artzi et al. 2001a, Artzi et al. 2001b, Bolouri et al. 2001, Iasella et al. 2003, Yukna et al. 2003). Dieses Ergebnis wird auf die osteokonduktiven Eigenschaften der eingebrachten Materialien zurückgeführt (Brugnami et al. 1999, Froum et al. 2002). Wang und Tsao (2007) berichten auch beim alleinigen Einbringen von Füllmaterial (ohne Membrantechnik) von der Ausbildung guter Knochenqualität. Insbesondere bei der Verwendung von nicht resorbierbaren Membranen traten in manchen Fällen als Komplikation Weichgewebsdehiszenzen auf, diese überschritten jedoch nicht das bei einer Spontanheilung auftretende Ausmaß (Lekovic et al. 1997, Brugnami et al. 1999, Smukler et al. 1999, Fowler et al. 2000a, Fowler et al. 2000b, Yang et al. 2000). Bei der Einbringung von Füllmaterial ohne Membrantechnik konnte in manchen Fällen die Exfolation des Füllmaterials beobachtet werden. Hierdurch wurden die Endresultate der Kieferkammprophylaxe deutlich verschlechtert (Nemcovsky und Serfaty 1996).

Allen genannten Techniken gemein ist, dass es sich um chirurgische Maßnahmen handelt, die versuchen, die Wundheilung von extern, durch das Einbringen von Füllmaterialien in die Wundregion, zu steuern. 
Wichtig für das Gelingen der Maßnahmen ist, dass die Alveole nicht akut infiziert ist, und keinerlei Weichgewebsanteile intraalveolär vorhanden sind. Des Weiteren müssen alveoläre Blutungen auftreten, da beim Einbringen von Materialien in die Alveole deren Vermischung mit Blut essentiell für den Erfolg der Methode ist (Wang et al.2004).

Die hier aufgeführten Methoden zur Kieferkammprophylaxe erfüllen alle jedoch nicht diese Grundvoraussetzungen. Keine Methode bietet nämlich die Möglichkeit, Einsicht in die Alveole zu nehmen.

4.5 Klinische Bedeutung der Alveoloskopie

Die Technik der Stützimmersionsendoskopie, im besonderen der Alveoloskopie, ermöglicht es, Einblick in die Extraktionsalveole zu nehmen. Somit kann vor einem kieferkammerhaltenden Eingriff, der durch das Vorliegen von Weichgewebe in der Alveole negativ beeinflusst würde, mit der Endoskopie Weichgewebe detektiert werden. Das an den Alveolenwänden anhaftende Granulationsgewebe kann im Anschluss unter endoskopischer Sicht mittels Kürettage entfernt werden. Das endoskopische Vorgehen erspart zudem das Deperiostieren des Wundgebietes, das ebenfalls für eine Veränderung der Knochenoberfläche verantwortlich sein kann (Joudzbalys et al. 2008). Somit kommt das Endoskop nicht nur als diagnostisches Hilfsmittel, sondern auch als therapeutisches Kontrollinstrument zum Einsatz. Auch bei der Sicherstellung einer ausreichenden Durchblutung in der Alveole kommt dem Endoskop eine diagnostische Funktion zu. Die Anzahl der aus den Alveolenwänden austretenden Kapillaren kann mittels Endoskopie erfasst werden. Eine hohe Anzahl von Kapillaren lässt hierbei auf eine gute Durchblutung des Knochens schließen. Über die Vermessung der Alveole ist eine genaue Aussage über den Grad der Atrophie möglich. Auch die genaue Lage von knöchernen Dehiszenzen kann ermittelt und bei der späteren 
Augmentation mit Füllmaterial berücksichtigt werden. Somit stellt die Untersuchung der Extraktionsalveole mit der Stützimmersionsendoskopie einen wertvollen Beitrag zum Gelingen von kieferkammerhaltenden Maßnahmen dar. Allerdings beschränkt sich die endoskopische Untersuchung von Extraktionsalveolen nicht nur auf die Unterstützung von ,guided bone regeneration"-Techniken. Vielmehr ermöglicht die Endoskopie die Erhebung zusätzlicher diagnostischer Informationen, deren Berücksichtigung eine Kieferkammatrophie im Vorfeld beschränken oder gar vermeiden können. So ermöglicht es die endoskopische Untersuchung der Alveole, unter Vergrößerung iatrogen in die Alveole eingebrachte Fremdkörper aufzuspüren. In der hier vorliegenden Arbeit handelte es sich bei den Fremdkörpern um feine Metallspäne, die als Abriebpartikel der im Rahmen einer Osteotomie verwendeten Knochenfräsen identifiziert werden konnten. Das Auffinden und die Entfernung dieser Partikel vermeidet die von Brooks et al. (2000) beschriebene, fremdkörperinduzierte, verzögerte Wundheilung, wie sie von Polyethylenpartikeln an Übergängen von Implantat und Knochen bekannt ist. Eine mit der verzögerten Wundheilung einher gehende vergrößerte Kieferkammatrophie kann damit umgangen werden. Aber nicht nur iatrogen in die Alveole eingebrachte Fremdkörper können unter endoskopischer Sicht dargestellt werden, auch in der Alveole verbliebene frakturierte Wurzelreste können sichtbar gemacht werden. Im Rahmen einer internen Osteotomie besteht hierbei die Möglichkeit, den verbliebenen Wurzelrest durch die bestehende Extraktionsalveole unter endoskopischer Sicht zu entfernen. Bei der konventionellen Vorgehensweise, die Wunde mit Mundspiegeln zu kontrollieren, behindert meist die starke Blutung eine genaue Beurteilung. Dies kann zur Folge haben, dass Wurzelreste in der Alveole verbleiben, da sie nicht als solche erkannt werden. Wird jedoch ein Wurzelrest in der Alveole entdeckt, so wird zu dessen Entfernung die vestibuläre Knochenlamelle oftmals großzügig abgetragen, um die Sichtverhältnisse für den Operateur zu verbessern. Somit 
leistet die endoskopische Kontrolle der Alveole über die Möglichkeit der internen Osteotomie einen großen Beitrag zum Erhalt des Kieferkammes . Im Hinblick auf die Qualitätssicherung bei implantologischen Eingriffen spielt die endoskopische Kontrolle des Implantatlagers eine große Rolle. Mit Hilfe der Endoskopie ist es möglich, Informationen über die Knochenqualität und -quantität zu erhalten. Die genaue Kenntnis über die Beschaffenheit des Implantatlagers bildet die Grundlage bei der Entscheidung, ob die gewünschte Region überhaupt als Implantationsstelle in Frage kommt und welcher Implantattyp zur Insertion kommt. So kommen bei einem überwiegend spongiösen Knochen selbstschneidende Implantate zum Einsatz, wohingegen in einem kompakten Knochen ein Gewindeschneider eingesetzt werden muss. Zusätzlich ist die genaue Kenntnis des Implantatlagers im Hinblick auf die spätere Belastungsfähigkeit des inserierten Implantats von Bedeutung. Neben der Analyse der vorliegenden Knochenstruktur und der Bestimmung des Atrophiegrades der Alveolenwände, erlaubt die endoskopische Untersuchung der Extraktionsalveole, auch die Lagebeziehung des Alveolenbodens zu anderen anatomischen Strukturen zu bestimmen. Von besonderem Interesse sind hierbei die Lage der Extraktionsalveole in Bezug auf die Kieferhöhlen und ob diese bereits in Form einer Mund-Antrum-Verbindung eröffnet sind, oder der noch verbleibende Abstand zum Nervkanal des Nervus alveolaris inferior oder zum Mundboden. Die Vermessung der Alveole gibt folglich Aufschluss über die noch verbleibende Knochendicke. Im Hinblick auf eine spätere Implantation ist dies eine wichtige Information bei der Entscheidungsfindung, ob und in welchem Maße eine Augmentation durchgeführt werden muss. 
4.6 Schlussfolgerungen

Als Fazit lässt sich formulieren, dass der Gebrauch des Endoskops bei der Untersuchung von Extraktionsalveolen nach Beseitigung der eingangs genannten Probleme und nach einer gewissen Einarbeitungszeit die genaue Darstellung der Grenzstrukturen der Alveole erlaubt. Des Weiteren erhält der behandelnde Zahnarzt wertvolle Informationen über die dreidimensionale Ausdehnung der Extraktionsalveole sowie deren knöcherne Beschaffenheit. Durch die Detektion von alveolären Defekten, die überwiegend vestibulär auftreten, und deren Therapie, können sekundäre Eingriffe für den Patienten vermieden werden.

Die Möglichkeit, unter Sichtkontrolle Granulationsgewebe sowie eingebrachte Fremdkörper zu entfernen, tragen zu einer komplikationslosen Wundheilung bei und können somit auch die sich anschließende Kieferkammatrophie vermindern. 


\section{Zusammenfassung}

Ziel der vorliegenden Arbeit war es Extraktionsalveolen mit Hilfe der Stützimmersionsendoskopie in vivo darzustellen und zu vermessen. Hierbei wurden 132 Extraktionsalveolen unmittelbar post extractionem endoskopisch untersucht. In 116 Fällen konnte die prae extractione angefertigte Panoramaschichtaufnahme ausgewertet werden.

Es ergaben sich folgende Mittelwerte für die Strecke vom Alveolenboden bis zum Limbus alveolaris mesial :

Oberkiefer-Frontzähne röntgenologisch 10,3 mm und endoskopisch 9,4 mm, Oberkiefer-Prämolaren $9,1 \mathrm{~mm}$ respektive $8,5 \mathrm{~mm}$, Unterkiefer-Frontzähne $8,0 \mathrm{~mm}$ respektive $6,4 \mathrm{~mm}$, Unterkiefer-Prämolaren 9,2 $\mathrm{mm}$ respektive $8,1 \mathrm{~mm}$.

In 25 Fällen wurden bis zu $5 \mathrm{~mm}$ größere Werte bei der endoskopischen Vermessung bestimmt und in 6 Fällen wurden gleiche Messergebnisse im endoskopischen Bild und im Röntgenbild gemessen.

In 85 Fällen wurden bis zu 8,6 mm höhere Werte im Röntgenbild gemessen.

Dies legt die Vermutung nahe, dass es während der Extraktion zu Knochenverlusten gekommen ist.

Es ergaben sich folgende Mittelwerte für die Strecke vom Alveolenboden bis zum Limbus alveolaris oral und vestibulär:

Oberkiefer-Frontzähne oral 9,2 mm und vestibulär $8 \mathrm{~mm}$, Oberkiefer-Prämolaren 7,8 mm respektive 7,6 mm, Unterkiefer-Frontzähne $7 \mathrm{~mm}$ respektive $5,8 \mathrm{~mm}$, Unterkiefer-Prämolaren 7,6 $\mathrm{mm}$ respektive $6,2 \mathrm{~mm}$. Beim Vergleich der endoskopisch vermessenen Strecken vom Alveolenboden zum Limbus alveolaris oral und zum Limbus alveolaris vestibulär lag in 65 Fällen ein bis zu $8 \mathrm{~mm}$ geringerer Wert für die vestibuläre Alveolenwand vor. In 
31 Fällen lag ein bis zu 4 mm höherer Wert für die vestibuläre Knochenhöhe und in 36 Fällen lag eine Übereinstimmung von oraler und vestibulärer Alveolenwand vor.

Die Interpretation der Daten läuft darauf hinaus, dass man endoskopisch alveoläre Defekte erfassen kann. Diese treten in der überwiegenden Anzahl vestibulär auf.

Über die Vermessung der Alveole ist eine genaue Aussage über den Grad der Atrophie sowie die Lokalisation und Therapie von knöchernen Dehiszenzen möglich.Das Endoskop kommt hierbei nicht nur als diagnostisches Hilfmittel, sondern auch als therapeutisches Kontrollinstrument zum Einsatz. Die durch die Stützimmersionsendoskopie gewonnenen Erkenntnisse hinsichtlich der Morphologie der Extraktionsalveole stellen in Bezug auf die Weiterversorgung des Patienten nach der Extraktion einen Gewinn dar. 
6. Abkürzungsverzeichnis

A

Aa.

Abb.

Bsp.

bzw.

ca.

$\mathrm{cm}$

d.h.

et al.

etc.

ggf.

KV

$\mathrm{mA}$

MAV

$\mathrm{mm}$

N.

OP

OPM

Punkt 1

Punkt 2

Punkt 3

Punkt 4

Punkt rö1

Punkt rö2

Punkt rö4
Arteria

Arteriae

Abbildung

Beispiel

beziehungsweise

circa

Zentimeter

das heißt

et alii

et cetera

gegebenenfalls

Kilovolt

Milliampere

Mund-Antrum-Verbindung

Millimeter

Nervus

Operation

Operationsmikroskop

Alveolenboden

Limbus alveolaris oral

Limbus alveolaris vestibulär

Limbus alveolaris mesial

Wurzelspitze im Röntgenbild

Limbus alveolaris zentral

Limbus alveolaris mesial 
S.

SALSA

sek.

SIE

Strecke 1-2

Strecke 1-3

Strecke 1-4

Strecke rö1-2

Strecke rö1-4

v.a.

z.B.
Seite

subantroskopisch laterobasale Sinusbodenaugmentation Sekunde

Stützimmersionsendoskopie

Strecke vom Alveolenboden zum Limbus alveolaris oral Strecke vom Alveolenboden zum Limbus alveolaris vestibulär

Strecke vom Alveolenboden zum Limbus alveolaris mesial Strecke von der Wurzelspitze zum Limbus alveolaris zentral

Strecke von der Wurzelspitze zum Limbus alveolaris mesial vor allem zum Beispiel 
Literaturverzeichnis

Abrams H, Kopczyk P, Kaplan A (1987): Incidence of anterior ridge deformities in partially edentulous patients. J Prosthet Dent 푸, 191-194

Adams L, Wilding R (1985): A photogrammetric method for monitoring changes in the residual alveolar ridge form. J Oral Rehabil $\underline{12}$, 443-450

Adell R, Eriksson B, Lekholm U, Branemark P, Jemt T (1990): Long-term follow-up study of osseointegrated implants in the treatment of totally edentulous jaws. Int J Oral Maxillofac Implants $\underline{5}$, 347-359

Amler M (1969): The time sequence of tissue regeneration in human extraction wounds. Oral Surg Oral Med Pathol 27, 309-318

Amler M, Johnson P, Salman I (1960): Histological and histochemical investigations of human alveolar socket healing in undisturbed extraction wounds. J Am Dent Assoc 61, $32-44$

Araujo M, Lindhe J (2005): Dimensional ridge alterations following tooth extraction. An experimental study in the dog. J Clin Periodontol $\underline{32}, 212-218$

Araujo M, Berglundh T, Lindhe J (1997): On the dynamics of periodontal tissue formation in degree 3 furcation defects. An experimental study in dogs. J Clin Periodontol 24, 738-746 
Araujo M, Sukekava F, Wennström J, Lindhe J (2005): Ridge alterations following implant placement in fresh extraction sockets: An experimental study in the dog. J Clin Periodontol $\underline{32}, 645-652$

Araujo M, Wennström J, Lindhe J (2006): Modeling of the buccal aand lingual bone walls of fresh extraction sites following implant installation. Clin Oral Implants Res 17, 606-614

Artzi Z, Tal H, Dayan D (2000)Porous bovine bone mineral in healing of human extraction sockets. Part 1: histomorphometric evaluations at 9 month. J Periodontol $\underline{71}, 1015-1023$

Artzi Z, Nemcovsky C, Tal H (2001a): Efficacy of porous bovine bone mineral in various types of osseous deficiencias: clinical observations and literature review. Int J Periodontics Restorative Dent 21, 395-405

Artzi Z, Tal H, Dayan D (2001b): Porous bovine bone mineral in healing of human extraction sockets: 2 . Histochemical observations at 9 month. $\mathbf{J}$ Periodontol $\underline{72}, 152-159$

Ashman A, Froum S, Rosenlicht J(1994): Replacement therapy. NY State Dent J $\underline{60}, 12-15$

Atwood D (1971): Reduction of residual ridges: A major oral disease entity. J Prosthet Dent 26, 266-279

Atwood D (2001): Some clinical factors related to the rate of resorption of residual ridges.1962. J Prosthet Dent $\underline{86}, 119-125$ 
Atwood D, Coy W (1971): Clinical, cephalometric and densitometric study of reduction of residual ridges. J Prosthet Dent 26, 280-295

Avradopoulos V, Wilder R, Chichester S, Offenbacher S (2004): Clinical and inflammatory evaluation of perioscopy on patients with chronic periodontitis. $\mathrm{J}$ Dent Hyg $\underline{78}, 30-38$

Bahcall J, Barrs J (2003): Orascopic visualization technique for conventional and surgical endodontics. Int Endod J 36, 441-447

Bahcall J, Di Fiore P, Poulakidas T (1999): An endoscopic technique for endodontic surgery. J Endod 25, 132-135

Baldassari-Cruz L, Lilly J, Rivera E (2002): The influence of dental operating microscope in locating the mesiolingual canal orifice. Oral Surg Oral Med Oral Pathol Oral Radiol Endod 93, 190-194

Barone A, Rispoli L, Vozza I, Quaranta A, Covani U (2006): Immediate restoration of single implants placet immediately after tooth extraction. $\mathbf{J}$ Periodontol 77, 1914-1920

Baumann A, Ewers R (1999): Minimal invasiver Sinuslift. Grenzen und Möglichkeiten im atrophen Oberkiefer. Mund Kiefer Gesichtschir $\underline{3}$, 70-73

Baylink D, Wergedal J, Yamamoto K, Manzke E (1974): Systemic factors in alveolar bone loss. J Prosthet Dent $\underline{31}$, 486-505 
Becker W, Hujoel P, Becker BE (2002): Effect of barrier membranes and autologous bone grafts on ridge width preservation around implants. Clin Implant Dent Relat Res $\underline{4}, 143-149$

Beer R, Mayerhöfer G (1995): Fortschritte in der Endodontie- Die operationsmikroskopgestützte Wurzelkanalbehandlung. Quintessenz $\underline{46}, 1437$ 1450

Behrbohm H: Endoskopische Chirurgie der Nasennebenhöhlen, die Kieferhöhlenendoskopie. Verlag Endo-Press, Tuttlingen 2003

Bernick S, Grant D (1978): Lymphatic vessels of the healthy and inflamed gingiva. J Dent Res $\underline{57}$, 8810-817

Birn H (1966): The vascular supply of the periodontal membrane. An investigation of the number and size of perforations in the alveolar wall. $\mathrm{J}$ Periodontal Res $\underline{1}, 51-68$

Biselli R (2001): Ein Instrument der Qualitätssicherung. ZMK 17, 443-444

Bodner L, Kaffe I, Cohen Z, Dayan D (1993): Long-term effect of desalivation on extraction wound healing: A densitometric study in rats. Dentomaxillofac Radiol 22, 195-198

Bolouri A, Haghighat N, Frederiksen N (2001): Evaluation of the effect of immediate grafting of mandibular postextraction sockets with synthetic bone. Compend Contin Educ Dent 22, 955-958 
Botticelli D, Persson L, Lindhe J, Berglundh T (2006): Bone tissue formation adjacent to implants placed in fresh extraction sockets: an experimental study in dogs. Clin Oral Implants Res 17, 351-358

Box K (1949): Evidance of lymphatics in the periodontium. J Can Dent Assoc $\underline{15}, 8-12$

Brägger U, Hämmerle C, Lang N (1996): Immediate transmucosal implants using the principle of guided tissue regeneration (II). A cross-sectional study comparing the clinical outcome 1 year after immediate to standard implant placement. Clin Oral Implants Res $\underline{7}, 268-276$

Brooks R, Sharpe J, Wimhurst J, Myer B, Dawes E, Rushton N (2000): The effect of the concentration of high-density polyethylene particles on the boneimplant interface. J Bone Joint Surg Br $\underline{82}, 595-600$

Brugnami F, Then P, Moroi H, Kabani S, Leone C (1999): GBR in human extraction sockets and ridge defects prior to implant placement: clinical results and histologic evidence of osteoblastic and osteoclastic activities in DFDBA. Int J Peridontics Restorative Dent $\underline{19}$, 259-267

Büchs H (1966): Wundheilung und Antibiotika. Dtsch Zahnärztl Z 21 , 369-374

Burkhardt R (1999): Neue Wege in der plastisch-parodontalen Chirurgie. Schweiz Monatsschr Zahnmed 109,639-649

Byers M (1985): Sensory innervation of periodontal ligament of rat molars consists of unencapsulated Ruffini-like mechanoreceptors and free nerve endings. J Comp Neurol 231, 500-518 
Byers M, Holland G (1977): Trigeminal nerve endings in gingival, junctional epithelium and periodontal ligament of the rat molars as demonstrated by autoradiography. Anat Rec $\underline{188}, 509-523$

Cardaropoli G, Araujo M, Lindhe J (2003): Dynamics of bone tissue formation in tooth extraction sites. An experimental study in dogs. J Clin Periodontol $\underline{30,}$, 809-818

Carls FR, von Hochstetter A, Madek M, Engelke W (1995): Diagnostic accuracy of TMJ arthroscopy in correlation to histological findings. $\mathbf{J}$ Craniomaxillofac Surg 1995 Apr. 23(2), 75-80

Carlsson G, Bergmann B, Hedegard B (1967): Changes in contour of the maxillary alveolar process under immediate dentures. A longitudinal clinical and x-ray cephalometri study covering 5 years. Acta Odontol Scand 25, 45-75

\section{Carmargo P, Lekovic V, Weinlaender M, Klokkevold P, Kenney E,} Dimitrijevic B, Nedic M, Jancovic S, Orsini M (2000): Influence of bioactive glass on changes in alveolar process dimensions after exodontias. Oral Surg Oral Med Oral Pathol Oral Radiol Oral Endod 90, 581-586

Castelli W, Dempster W (1965):The periodontal vasculature and its responses to experimental pressures. J Am Dent Assoc 무, 890-905

Cawood J, Howell R (1988): A classification of the edentulous jaws. Int J Oral Maxillofac Surg 17, 232-236 
Covani U, Bortolaia C, Barone A, Sbordone L (2004): Bucco-lingual crestal bone changes after immediate and delayed implant placement. J Periodontol $\underline{75}$, 1605-1612

Covani U,Cornelini R, Barone A (2007): Vertical crestal bone changes around implants placed nto fresh extraction sockets. J Periodontol $\underline{78}, 810-815$

De Moor RJ, Calberson FL (2005): Root canal treatments in a mandibular second premolar with three root canals. J Endod $\underline{31}, 310-313$

Denissen HW, Kalk W (1991): Preventive implantations. Int Dent J 41, 17-24

Deporter D, Ten Cate A (1980): Collagen resorption by periodontal ligament fibroblasts at the hard tissue-ligament interfaces of the mouse periodontium. $\mathrm{J}$ Periodontol 51, 429-432

Detsch S, Cunningham W, Langloss J (1979): Endoscopy as an aid to endodontic diagnosis. J Endod $\underline{5}, 60-62$

Devlin H, Garland H, Sloan P (1996): Healing of tooth extraction sockets in experimental diabetes mellitus. J Oral Maxillofac Surg 노, 1087-1091

Edwall L: The vasculature of the periodontal ligament. In Berkovitz, BKB, BJ Moxham, HN Newman: The Periodontal Ligament in Health and Disease. Pergamon, Oxford 1982, 151-165

Engelke W (2000): Subantroscopical, laterobasal Sinus Floor Augmentation (SALSA). Endo World DENT $\underline{3}, 1-12$ 
Engelke W (2002a): Die Untersuchung von Implantatkavitäten mit der Stützimmmersionsendoskopie. Z Zahnärztl Implantol 18, 36-40

Engelke W (2002b): In situ examination of implant sites with support immersion endoscopy. Int J Maxillofac Implants 17, 703-705

Engelke W, Deckwer I (1997): Endoscopically controlled sinus floor augmentation. A preliminary report. Clin Oral Implants Res $\underline{8}, 527-531$

Engelke W, Hoch G (2002): Die systematische endoskopische Untersuchung des Implantatlagers. Zahnärztl Mitt $\underline{\text { 92, }}$, 32-35

Engelke W, Capobianco M (2004): Endoskopische Verfahren in der oralen Implantologie. Z Zahnärztl Implantol 20, 248-256

Engelke W, Capobianco M (2005a): Der aktuelle Stand der Odontoskopie. Teil 1: Grundlagen und klinische Verfahren. Dent Tribune (German Edition) 2 , $19+26$

Engelke W, Capobianco M (2005b): Der aktuelle Stand der Odontoskopie. Teil 2: Diagnostische Anwendung der Odontoskopie. Dent Tribune (German Edition) $\underline{3,6+8}$

Engelke W, Decco O, Rau M, Acosta M (2004): In vitro evaluation of micromovement of dental implants in bone specimen with contact endoscopy. Implant Dentistry 13(1) 88-94

Enlow D: Principles of bone remodeling. Charles C Thomas, Springfield, Illinois 1963 
Fallschüssel G (1986): Geistig-seelische Einflüsse bei Störungen im Kausystem: Fakten-Empirie-Hypothesen. Dtsch Zahnarztl Z 41, 271-275

Filippi A, Meier M, Lambrecht J (2006): Endoskopische Wurzelspitzenresektion- eine klinisch-prospektive Studie. Schweiz Monatsschr Zahnmed 116, 12-17

Fisher EW, Croft CB (1989): Antroscopy: Current practice-a survey of UK otolaryngists. J Laryngol Otol $\underline{103}, 747-749$

Fowler E, Breault L, Rebitski G (2000a): Ridge preservation utilizing an acellular dermal allograft and demineralised freeze-dried bone allograft. Part I. A report of 2 cases. J Periodontol 71, 1353-1359

Fowler E, Breault L, Rebitski G (2000b): Ridge preservation utilizing an acellular dermal allograft and demineralised freeze-dried bone allograft. Part II. Immediate endosseous implant placement. J Periodontol 71, 1360-1364

Fröhlich E (1958): Entwicklung und Morphologie der Weichgewebe des Parodontiums. Dtsch Zahnärztl Z $\underline{13}$, 221-240

Frost $\mathbf{H}$ : The laws of bone structure. Charles C Thomas, Springfield, Illinois 1964

Frost $\mathbf{H}$ : Bone modeling and skeletal modeling errors. Charles C Thomas, Springfield, Illinois 1973 
Froum S, Cho S, Rosenberg E, Rohrer M, Tarnow D (2002): Histological comparison of healing extraction sockets implanted with bioactive glass or demineralised freeze-dried bone allograft: a pilot study. J Periodontol $\underline{73}$, 94-102

Gabka J, Harnisch H : Operationskurs für Zahnmediziner. Thieme, Stuttgart 1973

Garber D, Salama M, Salama H (2001): Immediate total tooth replacement. Compend Contin Educ Dent 22, 210-216+ 218

Geisinger ML, Mealey BL, Schoolfield J, Mellonig JT (2007): The effectiveness of subgingival scaling and root planing: an evaluation of therapy with and without the use of the periodontal endoscope. J Periodontol $\underline{78}, 22-28$

Gergely E, Bartha N (1961): Die Rolle der Wurzelhaut bei der Heilung von Extrakrionswunden. Dtsch Stomatol 10, 162-167

Hahn W, Lange D (1966): Zahnentfernung und Versorgung der Alveole als erste praeprothetisch-chirurgische Maßnahme. Dtsch Zahn Mund Kieferheilkd $\underline{4}, 179-187$

Hannam AG : The innervation of the periodontal ligament. In: Berkovitz, BKB, BJ Moxham, HN Newman: The Periodontal Ligament in Health and Disease. Pergamon, Oxford 1982, 173-179

Hayashi S (1932): Untersuchungen über die arterielle Blutversorgung des Parodontiums. Dtsch Monatsschr Zahnheilkd 50, 145 
Held S, Kao Y, Wells D (1996): Endoscope-an endodontic application. J Endod $\underline{22}, 327-329$

Hellwig E, Klimek J, Attin T: Einführung in die Zahnerhaltung. 2. Auflage. Urban\& Fischer Verlag, München 1999

Humphries S, Devlin H, Worthington H (1989): A radiographic investigastion into bone resorption of mandibular alveolar bone in elderly edentulous adults. J Dent 17, 94-96

\section{Iasella J, Greenwell H, Miller R, Hill M, Drisko C, Bohra A, Scheetz J} (2003): Ridge preservation with freeze-dried bone allograft and a collagen membrane compared to extraction alone for implant site development: a clinical and histologic study in humans. J Periodontol $\underline{74}$, 990-999

Iizuka T, Miller S, Marks S (1992): Alveolar bone remodelling after tooth extraction in normal and osteopetrotic (ia) rats. J Oral Pathol Med 21, 150-155

Immenkamp E (1972): Erfahrungen mit Panorama-Röntgenaufnahmen in der kieferchirurgischen Praxis. Dtsch Zahnärztl Z 27, 997-1004

Isaksson S, Ekfeldt A, Alberius P, Blomqvist J (1993): Early results from reconstruction of severely atrophic (Class VI) maxillas by immediate endosseous implants in conjunction with bone grafting and Le Fort I osteotomy. Int J Oral Maxillofac Surg 22, 144- 148

Jahangiri L, Devlin H, Ting K, Nishimura I (1998): Current perspectives in residual ridge remodelling and its clinical implications: a review. J Prosthet Dent $\underline{80}, 224-237$ 
Johnson K (1969): A sudy of the dimensional changes occurring in the maxilla following tooth extraction. Aust Dent J $\underline{14}, 241-244$

Joudzbalys G, Bojarskas S, Kubillius R, Wang H-L(2008): Using the support Immersion Endoscope for socket Assessment.J Periodontol 79, 64-71

Jung T (1972): Die Wiedergabe der Frontzahnregion auf Panoramaschichtaufnahmen. Dtsch Zahnärztl Z 27, 972-977

Kim S (1997): Principles of endodontic microsurgery. Dent Clin North Am $\underline{41}$, $481-497$

Kingsmill V (1999): Post-extraction remodelling of the adult mandible. Crit Rev Oral Biol Med 10, 384-404

Komatsuzaki Y, Ochi K, Sugiura N, Hyodo M, Okamoto A (2003): Videoassisted submandibular sialadenectomy using an ultrasonic scalpel. Auris Nasus Larynx $\underline{2}, 75-78$

Krekeler G (1993): Parodontalbehandlung beim Risikopatientan. In: Ketterl, W, Deutscher Zahnärztekalender 52. Jg, Hanser Verlag München 1993

Krüger E: Lehrbuch der chirurgischen Zahn- Mund- und Kieferheilkunde, Band 2: Spezielle Chirurgie, 6.Auflage, Quintessenz-Verlag, Berlin 1981

Krüger E: Lehrbuch der chirurgischen Zahn-, Mund- und Kieferheilkunde, Band 2: Spezielle Chirurgie. 7. Auflage; Quintessenz-Verlag, Berlin 1993 
Kurihara S, Enlow DH (1980): An electron microscopic study of attachments between periodontal fibers and bone during alveolar remodeling. Am $\mathrm{J}$ Orthodont $\underline{77}, 516$

Kwan J: (2005): Enhanced periodontal debridement with the use of micro ultrasonic, periodontal endoscopy. J Calif Dent Assoc 33, 241-248

Lam R (1960): Contour changes of the alveolar processes following extractions. J Prosthet Dent $\underline{10}, 25-32$

Lambrecht JT, Härle F (1987): Die Reaktion der Kieferhöhle auf die Wurzelspitzenresektion von Prämolaren und Molaren. Dtsch Zahnärztl Z $\underline{42}$, $265-267$

Landsberger R(1923): Histologische Untersuchungen über das alveoläre Wachstum und eine Beziehung zu der Entwicklung des Zahnkeimes. Dtsch Monatsschr Zahnheilkd 1ㅜ, 417

Lang N, Brägger U, Hämmerle C, Sutter F (1994): Immediate transmucosal implants using the principle of guided tissue regeneration. I. Rationale, clinical procedures and 30-month results. Clin Oral Implants Res $\underline{5}, 154-163$

Lauer G, Schmelzeisen R (1999): Endoscope-assisted fixation of the mandibular condylar process fractures. J Oral Maxillofac Surg 푸, 36-39

Lee F (2001): Endoscopic extraction of an intranasal tooth: a review of 13 cases. Laryngoscope $\underline{6}, 1027-1031$ 
Lekholm U, Zarb G: Patientenselektion und Aufklärung der Patienten, in: Gewebeintegrierter Zahnersatz; hrsg. v. Branemark P, Zarb G, Albrektsson T; Quintessenz-Verlag, Berlin 1985, 195-206

\section{Lekovic V, Kenney E, Weinlaender M, Han T, Klokkevold P, Nedic M,} Orsini M(1997): A bone regenerative approach to alveolar ridge maintenance following tooth extraction. Report of 10 cases. J Periodontol 68, 563-570

Lin W, McCulloch C, Cho M (1994): Differentiation of periodontal ligament fibroblasts into osteoblasts during socket healing after tooth extraction in the rat. Anat Rec 240, 492-506

Linden F van, Boersma H, Zelders T, Peters K, Raaben J (1972): Threedimensional analysis of dental casts by means of Optocom. J Dent Res $\underline{51}, 1100$

Listgarten M (1973): Intracellular collagen fibrils in the periodontal ligament of the mouse, rat, hamster, guinea pig and rabbit. J Periodontal Res $\underline{8}$, 335-342

MacMillan HW (1924): The structure and function of the alveolar process. J Natl Dent Assoc 11, 1059

Marshall G, Lipsey M, Heuer M, Kot C, Smarz R, Epstein M (1981): An endodontic fiber optic endoscope for viewing instrumented root canals. J Endod 7, $85-88$

Melcher A, Chan J (1981): Phagocytosis and digestion of collagen by gingival fibroblasts in vivo: A Study of serial sections. J Ultrastruct Res $\underline{77}, 1-36$ 
Melcher A, Eastoe J E E: The connective tissue of the periodontium. In:

Melcher, AH, Bowen WH: Biology of the Periodontium. Academic Press. London 1969, pp 167-171

Mercier P (1985): Ridge form in preprosthetic surgery. Oral Surg Oral Med Oral Pathol $\underline{60}, 235-243$

Mercier P (1988): Ridge reconstruction with hydroxylapatite. Part 1. Anatomy of the residual ridge. Oral Surg Oral Med Oral Pathol $\underline{65}$, 505-510

Meyer H (1935): Heilungsvorgänge in der Alveole nach normaler Zahnextraktion. Schweiz Monatssch Zahnheilkd 45, 571-601

Meyer W (1957): Der Verschluss der Extraktionswunde. Dtsch Zahn Mund Kieferheilkd 27, 118-127

Michaud RM, Schoolfield J, Melloning JF, Mealey BL (2007): The efficacy of subgingival calculus removal with endoscopy-aided scaling and rootplaning: a study on multirooted teeth. J Periodontol 12 , 2234-2245

Müller H: Parodontologie1. Auflage. Georg Thieme Verlag, Stuttgart 2001

Mutschelknauss R : Anatomie und Physiologie des Parodontiums; in:

Lehrbuch der klinischen Parodontologie; hrsg. v. Mutschelknauss R;

Quintessenz Verlags-GmbH, Berlin 2000, 69-90

Nance R, Tyndall D, Levin LG, Trope M (2000): Identification of root canals in molars by tuned-aperture computed tomography. Int Endod J 33, 392-396 
Nemcovsky C, Serfaty V (1996): Alveolar ridge preservation following extraction of maxillary anterior teeth. Report on 23 consecutive cases. $\mathbf{J}$ Periodontol 67, 390-395

Nemcovsky C, Artzi Z (2002): Comparative study of buccal dehiscence defects in immediate, delayed and late maxillary implant placement and second-stage surgery. J Periodontol $\underline{73}, 754-761$

Nemcovsky C, Artzi Z, Moses O, Gelernter I (2002): Healing of marginal defects at implants placed in fresh extraction sockets or after 4-6 weeks of healing. A comparative study. Clin Oral Implants Res $\underline{13}$, 410-419

Ostler M, Kokich V (1994): Alveolar ridge changes in patients congenitally missing mandibular second premolars. J Prosthet Dent $\underline{71}$, 144-149

Ozawa T, Tsuchida M, Yamazaki Y, Arai T, Nakamura J (1999): Clinical application of a fiberscope for periodontal lesions: Case reports. Quintessence Int $\underline{30}, 615-622$

Ozawa T, Tsuchida M, Yamazaki Y, Arai T (2003) : Minimally invasive periapical curettage of foreign materials in periapical lesions using a fiberscope. Int Dent J $\underline{53}, 314-322$

Paatero Y (1954): Pantomography in theory and use. Acta Radiol 41, 321-335

Paatero Y (1961): Pantomography and Orthopantomography. Oral Surg $\underline{14}$, 947-953 
Paolantonio M, Doci M, Scarano A, d’Archivio D, di Placido G, Tumini V, Piattelli A (2001): Immediate implantation in fresh extraction socktes. A controlled clinical and histological study in man. J Periodontol $\underline{72}, 1560-1571$

Pasler F: Zahnärztliche Radiologie. 1.Auflage. Georg Thieme Verlag, Stuttgart 1981

Pasler F: Zahnärztliche Radiologie.3.Auflage. Georg Thieme Verlag, Stuttgart 1995

Pearson C H: The ground substance of the periodontal ligament.In: Berkovitz BKB, Moxham BJ, Newman NH: The periodontal Ligament in Health and Disease. Pergamon, Oxford $1982,119-125$

Pecora G, Andreana S (1993): Use of dental operating microscope in endodontic surgery. Oral Surg Oral Med Oral Pathol Oral Radiol Endod 75, $751-758$

Perrin P, Jacky D, Hotz P(2002): Das Operationsmikroskop in der zahnärztlichen Praxis:minimalinvasive Füllungen. Schweiz Monatsschr Zahnmed 112, 723-729

Picton DCA: The effect of external forces on the periodontium. In: Melcher AH, WH Bowen: Biology of the Periodontium. Academic Press, London 1969, $363-368$

Pietrokovski J, Massler M (1967): Alveolar ridge resorption following tooth extraction. J Prosthet Dent $\underline{7}, 21-27$ 
Plagmann H: Lehrbuch der Parodontologie. Carl Hanser Verlag, München 1998

Raurell A, Southern S, Fenton O (2006): Use of the endoscope intraorally in palate surgery. Plast Reconstr Surg 3, 810-811

Rohner D, Yeow V, Hammer B (2001): Endoscopically assisted Le Fort I osteotomy. J Craniomaxillofac Surg 29, 360-365

\section{Rothamel D, Schwarz F, Herten M, Chiriac G, Pakravan N, Sager M,} Becker J (2007): Kieferkammveränderungen nach Versorgung frischer Extraktionsalveolen mit poly-lactidvernetzten B-TCP Wurzelreplikaten- eine histomorphometrische Tierstudie. Mund Kiefer Gesichtschir 11, 89-97

Rottke B (1972): Die Bedeutung der Panoramadarstellung in der Kieferchirurgie. Dtsch Zahnärztl Z 27, 961-964

Saadoun A (2002): Immediate implant placement and temporization in extraction and healing sites. Compend Contin Educ Dent 23, 309-312+314$316+318$

Schmidseder R, Lambrecht JT (1978): Anwendungsmöglichkeiten und Indikationen der Sinuskopie aus zahnärztlicher und kieferchirurgischer Sicht. Zahnärztl Prax 29, 22-23

Schon R, Gutwald R, Schramm A, Gellrich NC, Schmelzeisen R, (2002):

Extraoral and intraoral endoscopically assisted management of collum fractures. Mund Kiefer Gesichtschir $\underline{6}$, 236-240 
Schroeder H: The periodontium; in: Handbook of microscopic anatomy. 5. Auflage,Springer-Verlag, Berlin 1986, 233-296

Schroeder H: Orale Strukturbiologie: Entwicklungsgeschichte, Struktur und Funktion normaler Hart-und Weichgewebe der Mundhöhle und des Kiefergelenks. 5.Auflage. Georg Thieme Verlag, Stuttgart 2000

Schropp L, Wenzel A, Kostopoulos L, Karring T (2003): Bone healing and soft tissue contour changes following single-tooth extraction: a clinical and radiographic 12-month prospective study. Int J Periodontics Restorative Dent $\underline{23}, 313-323$

Schubert C : Untersuchung zur Primärstabilität von Implantaten in Abhängigkeit von der Implantatlagerstruktur. Med. Diss. Göttingen 2005

Schwartz-Arad D, Chaushu G (1998): Immediate implant placement: a procedure without incisions. J Periodontol $\underline{69}$, 743-750

Sennhenn-Kirchner S, Engelke W(2003): Odontoskopie und Laser. Neue Wege in der Periimplantitis-Therapie.Laser J $\underline{3}, 13-16$

Serino G, Biancu S, Iezzi G, Piattelli A (2003): Ridge preservation following tooth extraction using a polylactide and polyglycolide sponge as space filler: a clinical and histological study in humans. Clin Oral Implants Res 14, 651-658

Shore R, Berkovitz B (1979): An ultrastructural study of periodontal ligament fibroblasts in relation to their possible role in tooth eruption and intracellular collagen degradation in the rat. Arch Oral Biol 24, 155-164 
Sicher H (1954): The principal fibers of the periodontal membrane. Br Dent J $\underline{55}, 2-28$

Slaton CC, Loushine RJ, Weller RN, Parker MH, Kimbrough WF, Pashley D(2003): Identification of resected root-end dentinal cracks:a comparative study of visual magnification. J Endod $\underline{8}, 519-522$

Smukler H, Landi L, Setayesh R (1999): Histomorphometric evaluation of extraction sockets and deficient alveolar ridges treated with allograft and barrier membrane: a pilot study. Int J Oral Maxillofac Implants 14,407-416

Soehren S, Van Swol R (1979): The healing extraction site: a donor area for periodontal grafting material. J Periodontol $\underline{50}, 128-133$

Sonnabend E: Zahnärztliche Röntgenologie. Urban und Schwarzenberg, München 1977

Sonnabend E, Ring A (1972): Die Bedeutung der Panoramadarstellung in der Zahnerhaltung und Parodontologie. Dtsch Zahnärztl Z 27, 965-969

Spray JR, Black CG, Morris HF, Ochi S (2000): Influence of bone thickness on facial marginal bone response: Stage 1 placement through stage 2 uncovering. Ann Periodontol $\underline{5}, 119-128$

Stambaugh R (2003): Perioscopy-The New Paradigm. Dimensions Dent Hyg 1, 12-13 und $15-16$ 
Stambaugh R, Myers G, Ebling W, Beckman B, Stambaugh K (2000a):

Endoscopic visualization of submarginal root surfaces. J Dent Res $\underline{79}$ (special issue), 600 (abstract 3656)

Stambaugh R, Myers G, Watanabe J, Laas C, Stambaugh K (2000b): Endoscopic instrumentation of the subgingival root surface in periodontal therapy. J Periodontal Res $\underline{79}$ (special issue), 489 (abstract 2762)

Stambaugh R, Myers G, Ebling W, Beckman B, Stambaugh K (2002): Endoscopic visualization of the submarginal gingival dental sulcus and tooth root surfaces. J Periodontol $\underline{73}$, 374-382

Suarez-Cunqueiro M, Schon R, Gellrich N, Schmelzeisen R (2004):

Endoscopic assistance in the removal of a foreign body in the condylar process. J Craniofac Surg 1, 98-101

Suhonen J, Meyer B (1996): Polylactic acid (PLA) root replica in ridge maintenance after loss of a vertically fractured incisor. Endod Dent Traumatol $\underline{12}, 155-160$

Takata T, Donath K (1988): The mechanism of pocket formation. A light microscopic study on undecalcified human material. J Periodontol $\underline{59}, 215-221$

Tallgren A (1972) The continuing reduction of the residual alveolar ridges in complete denture wearers: a mixed-longitudinal study covering 25 years. J Prosthet Dent 27, 120-132 


\section{Taschieri S, Del Fabbro M, Testori T, Francetti L, Weinstein R (2006):}

Endodontic surgery using 2 different magnification devices: preliminary results of a randomized controlled study. J Oral Maxillofac Surg 64, 235-242

Ten Cate A, Deporter D (1974): The role of the fibroblast in collagen turnover in the functioning periodontal ligament of the mouse. Arch Oral Biol $\underline{19}$, 339340

Ten Cate A, Deporter D (1975): The degradative role of the fibroblast in the remodelling and turnover of collagen in soft connective tissue. Anat Rec $\underline{182}, 1$ 14

Ten Cate A, Deporter D, Freeman E (1976): The role of fibroblasts in the remoddeling of periodontal ligament during physiologic tooth movement. Am J Orthod $\underline{69}, 155$

Thanyakarn C, Hansen K, Rohlin M, Akesson L (1992). Measurements of tooth length in panoramic radiographs.1. The use of indicators. Dentomaxillofac Radiol.1,26-30

Tibbetts L, Shanelec D(1996): Current status of periodontal microsurgery. Curr Opin Periodontol $\underline{3}, 118-125$

Tibbetts L, Shanelec D(1998): Periodontal microsurgery. Dent Clin North Am $\underline{42}, 339-359$

Troulis M, Perrott DH, Kaban LB (1999): Endoscopic mandibular osteotomy and placement and activation of a semiburried distractor. J Oral Maxillofac Surg $\underline{57}, 1110-1113$ 
Troulis M, Williams W, Kaban L (2004): Endoscopic mandibular condylectomy and reconstruction :early clinical results. J Oral Maxillofac Surg $\underline{62}, 460-465$

Ulm C, Solar P, Blahout R, Matejka M, Gruber H (1992): Reduction of the compact and cancellous bone substances of the edentulous mandible caused by resorption. Oral Surg Oral Med Oral Pathol 74, 131-136

Velvart P (1996): Das Operationsmikroskop. Neue Dimension in der Endodontie. Schweiz Monatsschr Zahnmed 106, 357-364

von Arx T (2005): Frequency and type of canal isthmuses in first molars detected by endoscopic inspection during periradicular surgery.Int Endod $\mathrm{J} \underline{\mathbf{3}}$, 160-168

von Arx T, Hunenbart S Buser D (2001): Die Endoskopie in der endodontischen Chirurgie. Schweiz Monatsschr Zahnmed 111, 1303-1307

von Arx T, Frei C, Bornstein M (2003): Periradiculäre Chirurgie mit und ohne Endoskopie: eine klinisch-prospektive Vergleichsstudie. Schweiz Monatsschr Zahnmed 113, 860-865

Wagner W : Allgemeine Grundlagen enoraler Operationen. In: Horch H-H, Hrsg. Zahnärztliche Chirurgie. (Praxis der Zahnheilkunde Bd.9) Urban und Schwarzenberg München 1989, 55-74

Wang H, Tsao Y (2007): Mineralized bone allograft-plug socket augmentation: rationale and technique. Implant Dent $\underline{16}, 33-41$ 
Wang H, Kiyonobu K, Neiva R (2004): Socket augmentation: rationale and technique. Implant Dent $\underline{13}, 286.296$

Werbitt M, Goldberg P (1992): The immediate implant: bone preservation and bone regeneration. Int J Periodontics Restorative Dent_12, 206-217

Wheeler SL, Vogel RE, Casellini R (2000): Tissue preservation and maintenance of optimum esthetics: A clinical report. Int J Oral Maxillofac Implants $\underline{15}, 265-271$

Wiltfang J, Merten H, Ludwig A, Engelke W, Arzt T (1999):

Röntgenologische, endoskopische und sonographische Beurteilung der Kieferhöhle nach Sinuslift und simultaner Implantatinsertion. Mund Kiefer Gesichtschir $\underline{3}, 61-64$

Wiltfang J, Kessler P, Neukam F (2002): Endoskopisch unterstützte LeFort-IOsteotomie bei Distraktionsverfahren im Oberkiefer. Mund Kiefer Gesichtschir $\underline{6}, 231-235$

Yang J, Lee H, Vernino A (2000): Ridge preservation of dentition with severe periodontitis. Compend Contin Educ Dent 21, 579-583, quiz 584

Yilmaz S, Efeoglu E, Kilic A (1998): Alveolar ridge reconstruction and/or preservation using root form bioglass cones. J Clin Periodontol 25, 832-839

\section{Yukna R, Castellon P, Saenz-Nasr A, Owens K, Simmons J, Thunthy K,}

Mayer E (2003): Evaluation of hard tissue replacement composite graft material as a ridge preservation/augmentation material in conjunction with immediate hydroxylapatite-coated dental implants. J Periodontol $\underline{74}$, 679-686 
Yura S, Ohga N, Ooi K, Izumiyama Y (2007): Procedure of endoscopic removal of a gutta-percha point under the maxillary sinus mucosa by using an ultrathin arthroscope. Oral Surg Oral Med Oral Pathol Oral Radiol Endod $\underline{6}$, 5860

Zeren K (2006): Minimally invasive extraction and immediate implant placement: the preservation of esthetics. Int J Periodontics Restorative Dent $\underline{26}$, $171-178$ 


\section{Lebenslauf}

Am 09.05.1976 wurde ich als zweite Tochter der Eheleute Christel Weber, geb. Schierenberg und Dipl.Ing Helmut Weber in Salzgitter-Bad geboren.

1982 bin ich in die Grundschule am Ziesberg in Salzgitter-Bad eingeschult worden und wechselte nach Abschluss der vierten Klasse 1986 zur Orientierungsstufe am Eikel.

Ab 1988 besuchte ich bis 1995 das Gymnasium am Eikel in Salzgitter-Bad, im Mai 1995 erlangte ich dort die Allgemeine Hochschulreife.

Von Oktober 1995 bis März 1996 absolvierte ich im Städtischen Krankenhaus ein Soziales Jahr.

Zum Sommersemester 1996 begann ich mein Studium der Zahnmedizin an der Georg-August-Universität in Göttingen.

Im Frühjahr 1999 bestand ich die zahnärztliche Vorprüfung, und im Winter 2002 beendete ich mein Studium mit dem Staatsexamen. Im Dezember 2002 erhielt ich meine Approbation als Zahnärztin. 2003 absolvierte ich eine mehrwöchige Famulatur in Argentinien und erarbeitete einen Teil meiner Doktorarbeit.

Im Januar 2004 begann ich meine Assistenzzeit in der Gemeinschaftspraxis der Zahnärzte Hanf in Hankensbüttel, ab dem 01.Oktober 2005 war ich dort als Partner in der Gemeinschaftspraxis Hanf und Reindl selbständig.

Seit dem 01.01. 2009 bin ich in Elternzeit und widme mich dem Wohlergehen meiner Kinder Katharina und Johannes.

Celle im November 2010

Isabell-Andrea Reindl 